\title{
Fly palaeo-evo-devo: Immature stages of bibionomorphan dipterans in Baltic and Bitterfeld amber
}

\author{
Viktor A Baranov ${ }^{\text {Corresp., } 1}$, Mario Schädel ${ }^{1}$, Joachim T Haug ${ }^{1,2}$ \\ ${ }^{1}$ Biology II, Ludwig-Maximilians-Universität München, Planegg, Bayern, Germany \\ ${ }^{2}$ Geobio-Center, Ludwig-Maximilians-Universität München, Planegg, Bayern, Germany \\ Corresponding Author: Viktor A Baranov \\ Email address: baranow@biologie.uni-muenchen.de
}

Larvae of flies and gnats (Diptera) form a crucial component of many terrestrial and freshwater ecosystems in the extant biosphere. Larvae of Diptera play a central role in water purification, matter and energy transfer in riparian ecosystems in rivers, carbon cycling in lakes and forests as well as being major decomposers of dead organic matter. Despite all these important roles, dipteran larvae are most often ignored in palaeoecological studies, due to the difficulty of the taxonomic identification of fossil larva, but also, due to the perceived importance of adult dipterans in palaeoentomological and taxonomic studies. Despite that, much information on palaeoecosystems can be gained from studying fossil dipteran larvae, in particular for well preserved specimens from fossil resins (ambers and copals). Since ambers are selectively preserving fauna of trunks and leaf litter, it allows us to learn a lot about xylophages and saprophages of amber forests, such as Eocene Baltic amber forest. Here we present immature stages (larvae and pupa) of the dipteran ingroup Bibionomorpha, from Baltic and Bitterfeld amber forests. We have recorded at least four different larval morphotypes, one with four distinct instars, and at least three pupal morphotypes. One larva is recognised as a new species and can be interpreted either as a representative of a highly derived ingroup of Bibionidae or as a sister species to Bibionidae. Also represented by single larval specimens are the groups Pachyneura (Pachyneuridae) and Sylvicola (Anisopodidae). The majority of the recorded specimens are representatives of the group Mycetobia (Anisopodidae). Due to the abundance of immature stages of Mycetobia, we have been able to reconstruct the number of larval stages (4) and relative growth rate of these fossil dipterans. We discuss implications of these finds. 
1

2 Fly palaeo-evo-devo: Immature stages of

3 bibionomorphan dipterans in Baltic and Bitterfeld

4 amber

5

6

7 Viktor Baranov ${ }^{1}$, Mario Schädel ${ }^{1}$, Joachim T. Haug ${ }^{1,2}$

$8{ }^{1}$ Biology II, Ludwig-Maximilians-Universität München, Planegg, Bayern, Germany

$9{ }^{2}$ Geobio-Center, Ludwig-Maximilians-Universität München, Planegg, Bayern, Germany 10

11 Corresponding Author:

12 Viktor Baranov $^{1}$

13 Biology II, Ludwig-Maximilians-Universität München, Planegg, Bayern, Germany

14 Email address: baranow@biologie.uni-muenchen.de 


\section{Abstract}

18 Larvae of flies and gnats (Diptera) form a crucial component of many terrestrial and freshwater ecosystems in the extant biosphere. Larvae of Diptera play a central role in water purification, matter and energy transfer in riparian ecosystems in rivers, carbon cycling in lakes and forests as well as being major decomposers of dead organic matter. Despite all these important roles, dipteran larvae are most often ignored in palaeoecological studies, due to the difficulty of the taxonomic identification of fossil larva, but also, due to the perceived importance of adult dipterans in palaeoentomological and taxonomic studies. Despite that, much information on palaeoecosystems can be gained from studying fossil dipteran larvae, in particular for well preserved specimens from fossil resins (ambers and copals). Since ambers are selectively preserving fauna of trunks and leaf litter, it allows us to learn a lot about xylophages and saprophages of amber forests, such as Eocene Baltic amber forest. Here we present immature stages (larvae and pupa) of the dipteran ingroup Bibionomorpha, from Baltic and Bitterfeld amber forests. We have recorded at least four different larval morphotypes, one with four distinct instars, and at least three pupal morphotypes. One larva is recognised as a new species and can be interpreted either as a representative of a highly derived ingroup of Bibionidae or as a sister species to Bibionidae. Also represented by single larval specimens are the groups Pachyneura

34 (Pachyneuridae) and Sylvicola (Anisopodidae). The majority of the recorded specimens are 35 representatives of the group Mycetobia (Anisopodidae). Due to the abundance of immature 36 stages of Mycetobia, we have been able to reconstruct the number of larval stages (4) and relative growth rate of these fossil dipterans. We discuss implications of these finds. 
39

40

41

42

43

44

45

46

47

48

49

50

51

52

53

54

55

56

57

58

59

60

61

62

63

64

65

66

67

68

69

70

71

72

73

74

75

76

77

\section{Introduction}

Holometabola is a hyperdiverse group of organisms, representing the dominant part of animal life in terrestrial ecosystems (Grimaldi \& Engel, 2005). Representatives of the group such as bees, butterflies, beetles and mosquitoes are therefore the best known forms of Insecta to most people. The dominance of holometabolans has led researchers to consider Holometabola as one of the largest groups of Metazoa (Grimaldi \& Engel, 2005, Engel, 2019). The evolution of niche differentiation between the larva and the adult (see Haug, in press) has been interpreted as one of the driving factors of their success. The evolutionary independence of different life stages and phases (see Scholtz, 2005) has allowed holometabolans to utilize a very wide spectrum of habitats and ecological niches (Grimaldi \& Engel, 2005).

Larvae of flies and midges (representatives of the group Diptera) are successful in diverse habitats, from glaciers at the Antarctic mainland to the fast-drying rock pools of central Africa (Armitage et al., 1995; Marshall, 2012). Due to such variety of habitats occupied, larvae of Diptera have become involved in numerous critical ecosystem functions (Marshall, 2012). Dipteran larvae are crucial saprophages, recycling dead organic matter in both aquatic and terrestrial ecosystems, and therefore heavily influence biogeochemical cycles of matter and energy, for example in riparian ecosystems (Marshall, 2012; McAlister, 2017). This ecological role of larval forms of Diptera became especially important about 80 million years ago, in the Upper Cretaceous, when due to the Cretaceous Terrestrial Revolution (CTR) angiosperm plants have become the dominant players in the ecosystem (Fastovsky et al., 2004; Mckenna et al., 2015).

The emergence of angiosperm plants in terrestrial ecosystem probably led to an increased load of dead organic matter into terrestrial and freshwater ecosystems (Kalugina, 1974a, b; Mckenna et al., 2015). Such a drastic ecosystem change has led to shifts in the communities of various lineages of Insecta (Kalugina, 1974a, b). Such shifts included the extinction or decline of certain systematic and ecological groups. Among them were nectic and benthic oxyphilic forms living in dystrophic lakes. Vice versa, other groups, such as specialized pollinators or saprophages, have experienced an enormous diversification (Sinichenkova \& Zherikhin, 1996). Among the groups experiencing a pronounced diversification were many ingroups of Diptera (Grimaldi \& Engel, 2005). Numerous groups of dipterans with terrestrial larvae are associated with decaying organic material, such as dead wood, fungal fruit bodies, dead leaves, or animals corpses (Keilin \& Tate, 1940; Marshall, 2012). Among the most abundant extant saprophagous forms of Diptera (with predominantly terrestrial larvae) are representatives of Bibionomorpha (Marshall, 2012; Ševčík et al., 2016).

Bibionomorpha includes numerous ingroups diverse representatives. However, larvae of Bibionomorpha are predominantly restricted to terrestrial habitats (Fig. 1, modified and simplified from Ševčík et al., 2016).

The geological history of Bibionomorpha spans more than 220 million years (Blagoderov et al., 2007). Many representatives are known from the late Triassic (Blagoderov et 
78 al., 2007) and Jurassic (Kalugina and Kovalev, 1985). Despite the long evolutionary history of 79 the group and the ecological importance of their larval stages, very little attention has been paid 80 to the fossil record of immature stages of Bibionomorpha (Harris, 1983; Skartveit, 2008). This is 81 surprising, as immature representatives of Bibionomorpha, especially those of Anisopodidae, 82 seem to be quite common in amber, as we will demonstrate. Despite such abundance, 83 Anisopodidae larvae from amber were only mentioned in a single study focused on specimens 84 from Dominican amber (Grimaldi, 1991).

85

86

87

88

89

90

91

92

93

94

95

96

97

98

99

100

101

102

103

104

105

106

107

108

109

110

111

112

113

114

115

116

Here, we present a first overview of the immature stages of Bibionomorphan from amber, including larvae and pupae of Anisopodidae, larvae of Pachyneuridae and a species that seems closely related to Bibionidae. All specimens in focus of this study are preserved in Eocene Bitterfeld amber and Baltic ambers (Table 1). We also discuss the implications of the morphological and ecological diversity of immature representatives of Bibionomorpha in relation to the ecology and biogeochemistry of the Eocene amber forests.

\section{Materials \& Methods}

\section{Material}

All specimens in the center of this study, in total 56, are preserved in amber and come from various collections. A full list of the examined material is given in Table 1.

Part of the material (see Table 1, material marked as "Material from Hoffeins collection") was obtained commercially in 2005 and stems from Yantarnyj, Kaliningrad district (formerly Palmnicken, Königsberg); specimens have temporarily been part of the collection of Christel and Hans-Werner Hoffeins (CCHH). All specimens from this source are now deposited at the Senckenberg Deutsches Entomologisches Institut (SDEI; with inventory numbers listed in table 1).

Another part of the material comes from the private collection of Carsten Gröhn and is now deposited in the collection of the Center for Natural History in Hamburg (Centrum für Naturkunde, CeNak, formerly Geological-Paleontological Institute and Museum of the University of Hamburg, Geologisch-Paläontologisches Institut und Museum der Universität Hamburg, GPIH).

Part of the material has been commercially obtained from Jonas Damzen ("amberinclusions.eu") by one of the authors. This material is now permanently housed in the research collection of the Palaeo-Evo-Devo Research Group, Ludwig-Maximilians-Universtät, Munich, Germany (PED). One specimen is part of the collection of the Museum für Naturkunde Berlin (MfNB).

Further material was retrieved from the collection of the Center for Natural History in Hamburg (CeNak).

Information on syninclusions is provided in table 1 as well. All abbreviations of the collection names are according to the "The insect and spider collections of the world" website (Evenhuis, 2019).

Peer) reviewing PDF | (2019:06:38366:3:2:NEW 4 Sep 2019) 
117

118

119

120

121

122

123

124

125

126

127

128

129

130

131

132

133

134

135

136

137

138

139

140

141

142

143

144

145

146

147

148

149

150

151

152

153

154

155

156

For comparative purposes, we used extant larval representatives of Anisopodidae and Bibionidae (larvae, pupae, and adult) from the collection of the Zoological State Collection, Munich (Zoologische Staatssammlung München, ZSM), in particular, Sylvicola fenestralis (Scopoli, 1763) (adult and pupa, no collection number available), Mycetobia pallipes Meigen, 1818 (larvae, pupae and adult, no collection number available) and Penthetria funebris Meigen, 1804 (larvae, pupae and adult, no collection number available) as well as Bibio varipies Meigen, 1830, (Centrum für Naturkunde Hamburg - CeNak, no collection number assigned).

The morphological terminology largely follows Borkent and Sinclair (2017). Yet, to enhance the understandability for non-experts, we amended some of the special morphological terms with more general terms. As Insecta is an accepted ingroup of Eucrustacea s.1. "crustacean"-terms are given in square brackets were necessary to provide wider frame correspondence.

\section{Imaging methods}

The specimens were imaged using a Keyence VHX-6000 Digital microscope, with ring-light type illumination and/or cross-polarised, co-axial illumination. All photographic images presented in this paper are composite images. Images were assembled using panoramic stitching to overcome the limitation of the field of view at higher magnifications. For each single image a stack of images of shifting focus was recorded to overcome the limitation of the depth of field (Haug et al. 2008, 2011, 2013a). Fusion into sharp images and panoramic stitching was performed with the software implemented in the digital microscope (e.g. Haug et al. 2018, 2019). We also used the implemented HDR function of the digital microscope; therefore every single frame is a composite from several images taken under different exposure times (cf. Haug et al. 2013b).

In addition to that, extant and fossil material was imaged using a Keyence BZ-9000 fluorescence microscope with either a $2 \mathrm{x}, 4 \mathrm{x}, 10 \mathrm{x}$ or $20 \mathrm{x}$ objective depending on the size of the objects. Observations were conducted at a emitted wavelength of $532 \mathrm{~nm}$ since it was the most compatible with the fluorescence capacities of the fossil specimens (Haug et al. 2011). To counteract the limitation in the depth of the focus we recorded stacks of images which than were digitally fused to single in-focus images using CombineZP (GNU). Extant specimens were imaged using a ZEISS Stemi 508 Stereo Microscope (with 8:1 Zoom with double LED spot K and additional ring light) in combination with a DCM 510 ocular camera and. Adobe Photoshop Elements 11 was used to stitch different images to single panoramic images. The resulting images were post-processed in Adobe Photoshop Elements 11 to optimize the histogram and sharpness as well as to amend the images with color markings to highlight morphological structures.

Two specimens (Dip-00653, Dip-00660) were scanned using X-Ray computer tomograph Zeiss Xradia XCT-200 in the Zoological Institute and Museum of University of Greifswald. Volume rendering images of the scans were created using Drishti (GNU) (e.g. Hörnig et al. 2016). 
157

158

159

160

161

162

163

164

165

166

167

168

169

170

171

172

173

174

175

176

177

178

179

180

181

182

183

184

185

186

187

188

189

190

191

192

193

194

195

196

Micro-CT scanning of one specimen (MB.I.7295) was performed using a Nanotom $\mathrm{m}$ Phoenix (GE Sensing \& Inspection Technologies GmbH). Scans were reconstructed to tiff stacks with the built-in software. Tiff stacks were further processed with ImageJ and Osirix 5.8.2 (e.g. Haug et al. 2011; Nagler et al. 2017).

\section{Morphometry}

Maximum head capsule length (in dorsal view) and width of some larvae were measured, as suggested by Coomb et al. (1997), from photos, using ImageJ (public domain; Schneider et al., 2012). Statistical analysis of the data was performed in R (GNU), using the mblm-function of the mblm-package, with a Theil-Sen single median method as a baseline method for applying Sen slopes to the data (Komsta, 2013). Not all specimens of the Mycetobia larvae had well preserved head capsule, therefore measurements of the width and length were performed for 25 specimens.

\section{Taxonomy}

Wherever possible we decided not to use Linnean ranks ("rankless taxonomy"). Ranks represent arbitrary constructs in a way that they do not hold "comparative values" (Mayr, 1942, p. 291, line 3) and, in our view, do not contribute to an easier understanding of phylogenetic relations among species and higher groups. However, the rank of the genus is not as easy to dismiss as the ranks of higher (broader) systematic groups. This is solely due to its function as part of binomial species names. Even though there are ways to avoid this dilemma such as the application of uninomial nomenclature for species (Lanham, 1965) or the use of any higher systematic group (regardless ranked as genus or not) as part of the species name (Haug \& Haug 2016 following Béthoux 2010), the traditional, rank based, application of binomial names is still required by the International Code of Zoological Nomenclature (ICZN, Chapter 2, Article 5 \& App. B, 6.). To be consistent with the "Code" we establish a new generic name, even though there is only one species assigned to this name and thus the sole purpose of this name is to serve as part of the binomial species name. Hence, until a sister taxon (species or group) to the herein described species is found, the generic name is that of a monotypic taxon and thus no diagnosis can be given for it.

For the sake of consistency, reproducibility and to increase the speed of fossil biodiversity discovery, we applied a matrix-based description scheme, proposed by Haug et al., (2012). We think that such form of description, based on the alternating characters states, entered in the excel sheet are useful in providing consistent, streamlined description, albeit with numerous repetitions of the same phrases.

A single new species is described herein. The electronic version of this article will represent a published work according to the International Commission on Zoological Nomenclature (ICZN), and hence the new names contained in the electronic version are effectively published according to the ICZN from the electronic edition alone. This published work and the nomenclatural acts it contains have been registered in ZooBank, the online registration system of the ICZN. The ZooBank LSIDs (Life Science Identifiers) can be resolved 
197 and the associated information viewed through any standard web browser by appending the 198 LSID to the prefix http://zoobank.org/. The LSID for this publication is :

199 urn:lsid:zoobank.org:pub:7E6FFA31-9DA8-44A6-BE7D-55E6AE34B660. The online version of 200 this work is archived and available from the following digital repositories: PeerJ, PubMed 201 Central and CLOCKSS.

202

203

204

205

206

207

\section{Results}

208

Taxonomy

Diptera Linnaeus, 1758

209 Dinobibio gen. nov.

210 Life Science Identifier: urn:lsid:zoobank.org:act:8C8DCD9A-1A44-473E-9692-

211 54C7AE204B91.

212 Etymology: from Ancient Greek $\delta \varepsilon v$ ó $\varsigma$ (deinos), meaning 'terrible, potent or fearfully great', due

213 to the imposing nature of the larva, which bears large protuberances, and Bibio (ingroup of

214 Bibionidae).

215

216 Type species: Dinobibio hoffeinseorum sp. nov. by present designation.

217 Life Science Identifier: urn:lsid:zoobank.org:act:80D4F834-D0D4-404F-AE02-C8FF184D4943

218

219

Remark: no diagnosis can be given, since the new generic name does not refer to a natural group

220 but is only put up to provide a binomial name (see explanation above). However, for the purposes of consistency we are providing putative diagnosis, identical, but abbreviated in

222 comparison to the type species. Larva characterized by cylindrical body-shape; maxillary palp with additional strong process distally on the element 1 ; trunk protuberances expanding towards mid length and then tapering again; terminal abdominal spiracle, situated dorso-laterally, not 225

226

227

228

229

230

231

232

233

234 larger than the rest of the spiracles.

\section{Dinobibio hoffeinseorum sp. nov.}

(Figs. 2A, 2B; 3A-D, Fig. S1)

Holotype: a single fossil larva, GPIH-0024 The larva is well preserved, but lateral aspects are obscured by a silvery film (probably air bubbles) covering parts of the trunk.

235

Etymology: named after Christel and Hans-Werner Hoffeins for their immense contribution to 236 
237

238

239

240

241

242

243

244

245

246

247

248

249

250

251

252

253

254

255

256

257

258

259

260

261

262

263

264

265

266

267

268

269

270

271

272

273

274

275

276

Syninclusions: a single "acalyptrate" fly ("Acalyptrata" = non-monophyletic assemblage of lineages within Brachycera that are not part of Calyptrata). Syninclusion too poorly preserved to identify more precisely.

\section{Description:}

Habitus. Medium sized larva with a bowling-pin shaped body. Total length $6.4 \mathrm{~mm}$. Body differentiated into presumably 20 segments, ocular segment plus 19 post-ocular segments.

Head. Ocular segment and post-ocular segment 1-5 (presumably) forming distinct capsule (head capsule). Head capsule longer than wide. Head capsule in dorsal view not accessible due to orientation of the specimen. Hind part of head capsule partly retracted into anterior trunk. Dimensions of head capsule: $860 \mu \mathrm{m}$ long, width hard to access. Surface of head capsule with "warty" appearance, bearing numerous bulbous protrusions and smaller spine-like protrusions. Ocular segment without apparent stemmata (larval eyes). Ocular segment recognizable by its appendage derivative, clypeo-labral complex. Clypeus (clypear sclerite) dome-shaped, with several bulbous expansions on the top, total length $260 \mu \mathrm{m}$, oval in general shape (Figs. 3A, 3B). Labrum not discernible.

Post-ocular segment 1 recognizable by its appendages, antennae [antennulae]. Antenna arising from head capsule postero-laterally to the clypeus. Antennae sitting on large piedestal (socket); no subdivision of antenna into elements apparent. (Figs. 3A-D)

Post-ocular segment 2 (intercalary segment) without externally recognizable structures. (Figs. 3A-D)

Post-ocular segment 3 recognizable by its pair of appendages, mandibles. Mandible only accessible at the distal tip, proximal part obscured. (Figs. 3A-D)

Post-ocular segment 4 recognizable by its appendage, maxilla [maxillula]. Maxilla massive, organised into proximal part and distal part, palp [endopod]. Proximal part differentiated into two lobes, outer lobe and inner lobe. Inner lobe, possible lacinia [endite]. Possible lacinia rectangular in outline. Possible lacinia $100 \mu \mathrm{m}$ long, $200 \mu \mathrm{m}$ wide. Palp arising from outer lobe, cylindrical, with two elements, palpomeres. Element $1170 \mu \mathrm{m}$ long. Element 1 distally with strong conical outgrowth. Outgrowth $80 \mu \mathrm{m}$ long. Element 2 conical, $45 \mu \mathrm{m}$ long, without apparent armature. (Figs. 3A-D)

Post-ocular segment 5 recognisable by its appendages, forming the labium [conjoined left and right maxillae]. Labium massive, heavily sclerotized, with proximal part and distal parts, palps [endopods]. Labium occupying over $60 \%$ of the total length of the head capsule ventrally. Palp cylindrical, total length $35 \mu \mathrm{m}$ (Figs. 3C, 3D). Total length of the labium (without palp) $310 \mu \mathrm{m}$, width $200 \mu \mathrm{m}$.

Trunk. Trunk roughly bowling-pin shaped, diameter increasing posteriorly along the trunk, diameter of the trunk always larger than that of the head capsule (Figs. 2 A, B). Trunk with 12 visible units, interpreted as 3 thorax segments plus 8 abdominal units and a trunk end representing a conjoined structure of undifferentiated abdominal segments (9-11?). Trunk with 
277 abdominal units, progressively increasing in lateral aspect towards the posterior part of the body.

278 Segment $11400 \mu \mathrm{m}$ high, while 7 th-1790 $\mu \mathrm{m}$ high. Trunk lacks parapodia and/or creeping 279 welts. Trunk bears dozens of conical protuberances on the entire surface. Each segment of the 280 trunk, with the exception of the trunk end, carries 8 prominent, fleshy protuberances dorso281 laterally and ventrolaterally in groups of two, four at each side of the body. Protuberances widest 282 at the mid-length, slightly narrower proximally part and tapering distally, mean length ca. 270 $283 \mu \mathrm{m}$. Trunk surface with numerous small spines (Figs 2 A, B; Fig. S1). Trunk bears 10 pairs of 284 spiracles (openings of the tracheal system) (Figs. 2, A,B). Each spiracle situated in the centre of 285 an elevated ridge (Figs. 2 A, B).

286 Thorax consists of three segments, pro-, meso- and metathorax.

287 Prothorax sub-equal in width to the head capsule, $670 \mu \mathrm{m}$. Prothorax bears a pair of large 288 spiracles. Prothorax carries 8 prominent, fleshy protuberances dorso-laterally and ventrolaterally 289 in groups of two, four at each side of the body.

290 Mesothorax $580 \mu \mathrm{m}$ long. Mesothorax carries 8 prominent, fleshy protuberances dorso-laterally 291 and ventrolaterally in groups of two, four at each side of the body; Mesothorax with no spiracle 292 openings present.

293 Metathorax $560 \mu \mathrm{m}$ long. Metathorax carries 8 prominent, fleshy protuberances dorso-laterally 294 and ventrolaterally in groups of two, four at each side of the body. Metathorax bears a pair of 295 spiracles (Figs 2 A, B; Fig. S1).

296 Abdomen (posterior trunk) Height of abdominal units progressively increasing in lateral aspect 297 towards the posterior part of the body.

298 Abdominal units 1-8 each carrying 8 prominent fleshy protuberances dorso-laterally and 299 ventrolaterally in groups of two, four at each side of the body. Abdominal units 1-7 each 300 carrying a pair of spiracles laterally.

301 Abdominal unit 8 lacks spiracles.

302 Trunk end (undifferentiated abdomen segments 9-11?) shorter than abdominal unit 8. Trunk 303 end bears anus on the posterior part. Trunk end bears more than a dozen of conical protuberances 304 on the entire surface. No protuberances present in the immediate vicinity of the anus, on the 305 postero-dorsal surface of the trunk end. Trunk end bears posterior spiracles with a single ecdysial 306 scar (a site where the previous larval stage cuticle breaks from the spiracle). Posterior spiracle is 307 sub-equal to the rest of the spiracles.

308

309 Differential diagnosis: The larva is clearly different from any modern representative of 310 Bibionidae, of which immature stages are known based on the combination of the following 311 characters: cylindrical body-shape; a maxillary palp with additional strong process distally on the 312 element 1; trunk protuberances which are expanding towards mid length and then tapering again; 313 terminal abdominal spiracle (abdominal segment 10), situated dorso-laterally, not larger then the 314 rest of the spiracles; (Figs 2A, 2B; 3A-D).

315 
316 Systematic interpretation, general body features: The general body shape,the absence of 317 ambulatory legs on the thorax, as well as the spiracle arrangement is consistent with this larvae 318 being an immature stage of the group Diptera. The larval specimen GPIH-0024 is interpreted to 319 be clearly closely related to Bibionidae based on the following combination of characters (see 320 Fig. 4A-C; 5 A-C): Head capsule fully sclerotized, posterior part of it is retracted into the 321 prothorax; maxilla very short and stocky, with short and strong maxillary palp, head capsule 322 black and shiny; eyes absent, antenna rudimentary; tracheal system holopneustic ("type 1" 323 spiracles on the prothorax and metathorax, as well as on abdominal segments 1-7 \& 9). Body

324

325

326

327

328

329

330

331

332

333

334

335

336

337

338

339

340

341

342

343

344

345

346

347

348

349

350

351

352

353

354 heavily sclerotized, yet head capsule is sclerotized even more than the body. Prothorax is the longest segment of the trunk (Skartveit, 2017).

The very long and robust labium, the body with fleshy protuberances, bearing two rows of the protuberances dorsally and a single ecdysial scar on the posterior spiracle specimen, roughly resembles the condition in larvae of Penthetria Meigen, 1804 (Hennig, 1968, Skartveit, 2002), an ingroup of Bibionidae (Fig. 5A-C).

Systematic interpretation, head structures: The head capsule of the fossil larva is similar to that of larvae of Bibionidae. The antennae of the fossil larva are reduced as in larvae of Bibionidae. They are only represented by an undifferentiated conical piedestal in the fossil, similar to the condition in larvae of Bibio or Penthetria (both ingroups of Bibionidae; Fig. 5B, 5C). The maxilla of the fossil is robust, as it is in most larvae of Bibionidae. Yet, the larva differs in the structure of the maxillary palp (Fig. 4B, 4C): it is robust and cylindrical in general shape, similar to the representatives of Penthetria or Bibio (Figs. 4A-C, 5A-C), but differs drastically from the representatives of both groups by bearing a conical outgrowth distally on the first element of the palp (Figs 3A-D, 4A-C, 5A-C). This outgrowth is somewhat similar to the structure on the palpi of some extant larvae of Bibionidae. In particular, larvae of the ingroup of Bibionidae Dilophus possesses large, conical sensillae on the palpi. The outgrowth of the fossil larva is however much larger proportionally to the maxilla than that of larvae of Dilophus. Also it is situated on the distal part of the first element, not on the second element of the palp as it is the case for Dilophus (Krivosheina \& Mamaev, 1967).

Other larval forms of Bibionomorpha that possess large sensilla on the maxillary palps are larvae of fungus-gnats Mycomyinae (Mycetophilidae; Krivosheina \& Mamaev, 1967: figs. 31:1,31:6). In contrast to larvae of Mycomyinae, however, the outgrowths of the fossil larva are not articulated. We therefore argue that this is an unique character which is a putative autapomorphy of Dinobibio hoffeinseorum sp. nov..

The labium, in particular its proximal part, the mentum, is of the typical shape for larvae of Bibonidae (Figs. 3C, 3D), yet much broader and more robust than in any known larva of Bibionidae (s. 5A-C). The labium is occupying up to $60 \%$ of the entire width of the ventral area of the head, while the labium tin larvae of Bibionidae is much narrower, occupying about $20 \%$ of the ventral area of the head (Figs. 3 C, D, 5 B , C) (Skartveit, 2002). Mandibles and 
355

356

357

358

359

360

361

362

363

364

365

366

367

368

369

370

371

372

373

374

375

376

377

378

379

380

381

382

383

384

385

386

387

388

389

390

391

392

393

394

395

labrum are unavailable for a detailed examination due to being obscured by the other structures

of the head.

Systematic interpretation, trunk structures: The general shape the body of the fossil larva is cylindrical with no parapods or other organs of locomotion (Fig 2A, 2B). Fleshy protuberances are protruding from the cuticle of the abdomen of the fossil larva. Numerous larvae of Bibionidae are exhibiting this condition as well. In particular, cuticular protuberances are typical for larvae of Plecia or Penthetria (both ingroups of Bibionidae) (Figs. 5A-C).

The protuberances of $D$. hoffeinseorum sp. nov. however differ from the protuberances of known larvae of Bibionidae, by their characteristic shape. The proximal attachment of the protuberances is relatively narrow expanding towards midlength, and narrowing towards conical distal end. (Figs. 2A, 2B). That character is differentiating D. hoffeinseorum sp. nov. from larvae of Bibionidae. In the latter the protuberances are simply tapering towards the tip (Fig. 2B). Additionally, the largest protuberances of $D$. hoffeinseorum sp. nov. are situated at the thorax and abdominal segments 1 and 2 , in contrast to most larvae of Bibionidae, in which the length of the protuberances is increasing towards the posterior (Figs. 2A, 2B, Fig. S1). It is also possible, based on appearance, that the protuberances of $D$. hoffeinseorum sp. nov. are much more rigid than those of the known extant larvae of Bibionidae.

The tracheal system of the fossil larva is of the holopneustic type ("type 1",10 pairs of spiracles: one on the prothorax, one on the metathorax, one pair at abdominal units 1-7, and one pair at the trunk end; sensu Hennig, 1968). A holopneustic tracheal system is characteristic for larvae of Bibionidae.

The spiracle openings of the fossil larva are sitting on small elevated discs, representing a character state similar to that of some ingroups of Bibionidae. In larvae of Plecinae spiracle openings sit on conical outgrowths (Figs. 4A, 5B, 5C; cf. Skartveit, 2017). Most of the spiracles in the fossil are obscured by a silvery film, which, as it appears, formed by air, forced out from the tracheal system of the larva upon the entrapment in amber. Despite the obstruction of the view, the last tracheal spiracle pair (on abdominal unit 9) clearly has a single ecdysial scar, similar to larvae of Penthetria (Figs. 2A, 2B vs. 5A). In larvae of Bibionidae, the posterior spiraclesare positioned posterior-laterally on the trunk end (Skartveit, 2002, 2017; Skartveit and Willassen, 1996). In contrast to them, the posterior spiracles of the new larva are situated at the anterio-dorsal part of the trunk end. Also, the posterior spiracles of the new larva are not larger than the other spiracles of the same larva. This is in contrast to known larvae of Bibionidae.

In summary the fossil larva, here described as $D$. hoffeinseorum sp. nov. differs from any known larva of Bibionidae in three key characters: 1) a strong process at the distal end of element I of the maxilar palp, 2) a dorso-laterally position of spiracle 10. (on the trunk end); (Fig. $\mathrm{S} 1)$; protuberances of unique shape.

Systematic interpretation, summary: In fact, the larva described as Dinobibio hoffeinseorum sp. nov. is so different from known larval forms of Bibionidae concerning the general body pattern 
396

397

398

399

400

401

402

403

404

405

406

407

408

409

410

411

412

413

414

415

416

417

418

419

420

421

422

423

424

425

426

427

428

429

430

431

432

433

434

435

436

and the arrangement of the spiracles in the tracheal system, that it cannot be easily interpreted as an ingroup of Bibionidae (Skartveit, 2008, 2017). We can think of two possible explanations for the distinctiveness of the $D$. hoffeinseorum sp. nov. in comparison to larvae of Bibionidae 1) $D$. hoffeinseorum sp. nov. is not an ingroup of Bibionidae, but rather a sister species to the group. 2) D. hoffeinseorum sp. nov. is representing a highly derived branch of Bibionidae, that is now extinct.

Neither of these explanations can be conclusively excluded, until further specimens of D. hoffeinseorum sp. nov. will become available, but it is beyond any doubt that this new species is very distinct from the rest of the known larvae of Bibionomorpha. The larvae of $D$. hoffeinseorum sp. nov. is exhibiting a curious mixture of traits, in this combination not known from any other larva of Diptera (cf. Kirk Spriggs and Sinclair, 2017). It does however possess the characters known from larvae of Bibionidae and Mycetophilidae, yet in an unusual combination (i.e. see the discussion of the maxilla palpi element one outgrowth).

In fact, such "impossible" character combinations, are quite common in the fossil record, representing an "experimental" phase of evolution, when a number of traits were independently evolving in different lineages (e.g. Haug et al., 2019). Theccurrence of such an unusual combination of characters might be a natural result of the "Push of the Past" effect, caused by the fact that most of the lineages surviving until the present, done so as a result of the initial diversification (Budd and Mann, 2018). On the other hand the unique combination of characters in $D$. hoffeinseorum sp. nov. might be indicative of the active diversification in Bibionomorpha in the Eocene, which challenges the common view of the representatives of Insecta in the Baltic amber fossils as being "mostly modern" (Zherikhin, 2003).

We would like to note that some colleagues have expressed reservations about describing new taxa based on immature stages. Yet, when it is possible to provide proper comparative diagnostics it is perfectly valid (according to ICZN) and also common to do this. In the present case the larva is so distinct that it is well possible to recognise the larva as a separate taxonomic entity.

Pachyneuridae + Hesperinidae (unnamed monophyletic group, Krivosheina, 2012)

Pachyneuridae Schiner, 1864

Pachyneura Zetterstedt, 1838

(Figs. 6A, 6B, 7A, 7B, 8A-D)

Material: A single fossil larva from the collection of Carsten Gröhn, which is now part of the CeNak collection (Hamburg) with the collection number GPIH-L-7516. Specimen moderately well preserved, with posterior parts of the trunk obscured by cracks, lateral view not available. It appears that the specimen was desiccated before being encased in amber as evident from its somewhat distorted appearance.

Syninclusions: "Stellate hairs" (oak leaf trichomes). 
437

438

439

440

441

442

443

444

445

446

447

448

449

450

451

452

453

454

455

456

457

458

459

460

461

462

463

464

465

466

467

468

469

470

471

472

473

474

475

476

\section{Description:}

Habitus. Medium sized larva with an dorso-ventrally flattened, spindle-shaped body. Total length $2.8 \mathrm{~mm}$. Body differentiated into presumably 20 segments, ocular segment plus 19 postocular segments (Figs 6A, B, 7A, B).

Head. Ocular segment and post-ocular segment 1-5 (presumably) forming a distinct capsule (head capsule). Head capsule wider than long. Hind part of head capsule not retracted into anterior trunk. Dimensions of head capsule: $450 \mu \mathrm{m}$ long, $770 \mu \mathrm{m}$ wide. Surface of head capsule smooth and glossy. Ocular segment without apparent stemmata (larval eyes) (9 A-D).

Ocular segment recognizable by its appendage derivative, clypeo-labral complex. Clypeus (clypear sclerite) roughly rectangular, $200 \mu \mathrm{m}$ long, $380 \mu \mathrm{m}$ wide. Labrum small, weakly sclerotized (Fig. 8C).

Post-ocular segment 1 without externally recognizable structures. Antenna not discernible, probably reduced. (Fig. $8 \mathrm{~A}$ ).

Post-ocular segment 2 (intercalary segment) without externally recognizable structures (Fig. $8 \mathrm{C})$.

Post-ocular segment 3 recognizable by its pair of appendages, mandibles. Mandible total length $220 \mu \mathrm{m}$, with 3 strong teeth on the apex, apical and subapical teeth sub-equal (all ca. $22 \mu \mathrm{m}$ in length), molar tooth shorter (16 $\mu \mathrm{m})$ (Fig. 8C).

Post-ocular segment 4 recognizable by its appendage, maxilla [maxillula]. Maxilla massive, organized into proximal part and distal part or palp [endopod]. Very proximal region with sclerite (hypostomal bridge). Further distal proximal part differentiated into two lobes, outer lobe and inner lobe. Inner lobe wth possible lacinia [endite]. Possible lacinia rectangular in outline, $100 \mu \mathrm{m}$ long, $70 \mu \mathrm{m}$ wide. Palp arising from outer lobe, cylindrical, with two elements (palpomeres). Element $1104 \mu \mathrm{m}$ long, $45 \mu \mathrm{m}$ long, with 4 hair-like setae distally (Fig. 8C).

Post-ocular segment 5 recognizable by its appendages, forming the labium [conjoined left and right maxillae]. Labium largely obscured by the large possible lacinia (Fig. 8C).

Trunk with 12 visible units, interpreted as 3 thorax segments plus 8 abdominal units and a trunk end, representing a conjoined structure of possibly undifferentiated abdominal segments (9-11?) (Figs 6A, B; 7 A, B). Trunk widest at about half of the length with $910 \mu \mathrm{m}$, diameter decreasing posteriorly to $280 \mu \mathrm{m}$. Trunk with elevated ridges (possible creeping welts) at units 1-6 (three thorax units, and first three units of the abdomen). Trunk surface with numerous small spines. Trunk bears 10 pairs of spiracles (openings of the tracheal system). Spiracles surrounded by lightly-coloured fields on the otherwise heavily sclerotized trunk units. Spiracles appear to have single ecdysial scars.

Thorax consists of three segments, pro-, meso- and metathorax.

Prothorax $80 \mu \mathrm{m}$ long. Prothorax bears a pair of large spiracles. Prothorax subdivided into two parts by annular constriction.

Mesothorax $95 \mu \mathrm{m}$ long. No spiracle openings present. Mesothorax bears two lateral setae (ca. $70 \mu \mathrm{m}$ long ) on each side of the segment. 
477 Metathorax $90 \mu \mathrm{m}$ long. Metathorax bears two groups of dorsal setae (20-40 $\mu \mathrm{m}$ long), and two 478 lateral setae (ca $70 \mu \mathrm{m}$ long ) on each side of the segment. Metathorax bears a pair of spiracles.

479 Abdomen (posterior trunk) Abdominal units progressively increasing in dorsoventral aspect 480 towards the posterior part of the body, until reaching midlength of the abdomen, then decreasing 481 again, towards the trunk end.

482 Abdominal units 1-4, 6 bear two groups of dorsal setae (20-40 $\mu \mathrm{m}$ long), and two lateral setae 483 (ca $70 \mu \mathrm{m}$ long ) on each side of the segment. Units 1-8 each bearing a pair of spiracles laterally. 484 Abdominal unit 5 (abdomen segment 5) bears two lateral setae (ca $70 \mu \mathrm{m}$ long ) on each side of 485 the segment.

486 Abdominal unit 7 (abdomen segment 7) bears two lateral setae (ca $70 \mu \mathrm{m}$ long ) on each side of 487 the segment.

488 Trunk end (undifferentiated abdomen segments 9-11?) obscured by cracks.

489

490

491

492

493

494

495

Systematic interpretation: The general body shape, as well as absence of ambulatory legs on the thorax, and the spiracle arrangement is consistent with this larva being an immature stage of Diptera. Numerous characters indicate that this is a larval form of Bibionomorpha: The larva possesses a very wide head capsule. The body as a whole is somewhat flattened dorso-ventrally, bearing six pairs of small ridges on the ventral side of the first six segments of the trunk (Figs. $6 \mathrm{~A}, 6 \mathrm{~B}, 7 \mathrm{~A}, 7 \mathrm{~B})$.

497

498

499

500

501

502

503

504

505

506

507

508

509

510

511

512

513

514

515

516

517

The specimen is unusual by the combination of a holopneustic tracheal system ("type 2": spiracles (Hennig, 1968) on the prothorax, metathorax and abdominal segments 1-8, Fig 6B), presence of long setae on the abdomen, the head capsule being wider than long (Figs. 6A, 6B, 7A, 7B), prothorax being subdivided by a transversal furrow into the two rings (Figs. 6B, 7B). All spiracles are surrounded by a lighter coloured area, in contrast to the more sclerotized parts of the segments. There are no other known larvae of Bibionomorpha with this state of characters. It is possible however that the lighter areas are actually taphonomic artefacts, caused by air extrusions from the tracheal system upon the entrapment in amber.

The tracheal system with ten pairs of spiracles on the pro- and metathorax as well as on abdominal units 1-8 (Fig. 6B), is a synapomorphy of the bibionomorphan ingroups

Pachyneuridae + Hesperinidae (Krivosheina, 2012). The fossil is however distinct from larvae of Hesperinidae by bearing a large number of long setae (up to $70 \mu \mathrm{m}$ long) on the abdominal units. Larvae of Hesperinidae possess only very short setae (Kivosheina, 2012). Pachyneura (only ingroup of Pachyneuridae sensu Paramonov and Salmela 2015) includes two species Pachyneura fasciata Zetterstedt, 1838 and P. oculata Krivosheina \& Mamaev, 1972. Due to the suboptimal preservation of the larva, we decided not to formally describe a new species, as the resulting holotype would be not optimal for future comparative work.

In general, based on the combination of morphological characters, the larva appears to be a typical larva of Pachyneura (Pachyneuridae see Paramonov and Salmela 2015). This is the first and thus oldest fossil record of Pachyneuridae sensu Paramonov and Salmela (2015).

Cramptonomyiidae, the sister group of Pachyneuridae+Hesperinidae, is present in the fossil 
518 record with representatives of its ingroups Tega Blagoderov, Krzeminska and Krzeminski, 1993

519 and Pivus Blagoderov, Krzeminska and Krzeminski, 1993 from Upper Jurassic respectively the

520 Lower Cretaceous of Asia (Blagoderov et al., 1993).

521

522

523 Anisopodidae Knab, 1912

524 Mycetobia Meigen, 1818

525

526

527

528

529

530

531

532

533

534

535

536 Habitus. Medium sized larva with roughly vermiform body (9 A, B). Total length 1.8-10.2 mm

537

538

539

540

541

542

543

544

545

546

547

548

549

550

551

552

553

554

555

556

557

Material: 53 specimens of larvae and pupa in total were examined, see Table 1 for a complete list of the material. We were not able to distinguish distinct morphotypes for the larvae of Mycetobia, while for the pupae three distinct morphotypes are apparent.

Larvae

(Figs. 9 A-D; 10 A-E; Figs. S2-S10)

Material: see table 1 and Figs . 9 A-D; 10 A-E, Figs. S2-S10.

Description:

(all life stages; see table 2 for the summary of the morphometrics of the studied specimens) (10 A, B).

Body differentiated into presumably 20 segments, ocular segment plus 19 post-ocular segments (9 A-D, 10A-E).

Head. Ocular segment and post-ocular segment 1-5 (presumably) forming distinct capsule (head capsule). Head capsule longer than wide. Head capsule well developed, fully sclerotized dorsally, partially sclerotized ventrally. Hind part of head capsule not retracted into anterior trunk. Dimensions of head capsule: length 99-512 $\mu \mathrm{m}$ ( $\mathrm{n}=25$, all life stages), width 85-420 $\mu \mathrm{m}$ ( $n=26$, all life stages). Surface of head capsule smooth and glossy.

Ocular segment without apparent stemmata (larval eyes). Ocular segment recognisable by its appendage derivative, clypeo-labrum complex (Figs 10 A, D).

Post-ocular segment 1 recognizable by its appendages, antennae [antennulae]. Antenna represented by a single, cone-shaped element bearing a mushroom-like sensillum distally (Figs. 10 A, B, D, E).

Post-ocular segment 2 (intercalary segment) without externally recognizable structures (Figs. $10 \mathrm{~A}, \mathrm{~B})$.

Post-ocular segment 3 recognizable by its pair of appendages, mandibles. Mandible divided into large, unsclerotized proximal portion, and heavily sclerotized distal portion, bearing numerous teeth. (Figs. 10 A, B, D,E).

Post-ocular segment 4 recognisable by its appendage, maxilla [maxillula]. Maxilla massive, organised into proximal part and distal part or palp [endopod]. Maxilla fleshy, very weakly 
558 sclerotized, only general outline visible. Proximal part differentiated into two lobes, outer lobe

559

560

561

562

563

564

565

566

567

568

569

570

571

572

573

574

575

576

577

578

579

580

581

582

583

584

585

586

587

588

589

590

591

592

593

594

595

596

597 and inner lobe. Palp small, stump-like (Figs. 10 A, B).

Post-ocular segment 5 recognisable by its appendages, forming the labium [conjoined left and right maxillae]. Labium, especially proximal part (mentum), narrow and weakly sclerotized, trapezium-shaped. No distal structures (palpi) apparent. Posterior tentorial pits (external anchor point of the internal skeleton of the head capsule) present (Figs. $10 \mathrm{~A}, \mathrm{~B}$ ).

Trunk. Trunk composed of 11 visible units: pro-, meso- and metathorax, 7 abdominal units and the trunk end. Trunk worm-like, units sub-equal in diameter (Figs. 9 A, B). Trunk lacks

parapodia and/or creeping welts. Trunk bears two pars of spiracles: one on prothorax (Fig. 9 C) and one on trunk end (Figs. 9 C, D).

Thorax consists of three segments, pro-, meso- and metathorax.

Prothorax bears small, cone-shaped, anterior spiracles situated on posterolatero-dorsal surface. Prothorax subdivided into two unequal parts by annular constriction.

Meso- and metathorax subequal to prothorax in length, but without annular constriction (Figs. $9 \mathrm{~A}, \mathrm{~B})$.

Abdomen (posterior trunk) with abdominal units cylindrical, roughly equal to each other in diameter.

Abdominal units 1-7 subdivided into two unequal parts by annular constriction Trunk end (undifferentiated abdomen segments 8-11?) subdivided into three unequal parts by two annular constrictions, with perianal shield (modified area of the last unit surrounding the anal aperture) on the ventral side. Trunk end bears posterior spiracles situated on the mediopostero-dorsal surface of the unit. Spiracular field surrounded by 5 short lobes, bearing no apparent hairs (Figs. 9 A-D).

\section{Systematic interpretation:}

The general body shape, as well as the absence of ambulatory legs on the thorax, and the spiracle arrangement are consistent with these larvae being immature stages of the group Diptera. The larvae furthermore show a distinct combination of characters: slender, vermiform body; head sclerotized; dorsal part more strongly sclerotized than ventral one; mandible consists of fleshy proximal part more heavily sclerotised distal part; prothorax and abdominal units 1-7 each subdivided into two unequal parts by an annular constriction; respiratory system amphipneustic; anterior spiracles on a small cone on prothorax; posterior spiracles on spiracular field, on the posterior of the trunk; trunk end covered by a perianal shield; the trunk end further subdivided into three parts.

This character combination matches the condition in larvae of Anisopodidae (window gnats). Furthermore the fossil larvae show a spiracular disc surrounded by only very short lobes and weak setae (Fig. 9 A-D, 11 A-D). This character is an autapomorphy of Mycetobia (ingroup of Anisopodidae).

\section{Pupae}


598

599

600

601

602

603

604

605

606

607

608

609

610

611

612

613

614

615

616

617

618

619

620

621

622

623

624

625

626

627

628

629

630

631

632

633

634

635

636

637

638

Morphotype 1

(Fig. 12 A, B; Figs. S11-S26)

Material: see table 1 and Fig. 12 A, B; Figs. S11-S26

Description:

Habitus. Medium sized pupa, with generally comma-shaped body in lateral view (Figs. 12 A, B; Figs. S11-S26). Pupae coloured roughly in the same colour as the matrix of the amber. Total length 2.7-5.1 mm long ( $\mathrm{n}=14)$. See table 3 for a summary of the morphometrics. Body differentiated into presumably 20 segments, ocular segment plus 19 post-ocular segments. Ocular segment and post-ocular segment 1-8 (presumably) forming a single globose unit (Figs. 12 A, B; Figs. S11-S26).

Ocular segment recognizable by its appendage derivative, clypeo-labrum complex and pair of large compound eyes. Labrum oval, slightly invaginated, membranous. Clypeus continuous with labrum (Figs. 12 A, B, Fig. S21). Frons (frontal sclerite) with a pair of short setae, situated on top of small conical warts. Setae of frontal sclerite longer than warts (Figs. 12 A, B; Fig. S 21).

Post-ocular segment 1 recognizable by its appendages, antennae [antennulae]. Antenna consisting of 16 elements. Antennae moderately long, following the dorso-posterior outlines of the compound eyes.

Post-ocular segment 2 (intercalary segment) without externally recognizable structures (Figs. 12 A, B; Fig. S21).

Post-ocular segment 3 without externally recognizable structures (mandibles) (Figs. 12 A, B; Fig. S21).

Post-ocular segment 4 recognizable by its appendage, maxilla [maxillula]. Maxilla with proximal part (non-serrated "lacinia") and distal part, palp [endopod] (Figs. 12 A, B; Fig. S 21). Post-ocular segment 5 recognizable by its appendages, forming the labium [conjoined left and right maxillae]. Proximal parts of labium membranous, bears labial palps (Figs. 12 A, B; Fig. S 21).

Thorax consists of three segments, pro-, meso- and metathorax. Each bears a pair of (ambulatory) appendages (fore-, mid- and hind legs). Wings on mesothorax; halterae on metathorax. Thorax segments forming a single semiglobose structure, closely enveloping the head (Figs. 12 A, B; Fig. S21).

Ambulatory appendages (legs) U-shaped folded, running between the wings: mid- and hind legs terminating above the mid-length of the first posterior trunk (abdomen) unit. Ambulatory appendages curving between the wing tips, and then, diverging again after passing the tips of the wings (Figs. 12 A, B; Figs. S21, 25, 26). All ambulatory appendages subdivided into the elements: coxa, trochanter, femur, tibia and tarsus (subdivided into 5 elements).

Prothorax bears thoracic horns (modified spiracle 1). Thoracic horns club shaped, situated posterior to the eyes on the dorsal surface of the prothorax (Figs. 12 A, B). Prothorax bears 1st thoracic appendage pair (forelegs). Forelegs with femur and tibia forming a U-shaped loop, with

Peer] reviewing PDF | (2019:06:38366:3:2:NEW 4 Sep 2019) 
639 anteriormost point of the loop reaching the level at which the maxillae arise.

640 Mesothorax bears a pair of wings. Base of the wing aligned with the tip of the antennae.

641 Midlegs underlying the forelegs, reaching beyond the tip of the wing.

642 Metathorax with a pair of spiracles. Hind legs underlying the forelegs and midlegs, reaching

643 beyond the tip of the wing (Figs. $12 \mathrm{~A}, \mathrm{~B}$ ).

644 Length of head and thorax combined 1.0-2.3 mm ( $\mathrm{n}=14)$. Abdomen 1.8-3.6 mm long $(\mathrm{n}=14)$.

645 Abdomen (posterior trunk). With 9 units.

646 Abdominal units 1-8 each bearing two rings of strong hooklets. 12 hooklets in the first ring,

647 circa 70 hooklets in the second ring (Figs. 12 A, B). Abdominal units 2-8 each bearing a pair of

648 small spiracles (Figs. 12 A, B, Fig. S21).

649

650

Trunk end (undifferentiated abdomen segments 9-11?) bears a pair of the lateral expansions

651 (anal lobes) $8+2$ hooklets. Hooklets arranged in 2 rings, two additional hooklets located on the

652 anal lobes (Figs. 12 A, B; Fig. S21). Abdomen length 1.7-3.6 mm (n=14).

653

654

Mycetobia pupa morphotype 2

655 (Figs.13 A, B, Fig. S 27)

656

657

Material: This morphotype is represented by two pupae in our material; one specimen in the

658 amber piece GPIH-7514 (originally from the collection of Carsten Gröhn), a second specimen in

659 the amber piece PED-4866.

660

661

Description:

662 Habitus. Medium sized pupa, with generally comma-shaped body in lateral view. Pupa in

663 whitish-green to brown colours. Total length $4.3-5.3 \mathrm{~mm}$ long $(\mathrm{n}=2)$.

664 Body differentiated into presumably 20 segments, ocular segment plus 19 post-ocular segments.

665 Anterior part of the body composed of head and thorax, visible as a single globose structure

666 (Figs 13 A, B; Fig. S 27).

667 Ocular segment and post-ocular segment 1-5 (presumably) forming distinct capsule (head

668 capsule).

669 Ocular segment and post-ocular segment 1-5 (presumably) forming distinct caspule (head

670 capsule). Ocular segment recognizable by its appendage derivative, clypeo-labrum complex and

671 pair of large compound eyes. Labrum oval, slightly invaginated, membranous. Clypeus

672 continuous with labrum (Figs 13 A, B; Fig. S 27). Frons (frontal sclerite) of post-ocular segment

6731 with a pair of short setae, situated on top of small conical warts. Setae of frontal sclerite shorter 674 than warts.

675 Post-ocular segment 1 recognizable by its appendages, antennae [antennulae]. Antenna

676 consisting of 16 elements. (Figs 13 A, B; Fig. S 27). Antennae moderately long, following the

677 dorso-posterior outlines of the compound eyes.

678 Post-ocular segment 2 (intercalary segment) without externally recognizable structures.

679 Post-ocular segment 3 without externally recognizable structures (mandibles). 
680 Post-ocular segment 4 recognizable by its appendage, maxilla [maxillula]. Maxilla organised

681

682

683

684

685

686

687

688

689

690

691

692

693

694

695

696

697

698

699

700

701

702

703

704

705

706

707

708

709

710

711

712

713

714

715

716 Material: Morphotype 3 is represented by 2 specimens, one actual pupa and one adult emerging

717 from exuvium: table 1 and Figs. 14 A, B; Figs. S 28, 29.

718

719

into proximal part (non-serrated "lacinia") and distal part, palp [endopod].

Post-ocular segment 5 recognizable by its appendages, forming the labium [conjoined left and right maxillae]. Proximal part of labium membranous, bears labial palps (Figs 13 A, B; Fig. S 27).

Thorax consists of three segments, pro-, meso- and metathorax. Each bears a pairs of (ambulatory) appendages (fore, mid-and hind legs). Wings on mesothorax. Halterae on metathorax.

Thorax segments forming a single semiglobose structure, closely enveloping the head (Figs 13 A, B; Fig. S 27).

Ambulatory appendages (legs) U-shaped folded, running between the wings; mid- and hind legs terminating anterior to the mid-length of the first posterior trunk (abdomen) unit.

Ambulatory appendages do not curve between the wing tips, width of the legs stays constant, without divergence distally at the tips (Figs 13 A, B; Fig. S 27). All ambulatory appendages subdivided into the elements: coxa, trochanter, femur, tibia and tarsus (subdivided into 5 elements).

Prothorax bears thoracic horns (modified spiracle 1). Thoracic horns club shaped, situated posterior to the eyes on the dorsal surface. Forelegs superimposed over the thorax appendages 2 and 3, not reaching wings tip. Forelegs with femur and tibia forming a U-shaped loop, with anteriromost point of the loop reaching the level at which maxillae arise.

Mesothorax bears a pair of wing. Antennae do not reach the base of the wing. Midlegs underlying the forelegs, reaching beyond the tip of the wing.

Metathorax bears a pair of halterae and a pair of spiracles. Hindlegs underlying the forelegs and midlegs, reaching beyond the tip of the wing (Figs 13 A, B; Fig. S 27).

Length of head and thorax combined 1.9-2.2 $\mathrm{mm}(\mathrm{n}=2)$.

Abdomen (posterior trunk). With 9 units.

Abdominal units 1-8 each bearing two rings of strong hooklets. Four hooklets in the first ring, circa 48 hooklets in the second ring.

Trunk end (undifferentiated abdomen segments 9-11?) bears 6 hooklets, two at the anal lobes (Figs 13 A, B; Fig. S 27). Abdomen 2.7-3.2 mm long ( $\mathrm{n}=2$ ).

Mycetobia pupa morphotype 3

(Figs. 14 A, B; Figs. S 28, 29)

Description:

Peer] reviewing PDF | (2019:06:38366:3:2:NEW 4 Sep 2019) 
720 Habitus. Medium-size insect pupae, with generally comma-shaped body. Pupae brown. Total

721

722

723

724

725

726

727

728

729

730

731

732

733

734

735

736

737

738

739

740

741

742

743

744

745

746

747

748

749

750

751

752

753

754

755

756

757

758

length $0.82-0.86 \mathrm{~mm}$ long $(\mathrm{n}=2)$. Body differentiated into presumably 20 segments, ocular segment plus 19 post-ocular segments (Figs. 14 A, B; Figs. S 28, 29). Anterior part of the body composed of head and thorax, visible as a single globose structure.

Ocular segment and post-ocular segment 1-5 (presumably) forming distinct capsule (head capsule). Ocular segment and post-ocular segment 1-5 (presumably) forming a distinct capsule (head capsule). Ocular segment recognisable by its appendage derivative, clypeo-labrum complex and pair of large compound eyes. Labrum oval, slightly invaginated, membranous. Clypeus continuous with labrum (Figs. 14 A, B. Frons (frontal sclerite) with a pair of short setae, situated on the top of small conical warts (Figs. 14 A, B; Figs. S 28, 29).

Post-ocular segment 1 recognisable by its appendages, antennae [antennulae]. Antenna consisting of 16 elements. Antennae moderately long, following the dorso-posterior outlines of the compound eyes.

Post-ocular segment 2 (intercalary segment) without externally recognisable structures. Post-ocular segment 3 without externally recognisable structures (mandibles) (Figs. 14 A, B; Figs. S 28, 29).

Post-ocular segment 4 recognisable by its appendage, maxilla [maxillula]. Maxilla with proximal part (non-serrated "lacinia") and distal part, palp [endopod] (Figs. 14 A, B; Figs. S 28, 29).

Post-ocular segment 5 recognisable by its appendages, forming the labium [conjoined left and right maxillae]. Proximal part of labium membranous, bears labial palps (Figs. 14 A, B; Figs. S $28,29)$.

Thorax consists of three segments, pro-, meso- and metathorax. Each bears a pairs of (ambulatory) appendages (fore, mid-and hindlegs). Wings on mesothorax. Halterae on metathorax.

Thorax segments forming a single semiglobose structure, closely enveloping the head of the pupa.

Ambulatory appendages U-shaped folded, running between the wings; mid- and hind legs terminating above the mid-length of the first posterior trunk (abdomen) unit. Ambulatory appendages curving between the wing tips, and then, diverging again after passing the tips of the wings (Figs. 14 A, B; Figs. S 28, 29). All ambulatory appendages subdivided into elements:: coxa, trochanter, femur, tibia and tarsus subdivided into 5 elements.

Prothorax bears thoracic horns (modified spiracle 1). Thoracic horns club shaped, situated posterior to the eyes on the dorsal surface of the prothorax. Prothorax bears 1st thoracic appendage pair (forelegs). Forelegs superimposed over the thorax appendages 2 and 3, not reaching wings tip. Forelegs with femur and tibia forming a $U$-shaped loop, with anteriormost point of the loop reaching the level at which maxillae arise (Figs. 14 A, B; Figs. S 28, 29).

Mesothorax bears a pair of wing. Midlegs underlying the forelegs, reaching beyond the tip of the wing (Figs. 14 A, B; Figs. S 28, 29). Base of the wing aligned with the tip of the antennae.

Peer) reviewing PDF | (2019:06:38366:3:2:NEW 4 Sep 2019) 
759 Metathorax bears a pair of halterae and a pair of spiracles. Hindlegs underlying the forelegs 760 and midlegs, reaching beyond the tip of the wing (Figs. 14 A, B; Figs. S 28, 29).. Base of the 761 wing aligned with the tip of the antennae.

762 Abdomen (posterior trunk) with 9 units.

763 Abdominal units 1-8 each bearing two rings of strong hooklets. 12 hooklets in the first ring,

764 circa 70 hooklets in the second ring.

765 Trunk end (undifferentiated abdomen segments 9-11?) bears a pair of the lateral expansions 766 (anal lobes) and $8+2$ hooklets. Hooklets arranged in 2 rings, two additional hooklets sitting on 767 anal lobes (Figs. 14 A, B; Figs. S 28, 29). Abdomen length 0.5-0.6 mm (n=2).

768

769

770

771

772

773

774

775

776

777

778

779

780

781

782

783

784

785

786

787

788

789

790

791

792

793

794

795

796

797

798

799

Systematic interpretation (all 3 morphotypes):

Pupae of all three morphotypes possess a single pair of wings on the mesothorax and developing halterae on the metathorax identifying them as pupae of the group Diptera. They are interpreted as representatives of Anisopodidae based on the following combination of characters: slender; antennae long, reaching, at least, until to the wing base; forelegs not reaching tip of wing, but mid and hindlegs reaching beyond the wings; thoracic horns small and oval to mushroom-like; spiracles present on metathorax and abdominal units 2-7. Last unit of abdomen bearing four pairs of strong denticles (Fig. 15 A-D).

Pupae of all three morphotypes possess characters autapomorphic for the group Mycetobia (ingroup of Anisopodidae): head bearing short frontal setae on conical warts; anterior and posterior margins of abdominal tergites bear rows of strong denticles.

Pupa morphotypes 1 and 2 can be distinguished from each other based on the number of denticles in the anterior row of the tergites, four in morphotype 2 and twelve in morphotype 1. Morphotype 1 can potentially include numerous species, indistinguishable in this stage and especially degree of preservation. Another diagnostic character differentiating the two morphotypes is the presence of a distal outward curvature of the legs of the morphotype 1, while morphotype 2 legs are of the constant width. Morphotype 3 is highly reminiscent of morphotype 1 but is significantly smaller, only about $30 \%$ of the total length of morphotype 1 .

It is worth mentioning that the morphotypes might in fact result from sexual dimorphism. Yet, the examination of pupae of the extant species Mycetobia pallipes did not show any notable sexual dimorphism among the examined (non-pharrate) pupae, also not concerning size. However, it will require examination of many more species of Mycetobia to draw any wellfounded conclusions.

Taxonomic attribution: The morphology of both the larvae and the pupae is entirely in line with corresponding stages of extant representatives of Mycetobia. At least some of the representatives of pupa morphotype 1 are most likely representatives of Mycetobia connexa, which is the most abundant species of Mycetobia in Baltic amber (Wojton et al., 2019). This is indicated by the common preservation in the amber piece PED-4395, which contains a single exuvium of a pupa of morphotype 1 as well as two adult representatives of Anisopodidae, a male and female (Figs. 


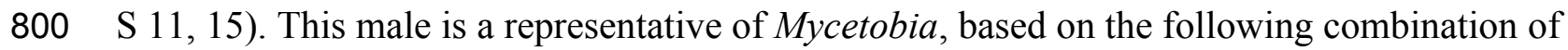
801 characters: wing without discal cell, medial vein with three branches, radial vein $2+3$ ending in 802 costa, radial vein $4+5$ ending proximal to the end of the costal vein, anal vein 1 very faint 803 (Hancock, 2017). It can be interpreted as a representative of Mycetobia connexa Meunier, 1899 804 based on the following combination of characters: antenna elements (flagellomeres) 8-13 up to 805 two times as long as wide; distal element of maxillary palp (palpomere) at most 3 times as long 806 as wide, thinned; subcostal vein ending proximal to radial sector bifurcation; radial vein 1 ending 807 on costal vein apex proximally of medial vein $1+2$ bifurcation; fork of medial vein $1+2$ wide; 808 medial vein $1+2$ elongated, as long as medial vein 1 ; medial vein 2 and medial vein $3+4$ 809 separated by a distance at least two times as the distance between ends of the medial vein 1 and 810 medial vein 2; radial vein $2+3$ two and $50 \%$ as long as radial sector or shorter; tarsus of foreleg $81130 \%$ of the length of entire leg (including the coxa; Figs. S 11, 15) (Wojton et al., 2019a). We 812 interpret the male and the female of the Mycetobia inclusions in this piece as both being 813 representatives of $M$. connexa based on the identical wing venation and similar antennae. We 814 have associated the pupal exuvium with the adults, based on their proximity in amber (Figs. S 815 11, 15).

816 It is so far impossible to determine associations of the studied larvae with any of the 817 seven species of Mycetobia currently known from Eocene European ambers (Wojton et al., 818 2019). Future records of pupal exuvia with emerging or pharate adults and/or associated larval 819 exuvia may allow for the association of further life stages. The record of three pupal 820 morphotypes of Mycetobia in Baltic and Bitterfield amber is unsurprising, given the relatively 821 high species richness of Mycetobia in those Lagerstätten (Wojton, et al., 2019).

822

823

824 Anisopodidae Knab, 1912

825 Sylvicola Fatio, 1867

826 (Figs. $16 \mathrm{~A}-\mathrm{D})$

827

828 Material: Single larva, in Baltic amber, DEI Dip-00641.

829

830 Description:

831 Habitus. Medium sized larva with roughly vermiform body. Total length $6.4 \mathrm{~mm}$. Body 832 differentiated into presumably 20 segments, ocular segment plus 19 post-ocular segments (Figs. $83316 \mathrm{~A}-\mathrm{D})$.

834 Head. Ocular segment and post-ocular segment 1-5 (presumably) forming distinct caspule (head 835 capsule). Head capsule longer than wide. Head capsule well developed, fully sclerotized 836 dorsally, partially sclerotized ventrally. Head capsule in dorsal view not accessible due to 837 orientation of the specimen. Hind part of head capsule not retracted into anterior trunk. Head 838 capsule $280 \mu \mathrm{m}$ long. Surface of head capsule smooth and glossy (Figs. 16 A-D). 
839 Ocular segment without apparent stemmata (larval eyes). Ocular segment recognisable by its

840 appendage derivative, clypeo-labrum complex. Labrum $70 \mu \mathrm{m}$ long (Figs. 16 A-D).

841 Post-ocular segment 1 recognizable by its appendages, antennae [antennulae]. Antenna conical,

842 consisting of one element, $44 \mu \mathrm{m}$ long.

843 Post-ocular segment 2 (intercalary segment) without externally recognizable structures.

844 Post-ocular segment 3 recognisable by its pair of appendages, mandibles. Mandible only

845 accessible at the distal tip, proximal part obscured. Mandible divided into large, unsclerotised

846 proximal portion, and heavily sclerotized distal portion, bearing numerous teeth.

847 Post-ocular segment 4 recognisable by its appendage, maxilla [maxillula]. Maxilla massive,

848 organised into proximal part and distal part, palp [endopod]. Proximal part of the maxilla fleshy,

849 very weakly sclerotized, only general outline visible. Maxilla bears six cone-like outgrows,

850 probably sensillae. Proximal part differentiated into two lobes, outer lobe and inner lobe (Figs.

85116 A-D).

852 Post-ocular segment 5 recognisable by its appendages, forming the labium [conjoined left and 853 right maxillae].

854 Trunk composed of 11 visible units: pro-, meso- and metathorax plus 8 abdominal units. Trunk 855 worm-like, units sub-equal in diameter. Trunk lacks parapodia and/or creeping welts. Trunk 856 bears two pars of spiracles, on prothorax and abdominal unit 8.

857 Thorax consists of three segments, pro-, meso- and metathorax.

858 Prothorax bears small, cone-shaped, anterior spiracles situated on postero-latero-dorsal surface.

859 Prothorax subdivided into two unequal parts by annular constriction.

860 Meso-and Metathorax subequal to prothorax, but without spiracles.

861 Abdomen (posterior trunk). Abdominal units are cylindrical, roughly equal to each other in 862 diameter (Figs. $16 \mathrm{~A}-\mathrm{D})$.

863 Abdominal units 1-7 subdivided into two unequal parts by annular constriction.

864 Trunk end (undifferentiated abdomen segments 8-11?) subdivided into three unequal parts by

865 two annular constrictions. Trunk end covered with perianal shield (modified area of the last unit

866 surrounding the anal aperture) on the ventral side. Trunk end bears posterior spiracles situated on

867 the medio-postero-dorsal surface of the unit. Spiracular field surrounded by five triangular,

868 setose lobes.

869

870 Systematic interpretation: The general body shape, as well as absence of the ambulatory legs on

871 the thorax, and the spiracle arrangement is consistent with this larva being an immature stage of

872 the group Diptera. Numerous characters indicate that the specimen is a larva of the group

873 Anisopodidae: body slender, vermiform; head fully sclerotized, dorsal part more strongly

874 sclerotized than ventral; mandible with fleshy proximal heavily sclerotized distal part; prothorax

875 and abdominal segments 1-7 subdivided into the two unequal parts by an annular constriction;

876 respiratory system amphipneustic; anterior spiracle forming small cone on prothorax; posterior

877 spiracles on spiracular field, on the posterior end; trunk end with perianal shield; the trunk end

878 subdivided into three parts. 
879

880

881

882

883

884

885

886

887

888

889

890

891

892

893

894

895

896

897

898

899

900

901

902

903

904

905

906

907

908

909

910

911

912

913

914

915

916

917

918

The fossil larva possesses a spiracular disc surrounded by triangular setose lobes. The character is autapomorphic for the group Sylvicola (ingroup of Anisopodidae). In larvae of other ingroups of Anisopodidae the spiracle is surrounded by roundish lobes, bare of setae. The structure of the spiracular disc can be used to distinguish between larvae of Mycetobia and Sylvicola (Hancock, 2017) also in fossilized resin.

The morphology of the fossil (Dip-00642) resembles extant larvae of Sylvicola to a high degree (cf. Keilin and Tate, 1940; Peterson,1981). Due to the preservation of the specimen, no characters could be observed to reliably differentiate between the fossil larva from larvae of the extant species Sylvicola fenestralis (Scopoli, 1763). It is also impossible to identify the larvae as a representative of any of the five known species of Sylvicola from Baltic amber, as all of them are known from adults only (Wojton, et al., 2018).

Syninclusions: stellate hairs and plant detritus are preserved in the same amber piece as the studied specimen.

\section{Discussion}

\section{Species diversity and morphological diversity}

Our investigations of Baltic and Bitterfeld amber material yielded at least four larval and three pupal morphotypes of Bibionomorpha. One larval type is even known from several instars.

There are probably numerous species of Mycetobia represented among the larval specimens. Yet, due to the degree of preservation it is impossible to distinguish them. The presence of several species within the material appears to be almost a certainty, taking into account the species diversity of Bibionomorpha in Baltic and Bitterfeld amber represented by adult forms, including at least 12 species of Anisopodidae (Wojton et al., 2018, 2019a, 2019b). Also, other bibionomorphan lineages show a quite rich fossil record in these amber Lagerstätten, again represented by adults, with at least 3 species of Hesperinidae, 10 species of Bibionidae and numerous species of the group Sciaroidea (Skartveit, 2002, 2008 ).

It is indeed surprising that the apparently abundant material of larvae and pupae of Bibionomorphan lineages in Eocene European amber has not attracted the attention of the scientific community earlier. There were some brief reports of pupae of Anisopodidae and Cecidomyiidae (Weitschat, 2009), but also these did not seem to attract much further attention. In a study by Haug et al. (2017), dealing with a group of dipteran pupae in a single amber piece, four specimens apparently representing morphotype 2 of Mycetobia have been reported (Haug et al., 2017), yet misidentified as pupae of Asilidae, due to the somewhat similar structure of the spines or denticles on the trunk. Other pupae of Anisopodidae, without specification of further reaching taxonomic details have been reported from Miocene Dominican amber (Grimaldi, 1991).

No further immature stages of bibionomorphans have been reported from amber so far (Skartveit, 2017). This is probably a reflection of the fact, that in palaeoentomology, immature

Peer) reviewing PDF | (2019:06:38366:3:2:NEW 4 Sep 2019) 
919 stages of the group Insecta often seem to be considered as 'inferior material' in comparison to 920 adults. A possible reason for that is the relative difficulty of relating of taxa described based on 921 larvae and pupae to the other taxa, which have been described based on adults. This might act as 922 disincentive in a field, where $\alpha$-taxonomy is still seen as a pinnacle of research achievement 923 (Azar et al., 2018).

924

925

926

927

928

929

930

931

932

933

934

935

936

937

938

939

940

941

942

943

944

945

946

947

948

949

950

951

952

953

954

955

956

957
Still, taking in account the seeming general scarcity of larval forms of Diptera preserved in amber (Andersen et al., 2015, Baranov et al., 2019), the high abundance of larvae of Bibionomorpha in Eocene European ambers is remarkable. The taphonomic window of the fossilized resins seems strongly biased towards flying, hence adult representatives of Insecta (or better Pterygota), especially for adult forms of Diptera (Solórzano Kraemer et al., 2015). Larvae of Diptera often live in aquatic habitats, soil, leaf litter or are internal parasites of plants and animals and thus have limited opportunities for entrapment in plant resins and the subsequent preservation as amber inclusions (Solórzano Kraemeret al., 2015, Kirk-Spriggs, 2017).

Perkovsky et al. (2012) have shown that there is a stable structural cohort of animals preserved in Baltic and Rovno amber, which they termed "Sciara zone Diptera", which made up to $20 \%$ of all inclusion in representative batches of Baltic and Rovno amber. "Sciara-zone Diptera" is represented mostly by flies of the groups Bibionomorpha and Tipulomorpha, possessing xylophagous or saprophagous larvae, which apparently were associated with the treetrunks in the Baltic amber forest (Perkovsky et al., 2012). Larval forms of "Sciara-zone Diptera", and especially those of Anisopodidae, are also living on tree trunks or right beneath them in the upper leaf-litter. This makes their preservation in fact highly likely in comparison to other larval forms of Diptera (Hancock, 2017). The preservation of a large number of immature of Mycetobia is in line with recent research on the entrapment bias in amber. This research (Sánchez-García et al., 2017, Solórzano Kraemer et al., 2018) has shown that the taphonomic window of amber deposits is positively selecting towards fauna associated with tree trunks, while negatively selecting against species from the certain other habitats, i.e. hygropetric water films [aquatic habitats formed by the thin layers of water seepagin from the soil] and true aquatic habitats (Sánchez-García et al., 2017).

Such a high abundance of larvae and pupae of Bibionomorpha provides an unprecedented look at the role of immature stages in the European Eocene amber forest. Since most of the immature stages of the Bibionomorpha in the studied material are closely reminiscent of corresponding stages of extant species, we can extrapolate the ecology of the fossil larval forms of Bibionomorpha to have been similar to their extant relatives (Seredszus and Wichard, 2008).

In fact, we have not been able to discern any substantial difference between studied larvae of Mycetobia, Sylvicola and Pachyneura preserved in amber and their extant counterparts. This is partially caused by the relatively low "resolution" of the characters in the fossil material, which does not allow to recognise more subtle differences between fossil larvae and their extant relatives. 
958

959

960

961

962

963

964

965

966

967

968

969

970

971

972

973

974

975

976

977

978

979

980

981

982

983

984

985

986

987

988

989

990

991

992

993

994

995

996

997

Extant larvae of Pachyneuridae are associated with dead wood in pristine forests (Paramonov and Salmela, 2015). We assume a similar life habit for the fossils.

Extant larval representatives of Mycetobia and Sylvicola are associated with decaying organic material, mostly plant tissue. Yet, dung or animal corpses might also be occasionally exploited (Hancock, 2017). We can therefore assume that abundant larvae of Mycetobia (but also the larva of Sylvicola) preserved in Eocene amber were originally likewise connected to decaying organic matter. It is quite conceivable that a subtropical, seasonal forest in the Eocene of Europe would yield plenty of decaying organic matter, in the form of leaf litter, dead plant or animal matter, bacterial biofilms and fungi (Hancock, 2017, Wojton et al., 2019b).

\section{Ontogeny of the fossil forms of Mycetobia}

The relatively large amount of immature ("preimaginal") specimens of the species group ("genus") Mycetobia, allows to do a limited quantitative analysis of the post-embryonic ontogeny of these flies (Fig. 17). Coombs et al. (1997) have shown that representatives of Anisopodidae have four larval stages in their development. This was not based on rearing larvae in the lab, but rather on looking at the distribution of several morphometric parameters. Head capsule length, head capsule width and body length have been measured for 303 larvae of Sylvicola fenestralis (Scopoli, 1763). Coombs et al. (1997) found that at least the head capsule width distribution followed a distinct four-peak pattern, corresponding to four supposed larval stages for this species.

'Dyar's rule', describes the pattern of larval development in Holometobola (Dyar, 1890). In particular, it describes the inter-moult growth within Holometabola occurring at a similar rate for each larval stage. As a short remark: this pattern is even more general and not only true for Holometabola, but also for other crustaceans (cf. 'Brook's law', e.g. Fowler, 1909). This strict pattern can be used to infer the number of larval stages from the available dataset on larval morphometry (Coombs et al., 1997). In particular, mean values for every size cohort of log-transformed datasets should follow a straight line, with high values of $\mathrm{R}^{2}$. If the mean values behave differently, deviating from a straight line, this would result in a larval stage (size cohort) missing from the plot (Dyar, 1890; Coombs et al., 1997). Coombs et al. (1997) have shown that the factor, with that the head capsule width increases between the larval stages of Sylvicola fenestralis, remains relatively constant (0.57-0.66) and follows Dyar's rule (Dyar, 1890; Coombs et al., 1997).

We applied the approach of Coombs et al. (1997) to our material and found that values of the head width and the head length of the fossil plotted in increasing order; (Figs. 18 A, 18 B) are falling into four discrete categories (Figs. 19 A, 19 B). The line charted through the ordered dot-plot has 3 clear breaks for both the head length and the width of the head, but not for the body length (Fig. 19). This indicates the presence of four larval stages (based on head capsule width). We think that the absence of such breaks in the body length plot, is connected to the taphonomic conditions of the larvae. It is possible that, upon the entrapment in amber, the larvae would shrink, obscuring the reconstruction of the original body length. In fact, McCoy et al.

Peer] reviewing PDF | (2019:06:38366:3:2:NEW 4 Sep 2019) 
998 (2018) have shown by actuo-taphonomic experiments that the specific type of the fossil resin, 999 desiccation prior to entombment and the composition of the gut microbiota all have a crucial 1000 impact on the preservation-quality of fossil insects. They have shown that the combination of the 1001 above mentioned factors will determine whether specimens will be preserved with soft tissue, as 1002 cuticular fossil only, or not at all (McCoy et al., 2019). Therefore, significant preservation biases 1003 can occur based on the identity of the insect and amber deposit. Therefore, it is even more

1004

1005

1006

1007

1008

1009

1010

1011

1012

1013

1014

1015

1016

1017

1018

1019

1020

1021

1022

1023

1024

1025

1026

1027

1028

1029

1030

1031

1032

1033

1034

1035

1036

1037 advisable to use only hard sclerotized structures (such as head capsule), which are less prone to be deformed, for morphometrical purposes.

We proceeded to calculate the mean value of the head width and length for each of the cohorts observed in the plot. Then, those mean values were plotted against the supposed larval stage. Dyar (1890) and Coombs et al. (1997) have shown that if the values of morphometric parameters plotted against the supposed number of the larval stages are following a linear trend, that means that the studied sample contains all larval stages of the studied species (Fig. 17).

In our case, we have separated the stages based on the width of the head capsule, as Coombs et al. (1997) have shown it to be the most reliable predictor of the life-stage distribution in the measured larvae (Figs. 17, 18B). In our data the average values for both the head width and the head length follow a perfect linearly increasing trend-. The $\mathrm{R}^{2}$ value for the head-width trend was 0.98 and 0.99 for the head length (Fig. 19).

Our data therefore supports the presence of four larval stages in the larval development of the Eocene Mycetobia species. The factor of growth between the stages is relatively steady, namely 0.6, and is consistent with Dyar's rule (Coombs et al., 1997; Table 2).

This is the first time that a full ontogenetic post-embryonic series of a dipteran could be reconstructed based on amber material. A more incomplete series of single larval stage, pupa and adult has been presented by Baranov et al. (2019). The reconstructed ontogeny of Mycetobia from amber demonstrates that during the Eocene Anisopodidae had lineages with representatives exhibiting derived morphologies and an ontogenetic development which is indistinguishable from extant forms of Anisopodidae (Wojton et al., 2019b).

\section{Larvae of Bibionomorpha and amber forest ecology}

Within the scientific community, a new understanding of the European Eocene amber forest (Seyfullah et al., 2018, Schmidt et al., 2019), as a warm-temperate seasonal forest, is currently emerging. This reconstruction is based on contemporary studies of palaeobotanical species complexes, fungi and microorganisms as well as isotope signatures, preserved in these ambers (Seyfullah et al., 2018; Schmidt e t al., 2019). This reconstruction has currently not yet triggered a re-interpretation of insect communities in these ambers, however it will likely cause such a reinterpretation in the future.

The major weakness of the current interpretation of the palaeoecology of Insecta in Eocene amber, is that it is based on a very coarse application of the uniformitarism principle to the ecology of now extinct groups (Grund, 2006; Seredszus and Wichard, 2011; Zelentsov et al., 2012; Baranov et al., 2015). This means there is a mechanistic phylogenetic inference, in which 
1038 fossil representatives of species groups ("genera") are automatically assumed to have the

1039

1040

1041

1042

1043

1044

1045

1046

1047

1048

1049

1050

1051

1052

1053

1054

1055

1056

1057

1058

1059

1060

1061

1062

1063

1064

1065

1066

1067

1068

1069

1070

1071

1072

1073

1074

1075

1076

1077 autecological traits of the seemingly closest modern relatives. Yet, this is a mere oversimplification and likely malicious for the results and conclusions of such studies (Gründ, 2006). Many authors, have shown that in case of large and ecologically "diverse genera", or "relic genera" (groups which which were much more diverse in the past), such inferences might lead to the widely inaccurate conclusions (e.g. Stebner et al., 2018, Baranov et al., 2019a, b). This problem is of course also a result of the (unreflected) use of taxonomical ranks, as a low ranks (such as the genus) appear to suggest a close relationship among the included species. However, the assignment of ranks is a completely arbitrary decision (Mayr, 1942) and neither consistently reflects the age of a group nor the relatedness among species belonging to this group and as much less in a way that this would be comparable on a larger systematic scale (Ereshefsky, 2002; Dubois, 2007).

It is worth noting in this aspect, that the paleoecology of many fossil species with aquatic larvae such as non-biting midges (Diptera, Chironomidae) or caddisflies (Trichoptera) is interpreted based on the larval ecology of their extant relatives, yet inferred by fossils of the adults (for examples see Wichard et al., 2009). It is done in this way, as these groups of Insecta are widely used in aquatic biomonitoring today, and their larval habitats are thought to be rather narrow and well known (Merrit and Cummins, 1996).

The weakness of this approach for palaeohabitat reconstructions, is that it represents a type of double-inference, in case it is based on adults. 1) One infers a close relationship between the fossil (adult) animal and its extant relatives, for which larval ecology is known. 2) One assumes that the larvae of the fossil adult animal behaved similar to their extant counterparts, without access to the larval morphology (Wichard et al., 2009).

A more direct interpretation of the ecology of larvae, which are more tied to particular habitats (in many lineages of Insecta larvae perform most of the ecological functions) is considered advantageous in comparison to the above mentioned double-inference. Such an advantage arises from the direct observation of the larval morphology, which in combination with the interpretation of the taphonomic situation and the possible presence of syninclusions can tell a lot about the ecology of an animal (Andersen et al., 2015; Baranov et al., 2019b).

Hence the observed details of immature forms of Bibionomorpha eliminate one level of assumptions and provide more direct indications of the palaeohabitat. The high abundance of immatures of Anisopodidae in Eocene European amber forests, may indicate moist conditions and a large amount of decaying organic matter on the forest floor, a habitat characteristic for extant representatives of Anisopodidae (Hancock, 2017). This is reaffirming similar conclusions made based on the abundant co-occurence of non-biting midges (Diptera, Chironomidae) with terrestrial larvae in Baltic amber (Andersen et al., 2015; Baranov et al., 2019). Secondly, the presence of a larva of Pachyneuridae (xylobiont-xylophages, living in the deep layer of xylem of old, still living trees) is indicative for pristine temperate forests in extant conditions (Krivosheina, 2006; Paramonov and Salmela, 2016). Therefore, in the Eocene it might translate to mature forest communities with large quantities of the dead wood. Hence, the findings of

Peer] reviewing PDF | (2019:06:38366:3:2:NEW 4 Sep 2019) 
1078 larval forms of Diptera provide a new independent source of information that can be used for

1079

1080

1081

1082

1083

1084

1085

1086

1087

1088

1089

1090

1091

1092

1093

1094

1095

1096

1097

1098

1099

1100

1101

1102

1103

1104

1105

1106

1107

1108

1109

1110

1111

1112

1113

1114

1115

1116

1117

palaeohabitat reconstruction.

\section{Conclusions}

This first examination of immatures of Bibionomorpha from Baltic and Bitterfeld amber is based on more than 60 specimens, representing three major ingroups of Bibionomorpha: Bibionidae (or a possible sister species to it), Pachyneuridae and Anisopodidae. Bibionidae (or its sister species) and Pachyneuridae are both represented by a single larval morphotype; Anisopodidae is represented by at least two larval morphotypes and at least three pupal morphotypes.

The larva of Pachyneura is the first fossil record for this group. The presence of this larva, indicates pristine, temperate forest conditions, with abundant old trees. This lines up well with the emerging new interpretation of the Baltic amber forest as a warm-temperate, seasonal ecosystem (Schmidt et al., 2019).

Window gnats (Diptera, Anisopodidae), are the most abundant immature stages of bibionomorphans in Bitterfeld and Baltic amber. A large number of fossil immatures allowed us to reconstruct the full post-embryonic ontogenetic series of fossil representatives of Mycetobia (Anisopodidae). This reconstruction is only the second one for dipterans in amber (first in Baranov et al., 2019b), and also the most complete. It demonstrates that in the Eocene representatives of Mycetobia, just as their extant counterparts, had four larval stages.

This study shows the large potential of future studies on fossil larvae of flies in amber. Contrary to the widespread opinion, these larvae are relatively abundant. Their abundance, and ecological information associated with them (plus the additional information from syninclusions and other clues about the taphonomy), might be crucial to further elucidate the new, emerging picture of the palaeoecosystems that are preserved by Baltic and Bitterfeld amber.

\section{Acknowledgements}

VB is grateful to M. Spies and D. Doczkal (ZSM Munich) for his invaluable help with collection of ZSM as well as help with the literature. VB is grateful to M. K. Hörnig (University of Greifswald) for conducting MicroCt scanning of the Anisopodidae pupa. VB, MS and JTH are grateful to C. \& H.-W. Hoffeins (Hamburg), C. Gröhn (Hamburg) and U. Kotthoff (CeNak, Hamburg) for providing access to the material. We are grateful to the editor and three anonymous reviewers for their efforts in improving this manuscript. Thanks to all people providing free software.

\section{References}

Andersen T, Baranov V, Goral T, Langton P, Perkovsky E, Sykes D. 2015. First record of a Chironomidae pupa in amber. Geobios 48(4): 281-286. 
1118 Armitage PD, Pinder LC, Cranston, P. S. (Eds.). 2012. The Chironomidae: biology and ecology 1119 of non-biting midges. Springer Science \& Business Media, London.

1120

1121

Azar D, Szwedo J, Jarzembowski E, Evenhuis N, Huang, D. 2018. "Palaeoentomology": A

1122 modern journal for a science dealing with the past. Palaeoentomology 1(1): 1-2.

1123

1124

Baranov V, Andersen T, Perkovsky, EE. 2015. Orthoclads from Eocene Amber from Sakhalin

1125

(Diptera: Chironomidae, Orthocladiinae). Insect Systematics \& Evolution 46(4): 359-378.

1126

1127

Baranov V, Giłka W, Zakrzewska M, Jarzembowski E. 2019a. New non-biting midges (Diptera:

1128 Chironomidae) from Lower Cretaceous Wealden amber of the Isle of Wight (UK). Cretaceous

1129 Research 95: 138-145.

1130

1131

Baranov V, Hoffeins C, Hoffeins, H-W, Haug JT. 2019b. More than dead males: reconstructing 1132 the ontogenetic series of terrestrial non-biting midges from the Eocene amber forest. Bulletin of Geosciences 94(2): 1-13.

1134

1135

Béthoux, O. 2010. Optimality of phylogenetic nomenclatural procedures. Organisms Diversity \& 1136 Evolution 10: 173-191 DOI: 10.1007/s13127-010-0005-3.

1137

1138

Blagoderov VA, Krzeminska E, Krzeminski W. 1993. Fossil and recent Anisopodomorpha

1139 (Diptera, Oligoneura): family Cramptonomyiidae. Acta zoologica cracoviensia, 35(3): 573-579.

1140

1141

Blagoderov V, Grimaldi DA, Fraser NC. 2007. How time flies for flies: diverse Diptera from the

1142

Triassic of Virginia and early radiation of the order. American Museum Novitates 3572: 1-39.

1143

1144

Borkent A, Sinclair BJ. 2017. Key to Diptera families-larvae. In: Kirk-Spriggs AH, Sinclair B J. 1145 (Eds.). Manual of Afrotropical Diptera. Volume 1: Introductory chapters and keys to Diptera families. Suricata 4. South African National Biodiversity Institute, Pretoria; pp. 357-405.

Budd, G E, Mann, R.P. 2018, History is written by the victors: The effect of the push of the past 1149 on the fossil record: Evolution, v. 72, no. 11, p. 2276-2291.

1150

1151

Coombs RM, Cleworth MA, Davies DH. 1997. Determination of instar for the window gnat 1152

1153 Sylvicola Fenestralis (Diptera: Anisopodidae). Water Research 31: 186-193.

1154

1155

Dubois, A. 2007. Phylogeny, taxonomy and nomenclature: the problem of taxonomic categories and of nomenclatural ranks. Zootaxa, 1519(1): 27-_8.

1156 
1157 Dyar HG. 1890. The number of molts of lepidopterous larvae. Psyche: A Journal of Entomology 1158 5(175-176): 420-422.

1159

1160

1161

1162

1163

1164

1165

1166

1167

1168

1169

1170

1171

1172

1173

1174

1175

1176

1177

1178

1179

1180

1181

1182

1183

1184

1185

1186

1187

1188

1189

1190

1191

1192

1193

1194

1195

1196

Engel, M. 2019. Natural Histories. Innumerable insects. The stories of the most diverse and myriad animals on Earth. Sterling, New York.

Ereshefsky, M. 2002. Linnaean ranks: Vestiges of a bygone era. Philosophy of Science, 69(S3): S305-S315.

Evenhuis, NL. 2019. The insect and spider collections of the world website. Available at: http://hbs.bishopmuseum.org/codens/ [Last accessed: 07.05.2019].

Fastovsky DE, Huang Y, Hsu J, Martin-McNaughton J, Sheehan PM, Weishampel DB. 2004. Shape of Mesozoic dinosaur richness. Geology 32: 877-880. https://doi.org/10.1130/G20695.1.

Fowler, GH. 1909. Biscayan plankton collected during a cruise of H.M.S. 'Research' 1900. Part xii. The Ostracoda. Transactions of the Linnean Society of London (2), Zoology, x, pp. 219-336, 12 pls.

Grimaldi DA. 1991. Mycetobiine woodgnats (Diptera, Anisopodidae) from the Oligo-Miocene amber of the Dominican Republic, and Old World affinities. American Museum novitates 3014: $1-24$.

Grimaldi D, Engel MS. 2005. Evolution of the Insects. Cambridge University Press.

Grund M. 2006. Chironomidae (Diptera) in Dominican amber as indicators for ecosystem stability in the Caribbean. Palaeogeography, Palaeoclimatology, Palaeoecology 241(3-4): 410416.

Harris AC. 1983. An Eocene larval insect fossil (Diptera: Bibionidae) from North Otago, New Zealand. Journal of the Royal Society of New Zealand 13(3): 93-105.

Haug, C, Mayer, G, Kutschera, V, Waloszek, D, Maas, A, Haug, J. T. 2011. Imaging and documenting gammarideans. International Journal of Zoology, art. 380829, DOI $10.1155 / 2011 / 380829$.

Haug, JT, Briggs, DE, Haug C. 2012. Morphology and function in the Cambrian Burgess Shale megacheiran arthropod Leanchoilia superlata and the application of a descriptive matrix. BMC Evolutionary Biology, 12(1), 162, https://doi.org/10.1186/1471-2148-12-162.

Peer) reviewing PDF | (2019:06:38366:3:2:NEW 4 Sep 2019) 
1197 Haug, C., Shannon, K. R., Nyborg, T. \& Vega, F. J. 2013b. Isolated mantis shrimp dactyli from 1198 the Pliocene of North Carolina and their bearing on the history of Stomatopoda. Bolétin de la 1199 Sociedad Geológica Mexicana 65, 273-284.

1200

1201

1202

1203

1204

1205

1206

1207

1208

1209

1210

1211

1212

1213

1214

1215

1216

1217

1218

1219

1220

1221

1222

1223

1224

1225

1226

1227

1228

1229

1230

1231

1232

1233

1234

1235

Haug, C., Herrera-Flórez, A. F., Müller, P. \& Haug, J. T. 2019. Cretaceous chimera-an unusual 100-million-year old neuropteran larva from the "experimental phase" of insect evolution. Palaeodiversity $12,1-11$.

Haug, J. T., Haug, C. and Ehrlich, M. 2008. First fossil stomatopod larva (Arthropoda: Crustacea) and a new way of documenting Solnhofen fossils (Upper Jurassic, Southern Germany). Palaeodiversity, 1: 103-109.

Haug, J. T., Haug, C., Kutschera, V., Mayer, G., Maas, A., Liebau, S., Castellani, C., Wolfram, U., Clarkson, E. N. K. and Waloszek, D. 2011. Autofluorescence imaging, an excellent tool for comparative morphology. Journal of Microscopy, 244: 259-272.

Haug, JT., Müller, C. H. G. and Sombke, A. 2013a. A centipede nymph in Baltic amber and a new approach to document amber fossils. Organisms Diversity and Evolution, 13: 425-432.

Haug, JT, Haug, C. 2016. "Intermetamorphic" developmental stages in 150 million-year-old achelatan lobsters - The case of the species tenera Oppel, 1862. Arthropod Structure \& Development 45: 108-121 DOI: 10.1016/j.asd.2015.10.001.

Haug JT. in press. Why the term "larva" is ambiguous, or what makes a larva?. Acta Zoologica early view: $1-22$.

Haug, J, Müller, P, Haug, C. 2018. The ride of the parasite: a 100-million-year old mantis lacewing larva captured while mounting its spider host. Zoological Letters 4, 31.

Hancock, E. G. 2017. Anisopodidae (Wood Gnats or Window Gnats). In: Kirk-Spriggs, AH, Sinclair BJ. (Eds.). Manual of Afrotropical Diptera. Volume 2: Nematocerous Diptera and lower Brachycera. Suricata 5. South African National Biodiversity Institute, Pretoria; pp. 633-640.

Hennig W.1968 Die Larvenformen Der Diptera. Teil 1. Akademie-Verlag. Berlin.

Hörnig, MK, Sombke, A, Haug, C, Harzsch, S,Haug, JT. 2016. What nymphal morphology can tell us about parental investment - a group of cockroach hatchlings in Baltic Amber documented by a multi-method approach. Palaeontologia Electronica 19(1), art. 5A, 20 pp.

Peer) reviewing PDF | (2019:06:38366:3:2:NEW 4 Sep 2019) 
1236 International Commission on Zoological Nomenclature. 2012. Available at

1237 http://www.nhm.ac.uk/hosted-sites/iczn/code/ (accessed 2 May 2019).

1238

1239

Kalugina NS. 1974a. Eutrophication as one possible cause for the changes in aquatic biocenoses

1240 towards the end of the Mesozoic, pp. 137-139. In: Antropogennoe evtrofirovanie vod

1241 [Anthropogenically eutrophied waters], Akademia Nauk SSSR, Chernogolov.

1242

1243 Kalugina NS. 1974b. Change in the subfamily composition of chironomids (Diptera,

1244 Chironomidae) as an indicator of possible eutrophication of bodies of water during the late

1245 Mesozoic. Journal of the Moscow Naturalist's Society 79: 45-56.

1246

1247

Kalugina NS, Kovalev VG. 1985. Jurassic Diptera of Siberia. Izdatelstvo Nauka, Moscow, 197

1248

1249

1250 $\mathrm{pp}$.

1251

1252

1253

1254

1255

Knab F. 1912. New species of Anisopodidae (Rhyphidae) from Tropical America. [Diptera:

Nemocera.]. Proceedings of the Biological Society of Washington 25:111-114.

Komsta L. 2013. mblm: median-based linear models. R package version 0.12 .

Krivosheina NP. 2006. Taxonomic composition of dendrobiontic Diptera and the main trends of 1256

1257

1258

1259

1260

1261

1262

1263

1264 their adaptive radiation. Zoologicheskii Zhurnal 85 (7): 842-852. [in Russian]

Krivosheina M. 2012. Key to the families and genera of the Palearctic Dipterous insects of the suborder Nematocera, based on larvae [in Russian], Moscow, KMK Scientific press, 244 pp.+.

Krivosheina NP, Mamaev BM. 1967. A Key to Dipteran Larvae Inhabiting Wood [In

Russian].Nauka Scientific Press, 266 pp.

1265

Krivosheina NP, Mamaev BM. 1972. New data on relict Diptera of the Pachyneuridae family.

1266 Nauchnye Doklady vysshey shkoly. Biological sciences 11: 13-18. [in Russian].

Lanham, U. 1965. Uninominal nomenclature. Systematic Zoology 14: 144-144.

1268

1269

Mayr, E. 1942. Systematics and the origin of species. New York: Columbia University Press.

1270

1271

Marshall SA. 2012. Flies. The natural history and diversity of Diptera. Firefly Press Ltd, 616 pp.

1272

1273 Meigen JW. 1804. Klassifikazion und Beschreibung der europäischen zweiflügligen Insekten.

1274 (Diptera Linn.). Erster Band, erste Abtheilung, mit VIII Kupfertafeln. - pp. I-XXVIII [=1-28],

1275 1-152, Tab. I-VIII [= 1-8]. Braunschweig. (Reichard). 
1276

1277

1278

1279

1280

1281

1282

1283

1284

1285

1286

1287

1288

1289

1290

1291

1292

1293

1294

1295

1296

1297

1298

1299

1300

1301

1302

1303

1304

1305

1306

1307

1308

1309

1310

1311

1312

1313

1314

1315
Meigen JW. 1818. Systematische Beschreibung der bekannten europäischen zweiflügeligen Insekten. Erster Theil mit elf Kupfertafeln. - pp. I-XXXVI [=1-36], 1-324, [1]. Aachen.

(Forstmann).

Merritt RW, Cummins KW. (Eds.). 1996. An introduction to the aquatic insects of North America. Kendall Hunt.

Mckenna DD, Wild AL, Kanda K, Bellamy CL, Beutel RG, Caterino MS, Farnum CW, Hawks DC, Ivie MA, Jameson ML, Leschen LAB, Marvaldi AE, McHugh JV, Newton AF, Robertson JA, Thayer MK, Whiting MF, Lawrance JF, Slipinski A, Maddison DR, Farrel, BD. 2015. The beetle tree of life reveals that Coleoptera survived end-Permian mass extinction to diversify during the Cretaceous terrestrial revolution. Systematic Entomology 40(4): 835-880. https://doi.org/10.1111/syen.12132

Nagler, C, Hyžný, M, Haug, JT. 2017. 168 million years old "marine lice" and the evolution of parasitism within isopods. BMC Evolutionary Biology 17, 76.

Perkovsky EE, Rasnitsyn AP, Vlaskin AP, Rasnitsyn SP. 2012. Contribution to the study of the structure of amber forest communities based on analysis of syninclusions in the Rovno Amber (Late Eocene of Ukraine). Paleontological Journal 46(3): 293-301.

Ponomarenko, AG. 2003. Ecological evolution of beetles (Insecta: Coleoptera). Acta zoologica cracoviensia 46.Suppl (2003): 319-328.

Sánchez-García, A, Nel, A, Arillo, A, Kraemer, MMS., 2017, The semi-aquatic pondweed bugs of a Cretaceous swamp: PeerJ, v. 5, p. e3760.

Schneider CA; Rasband WS, Eliceiri KW. 2012. "NIH Image to ImageJ: 25 years of image analysis". Nature methods 9(7): 671-675.

Schiner IR. 1864. Fauna Austriaca. Diptera. Vol. II. Wien :C. Gerolds Sohn,1862-64.

Schmidt AR., Sadowski E-M, Kunzmann L, Kaasalainen U, Seyfullah LJ, Rikkinen J. 2019. Reconstruction of amber forests using plants, lichens and fungi: a case study of the 'Baltic amber forest'. Abstracts of th 8th International Conference on Fossil insects, Arthropods and Amber. Santo-Domingo, 2019, 12-13

Scholtz, G. 2005. Homology and ontogeny: Pattern and process in comparative developmental biology. Theory in Biosciences124:121-143.

PeerJ reviewing PDF | (2019:06:38366:3:2:NEW 4 Sep 2019) 
1316

1317

1318

1319

1320

1321

1322

1323

1324

1325

1326

1327

1328

1329

1330

1331

1332

1333

1334

1335

1336

1337

1338

1339

1340

1341

1342

1343

1344

1345

1346

1347

1348

1349

1350

1351

1352

1353

1354

1355
Scopoli JA. 1763. Entomologia Carniolica exhibens insecta Carnioliæ indigena et distributa in ordines, genera, species, varietates. Methodo Linnæana. pp. 1-420, [1]. Vindobonae. (Trattner).

Seredszus F, Wichard W. 2011. Overview and descriptions of fossil non-biting midges in Baltic amber (Diptera: Chironomidae). Studia dipterologica 17: 121-129.

Ševčík J, Kaspřák D, Mantič M, Fitzgerald S, Ševčíková T, Tóthová A, Jaschhof M. 2016.

Molecular phylogeny of the megadiverse insect infraorder Bibionomorpha sensu lato

(Diptera). PeerJ: 4, e2563.

Seyfullah LJ, Beimforde C, Dal Corso J, Perrichot V, Rikkinen J, Schmidt AR. 2018. Production and preservation of resins - past and present. Biological Reviews 93(3): 1684-1714.

Skartveit J. 2002. The larvae of European Bibioninae (Diptera, Bibionidae). Journal of Natural History 36(4): 449-485.

Skartveit J. 2009. Fossil Hesperinidae and Bibionidae from Baltic amber (Diptera:

Bibionoidea). Studia dipterologica 15: 3-42.

Skartveit J. 2017. Bibionidae (March flies or Lovebugs). In: Kirk-Spriggs AH, Sinclair, BJ. (Eds.). Manual of Afrotropical Diptera. Volume 2: Nematocerous Diptera and lower Brachycera. Suricata 5. South African National Biodiversity Institute, Pretoria,pp. 497-504.

Skartveit J., Willassen E. 1996. Phylogenetic relationships in Bibioninae (Diptera, Bibionidae). Skarteveit, J. Studies on the systematics and life histories of Bibioninae (Diptera, Bibionidae). D. Phil. Thesis. University of Bergen, Bergen, Norway.

Solórzano-Kraemer MM, . Kraemer AS., Stebner F, Bickel DJ, Rust J. 2015. Entrapment bias of arthropods in Miocene amber revealed by trapping experiments in a tropical forest in Chiapas, Mexico. PloSOne 10(3): e0118820.

Solórzano Kraemer, MM, Delclòs, X, Clapham, ME, Arillo, A, Peris, D., Jäger, P, Stebner, F, Peñalver, E. 2018, Arthropods in modern resins reveal if amber accurately recorded forest arthropod communities: Proceedings of the National Academy of Sciences, v. 115, no. 26, p. 6739-6744.

Stebner F, Baranov V, Zakrzewska M, Singh H, Giłka W. 2017. The Chironomidae diversity based on records from early Eocene Cambay amber, India, with implications on habitats of fossil Diptera. Palaeogeography, Palaeoclimatology, Palaeoecology 475: 154-161.

Peer] reviewing PDF | (2019:06:38366:3:2:NEW 4 Sep 2019) 
1357 Wichard W, Gröhn C, Seredszus F. 2009. Aquatic insects in Baltic amber - Wasserinsekten im 1358 Baltischen Bernstein. Verlag Kessel, Remagen-Oberwinter. [in English and German].

1359

1360 Zelentsov NI., Baranov VA, Perkovsky EE, Shobanov NA. 2012. First records on non-biting 1361 midges (Diptera: Chironomidae) from the Rovno amber. Russian Entomological Journal 21: 79136287.

1363

1364 Zetterstedt JW. 1838. Sectio tertia. Diptera. Dipterologis Scandinaviae amicis et popularibus 1365 carissimus. Insecta Lapponica. Lipsiae [=Leipzig], 392 pp. 
1367

1368

1369

1370

1371

1372

1373

1374

1375

1376

1377

1378

1379

1380

1381

1382

1383

1384

1385

1386

1387

1388

1389

1390

1391

1392

1393

1394

1395

1396

1397

1398

1399

1400

1401

1402

1403

1404

1405

1406

1407

\section{List of figures}

Figure 1. Phylogenetic relationship among different lineages of Bibionomorpha sensu lato, loosely based and modified and Sevcik et al., 2016: "Figure 1 Bayesian hypothesis for relationships among selected taxa of Bibionomorpha based on DNA sequence data (18S, 28S, CAD, 12S, 16S, and COI), 5,018 characters". Position of the Perissommatidae were inferred from comparing phylogeny from Marshall, 2012 with Sevcik et al., 2016.

Figure 2. Dipteran larva, holotype of Dinobibio hoffeinseorum sp. nov. GPIH, accession number (GPIH-0024) in lateral view. (A) overview, composite image. (B) coloured version of A above. Abbreviations: a1-a8, abdominal segment 1-8; hc, head capsule; mp, maxillary process; ms, mesothorax; mt, metathorax, pt, prothorax; s1-s10, spiracle 1-10; te, trunk end.

Figure 3. Fossil dipteran larva, holotype of Dinobibio hoffeinseorum sp. nov. GPIH, accession number (GPIH-0024). (A) head capsule, latero-dorsal view; (B) coloured version of A. (C) head capsule, ventrolateral view. (D) coloured version of C. Abbreviations: an, antennae; cl, clypeus; hc, head capsule; lb, labium; md, mandible; mp, maxillary palp; mx, maxilla.

Figure 4. Extant larvae of Bibionidae. (A-B) Bibio varipies Meigen, 1830, CeNak, no collection number assigned. (C) Penthetria funebris Meigen, 1804, ZSM, no collection number assigned. (A) habitus ventral. (B) head capsule, ventral. (C) head capusle of fourth instar larva, ventral.

Figure 5 Extant larvae of Bibionidae. (A-C) Penthetria funebris Meigen, 1804, ZSM, no collection number assigned. A) fourth instar larva, habitus dorsal, arrows indicate the position of spiracles. (B) first instar larva, habitus ventral. (C) first instar larva, spiracle 1 (red arrow in B).

Figure 6. Fossil dipteran larva, Pachyneura, collection of GPIH, accession number (L-7617). (A) habitus, dorsal. (B) schematic drawing of habitus, dorsal. a2-a8, abdominal segment 2-8; cl, clypeus; Abbreviations: hc, headcapsule; ms, mesothorax; mt, metathorax; pt, prothorax; s1-s10, spiracle $1-10$.

Figure 7. Fossil dipteran larva, Pachyneura, collection of GPIH (L-7617). (A) habitus, ventral. (B) coloured version of A. Abbreviations: a1-a8, abdominal segments 1-8; c1-c6, creeping welts 1-6; hc, headcapsule; lb, labrum; md, mandibles; mp, maxillar palp; ms, mesothorax; mt, metathorax; mx, maxilla; pt, prothorax; te, trunk-end.

Figure 8. Fossil dipteran larva, Pachyneura, collection of GPIH, accession number (L-7617). (A) head capsule, dorsal view. (B) head capsule, ventral view. (C) coloured version of B. (D) head capsule ventral view, schematic drawing. Abbreviations: hb, hypostomal bridge; hc, head capsule; lb, labrum; md, mandibles; mp, maxilarry palps; mx, maxillae. 
1408 Figure 9. Fossil dipteran larva, Mycetobia, DEI, accession number Dip-00640. (A) habitus,

1409

1410

1411

1412

1413

1414

1415

1416

1417

1418

1419

1420

1421

1422

1423

1424

1425

1426

1427

1428

1429

1430

1431

1432

1433

1434

1435

1436

1437

1438

1439

1440

1441

1442

1443

1444

1445

1446

1447

dorsal view. (B) coloured version of A. (C) posterior spiracles, specimen 2 of B. (D) coloured version of C. Abbreviations: a2-a8, abdominal segments 2-8; as, anterior spiracle; hc, head capsule; ms, mesothorax; mt, metathorax; ps, posterior spiracle; pt, prothorax.

Figure 10. Fossil dipteran larva, Mycetobia, DEI accession number Dip-00640, specimen 1 of Fig. 8B.(A) head capsule, dorsal view. (B) anterior spiracle. (C) coloured version of A. (D) head capsule, ventral view. (E) coloured version of D. Abbreviations: an, antenna; as, anterior spiracle; hc, head capsule; lb, labrum; md, mandibles; mn, mentum; mp, maxilar palps; mx, maxillae; ps, posterior spiracle.

Figure 11. Extant dipteran larva, Mycetobia pallipes Meigen, 1818, ZSM, no collection number assigned. (A) habitus, lateral. (B) coloured version of A. (C) head capsule, lateral view. (D) coloured version of $\mathrm{C}$. Abbreviations: a2-a8, abdominal segment 2-8; as, anterior spiracle; hc, head capsule; md, mandible; mn, mentum; ms, mesothorax; mt, metathorax; mx, maxillae; pt, prothorax; tp, posterior pit of tentorium.

Figure 12. Fossil pupa, Mycetobia connexa (Mycetobia "morphotype 1"), GPIH, collection number 1851-DN. (A) habitus, ventro-lateral view. (B) coloured version of A. Abbreviations: a3-a7, abdominal segments 3-7; an, antennae; fs, frontal setae; p1, front legs; p2, midlegs; p3, hind legs; te, trunk-end; wn, wings.

Figure 13. Fossil pupa, Mycetobia "morphotype 2", PED, collection number PED-4866. (A) habitus, lateral view. (B) coloured version of A. Abbreviations: a1-a8, abdominal segments 1-8; an, antennae; ey, eyes; ms, mesothorax; mt, metathorax; p1, front legs; p2, midlegs; $p$, prothorax; te, trunk-end; th, thoracic horns; wn, wings.

Figure 14. Fossil pupa, Mycetobia "morphotype 3", pharate adult, DEI, collection number CCHH-DEI-608-2. (A) habitus, dorsal view. (B) habitus, ventral view.

Figure 15. Extant pupa, Mycetobia pallipes Meigen, 1818, ZSM, no collection number assigned, (A) habitus, dorsal view. (B) coloured version of A. (C) habitus, ventral view. (D) coloured version of C. Abbreviations: an-antennae; a3-a7, abdominal segments 3-7: ey, eyes; fs, frontal setae; mt, mesothorax; p1, front legs; p2, midlegs; p3, hind legs; te, trunk-end; th, thoracic horn; wn, wing.

Figure 16. Fossil larva, Sylvicola, DEI, collection number Dip-00642. (A) habitus, lateral view. (B) coloured version of A. (C) head capsule, lateral view. (D) coloured version of C.

Abbreviations: a1-a8, abdominal segments 1-8; an, antennae; as, anterior spiracle; hc, head capsule; lb, labrum; md, mandible, mn, mentum; mx, maxilla; ms, mesothorax; te, trunk end.

Peer] reviewing PDF | (2019:06:38366:3:2:NEW 4 Sep 2019) 
1448

1449

1450

1451

1452

1453

1454

1455

1456

1457

1458

1459

1460

1461

1462

1463

1464

1465

1466

1467

1468

1469

1470

1471

1472

1473

1474

1475

1476

1477

1478

1479

1480

1481

1482

1483

1484

1485

1486

1487

Figure 17. Reconstructed ontogenetic sequence for representatives of Mycetobia in the Eocene.

Figure 18. Summary of the statistical analysis. (A) biplot of fossil larvae of Mycetobia $(\mathrm{n}=36)$, head capsule length vs. head capsule width, red circles indicate hypothetical divisions into different larval stages based on the gaps in the data point distribution. I-IV, number of hypothetical larval stages. The number of specimens measured per stage is given at the plot; (B) distribution of the size cohorts within a sample of the fossil larvae of Mycetobia; upper-rowleft, histogram of the head capsule width distribution $(n=26)$; upper-row-center, histogram of the head capsule length distribution ( $\mathrm{n}=25)$; upper-row right, histogram of the body length distribution $(n=36)$; lower-row left, ranged plot (values ordered in ascending order) of the head capsule width, hypothetical division into different larval stages based on gaps in data point distribution indicated with I-IV as numbers of supposed larval stages; lower-row centered, ranged plot (values ordered in ascending order) of head capsule length; lower-row right, ranged plot (values ordered in ascending order) of body length.

Figure 19. Natural logarithm of the mean larval head capsule width (red) and head capsule length (blue) of fossil larvae of Mycetobia, plotted against associated instar number. The fourth larval stage is represented by a single specimen, therefore the actual values are plotted instead of the mean. Red dots and the line representing the head capsule width, while blue represents the head capsule length. Error bars are representative of the value's standard deviation.

\section{SUPPLEMENTARY FIGURES}

Figure S1. Fossil larva, holotype of Dinobibio hoffeinseorum sp. nov. GPIH, accession number (GPIH-0024). (A) ventro-lateral view. (B) dorso-lateral view; (C1-C2) spiracle 10. (D1-D2) spiracle 2. (E1-E2) spiracle 1.

Figure S2. Fossil larvae, Mycetobia with syninclusions, GPIH, collection number GPIH-0247. (A) overview of the amber piece. (B) caddisfly male, Polycentropodidae. (C) partial syninclusion of an adult beetle. 1-4, larvae of Mycetobia; 5, beetle; 6-10 larvae of Mycetobia; 11, caddisfly male, Polycentropodidae

Figure S3. Fossil larvae, Mycetobia with syninclusions, collection number Dip-00640. (A) Overview of the inclusions. (B-D) dipterans, non-biting midges (Chironomidae). (B) Rheosmittia pertenuis, male. (C) Orthocladiinae, female. (D) Rheosmittia pertenuis, male, second specimen. (E) partial inclusions of Mycetobia sp. larvae. 1-4 Mycetobia larvae; 5-6 R. pertenuis, males; 7 Orthocladiinae, female.

Figure S4. Fossil larvae, Mycetobia, DEI, collection number Dip-00639. (A) habitus. (B) trunk end, with posterior spiracles. (C) head capsule, ventral view. 
1488

1489

1490

1491

1492

1493

1494

1495

1496

1497

1498

1499

1500

1501

1502

1503

1504

1505

1506

1507

1508

1509

1510

1511

1512

1513

1514

1515

1516

1517

1518

1519

1520

1521

1522

1523

1524

1525

1526

1527

Figure S5. Fossil larvae, Mycetobia. (A) PED-5695. (B) DEI, collection number Dip-00654. (C) GPIH (BI-2350). (D) PED-4965.

Figure S6. Fossil larva, Mycetobia with syninclusions, collection of GPIH, collection number 3706-W. (A) mite. (B) fly, Phroidae. (C, D) larval specimen of Mycetobia. (C) ventral view. (D) dorsal view.

Figure S7. Fossil larvae, Mycetobia. A) Two specimens, GPIH (L-7592). (B) two specimens, GPIH (L-7592). (C) four specimens (1-4), PED, collection number PED-4748. (D) larva with syninclusions, PED, collection number PED-4970. 1, scale insect, (Coccoidea), nymph; 2, leaf hopper (Cicadellidae), nymph; 3, larva, Mycetobia; 4, non-biting midge (Chironomidae), female.

Figure S8. Fossil larvae, Mycetobia, DEI, collection number Dip-00649. (A) large larva. (B) specimens 1-3. (C) large larva.

Figure S9. Fossil larvae, Mycetobia with syninclusions. A) Overview of the amber piece Dip00656from the collection of DEI. (B-D) larvae, Mycetobia. (B) specimen 1. (C) specimen 2. (D) specimen 3. 1, 2, 5, larva, Mycetobia; 3, 8, 10, 14 gall midges (Cecidomyiidae); 4, mite (Acari); 6, fly ("Acalyptrata"); 7, beetle (Coleoptera); 9, 11-13, ants (Fromicidae).

Figure S10. Fossil larvae, Mycetobia, DEI, collection number Dip-00655. (A) specimen 1. (B) specimen 2.

Figure S11. Fossil pupa (exuvium), Mycetobia "morphotype 1" with syninclusions, collection number PED-4395. (A) pupal exuvim of Mycetobia "morphotype 1". (B) Mycetobia connexa, female. (C) partial beetle (Coleoptera).

Figure S12. Fossil pupa, Mycetobia connexa (Mycetobia "morphotype 1"), GPIH collection number AKBS-00071. (A) habitus, ventro-lateral view. (B) abdomen, dorsal view.

Figure S13. Fossil pupa, Mycetobia "morphotype 1" with syninclusions, DEI, collection number Dip-00651. (A) habitus, lateral view. (B) dipteran non-biting midge (Chrionomidae, Orthocladiinae). (C) fly (Sciaroidea).

Figure S14. Fossil pupa, Mycetobia connexa (Mycetobia "morphotype 1") with syninclusions, GPIH, collection number 1851-DN. (A) pupa (exuvium), Mycetobia "morphotype 1" and fungus gnat (Keroplatidae) male. (B) fly (Sciaridae) male. (C) fly (Bibionomorpha, probably Anisopodidae).

Peer) reviewing PDF | (2019:06:38366:3:2:NEW 4 Sep 2019) 
1528 Figure S15. Fossil pupa (exuvium), Mycetobia connexa (Mycetobia "morphotype 1") with

1529

1530

1531

1532

1533

1534

1535

1536

1537

1538

1539

1540

1541

1542

1543

1544

1545

1546

1547

1548

1549

1550

1551

1552

1553

1554

1555

1556

1557

1558

1559

1560

1561

1562

1563

1564

1565

1566

1567

syninclusions, collection number PED-4395. (A) Overview. (B) Mycetobia connexa male. (C)

Mycetobia connexa male, distal part of metathoracic tibia. 1, Mycetobia connexa male; 2 ,

Mycetobia connexa female; 3, pupal exuvium of M. connexa.

Figure S16. Fossil pupae, Mycetobia "morphotype 1". (A) DEI, collection number Dip-00657, dorsal view. (B) DEI, collection number Dip-00659, lateral view.

Figure S17. Fossil pupa, Mycetobia “morphotype 1", DEI, collection number Dip-00657

(Bitterfeld amber). (A) habitus, dorsal view. (B) habitus, ventral view.

Figure S18. Fossil pupa, Mycetobia "morphotype 1", DEI, collection number Dip-00655. (A) habitus, dorsal view. (B) habitus, ventro-lateral view.

Figure S19. Fossil pupa, Mycetobia "morphotype 1" with syninclusion, DEI, collection number Dip-00655 (specimen 2). (A) habitus, lateral view. (B) habitus, ventro-lateral view. (C) fly (Diptera, Sciaridae).

Figure S20. Fossil pupa (exuvium), Mycetobia “morphotype 1" collection number PED-4998. (A) habitus, ventral view. (B) habitus, dorsal view.

Figure S21. Fossil pupa (exuvium), Mycetobia "morphotype 1" (Bitterfeld amber), collection number Dip-00661. (A) habitus, ventral view. (B) habitus, dorsal view, (C) habitus, lateral view.

Figure S22. Fossil pupa, Mycetobia "morphotype 1" (Bitterfeld amber), DEI, collection number Dip-00650 . (A) habitus, dorsal view. (B) habitus, ventral view.

Figure S23. Fossil pupa, Mycetobia "morphotype 1" and syninclusions, GPIH, N-7095. A) overview. (B) pupa (upper left) Mycetobia "morphotype 1", (upper left) and larva of Neuroptera; lower right). (C, D) adult long-legged fly (Dolichopodidae). (C) specimen 1 (D) specimen 2.

Figure S24. Fossil pupa (exuvium), Mycetobia “morphotype 1", DEI, collection number Dip00653. (A) habitus, dorsal view. (B) habitus, ventral view. (C) habitus, lateral view.

Figure S25. Fossil pupa (exuvium), Mycetobia "morphotype 1", rendering of $\mu$-CT scans, DEI, collection number Dip-00653. (A) habitus, dorsal view. (B) habitus, ventral view. (C) habitus, lateral view. MicroCT scanning credit: Marie Hörnig.

Figure S26. Fossil pupa (exuvium), Mycetobia "morphotype 1", rendering of $\mu$-CT scans, MfNB, collection number MB.I.7295 (A) habitus, dorsal view. (B) habitus, lateral view.

PeerJ reviewing PDF | (2019:06:38366:3:2:NEW 4 Sep 2019) 
1568 (C) habitus, ventral view. (D) habitus, lateral view. All images red-blue stereo anaglyphs, please 1569 use red-cyan glasses to view.

1570

1571 Figure S27. Fossil pupae, Mycetobia and syninclusions. (A)“morphotype 1" and syninclusions, 1572 GPIH, collection number AKBS-00071. 1, largely unidentifiable (Insecta); 2, 3, 5-9, 13, 15 ant

1573 worker (Lasius schiefferdeckeri Mayr, 1868); 4, Fossil pupa, Mycetobia "morphotype 1"; 10 ant 1574 worker (Ctenobethylus goepperti (Mayr, 1868)). (B) syninclusions to "morphotype 2", PED, 1575 collection number PED-4866; adult rove beetle (Coleoptera: Staphylinidae), two adult gall 1576 midges (Diptera; Cecidomyiidae). (C) pupa of Mycetobia "morphotype 2", GPIH, collection 1577 number L-7514, habitus, ventral view.

1578

1579 Figure S28. Fossil pupa (pharate adult), Mycetobia "morphotype 3", rendering of $\mu$-CT scans, 1580 DEI, collection number Dip-00660. (A) habitus, lateral view, right body side, mirrored. (B) 1581 habitus, lateral view, left body side. (C) habitus, dorsal view. (D) habitus, ventral view. MicroCT 1582 scanning credit: Marie Hörnig.

1583

1584 Figure S29. Fossil pupa (pharate adult), Mycetobia "morphotype 3" DEI, collection number Dip1585 00652. (A) habitus, dorsal view. (B) habitus, ventral view. 


\section{Figure 1}

Phylogenetic relationship among different lineages of Bibionomorpha sensu lato, modified from Sevcik et al., 2016.

Figure 1. Phylogenetic relationship among different lineages of Bibionomorpha sensu lato, loosely based and modified and Sevcik et al., 2016: “Figure 1 Bayesian hypothesis for relationships among selected taxa of Bibionomorpha based on DNA sequence data (18S, 28S, CAD, 12S, 16S, and COI), 5,018 characters". Position of the Perissommatidae were inferred from comparing phylogeny from Marshall, 2012 with Sevcik et al., 2016. Figure 2. Dipteran larva, holotype of Dinobibio hoffeinseorum sp. nov. GPIH, accession number (GPIH-0024) in lateral view. (A) overview, composite image. (B) coloured version of A above. Abbreviations: a1-a8, abdominal segment 1-8; hc, head capsule; $\mathrm{mp}$, maxillary process; ms, mesothorax; mt, metathorax, pt, prothorax; s1-s10, spiracle 1-10; te, trunk end.

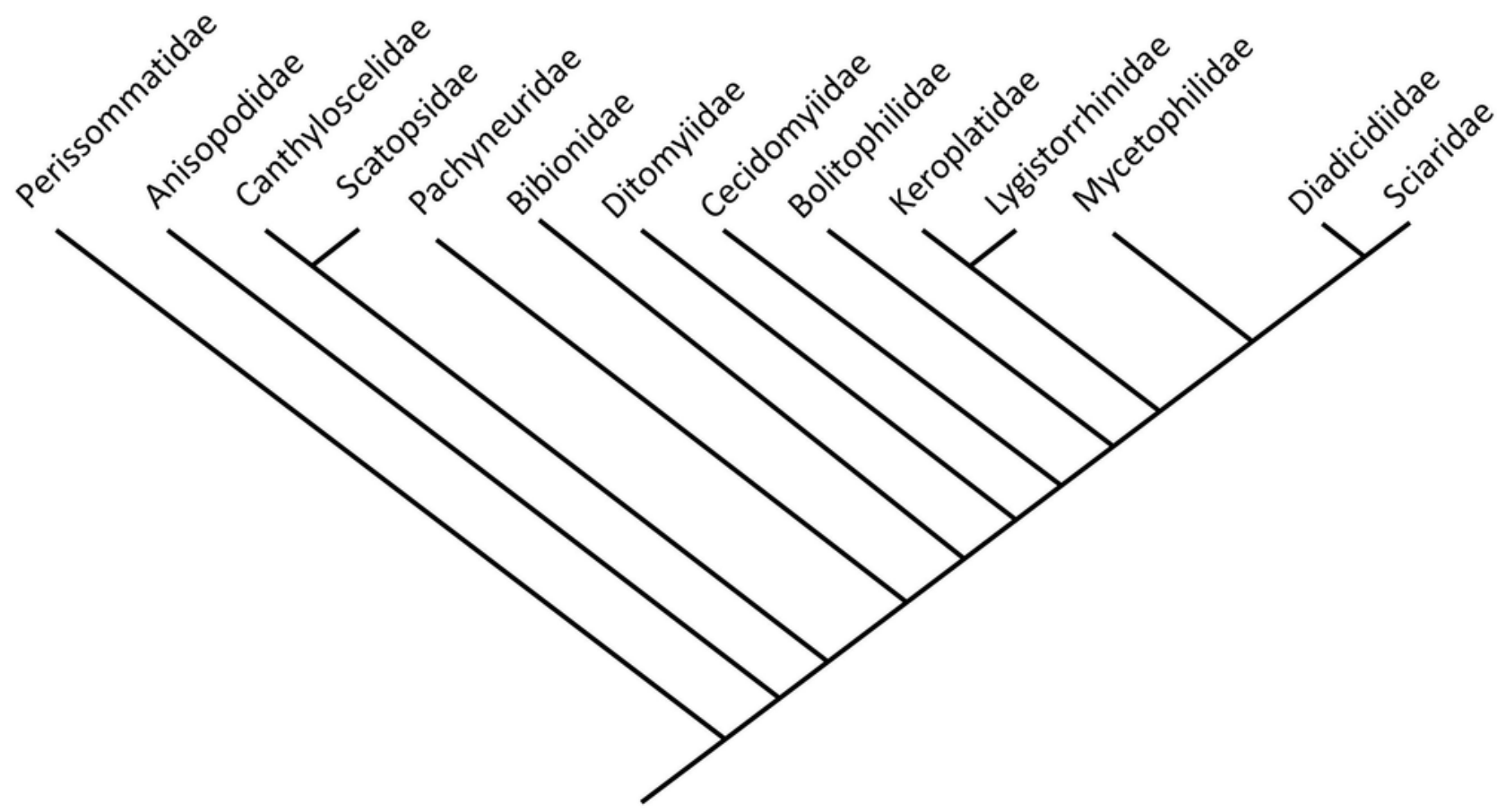




\section{Figure 2}

Dipteran larva, holotype of Dinobibio hoffeinseorum sp.n. GPIH, accession number (GPIH-0024) in lateral view.

(A) overview, composite image. (B) coloured version of A above. Abbreviations: a1-a8, abdominal segment 1-8; hc, head capsule; $\mathrm{mp}$, maxillary process; ms, mesothorax; $\mathrm{mt}$, metathorax, pt, prothorax; s1-s10, spiracle 1-10; te, trunk end.
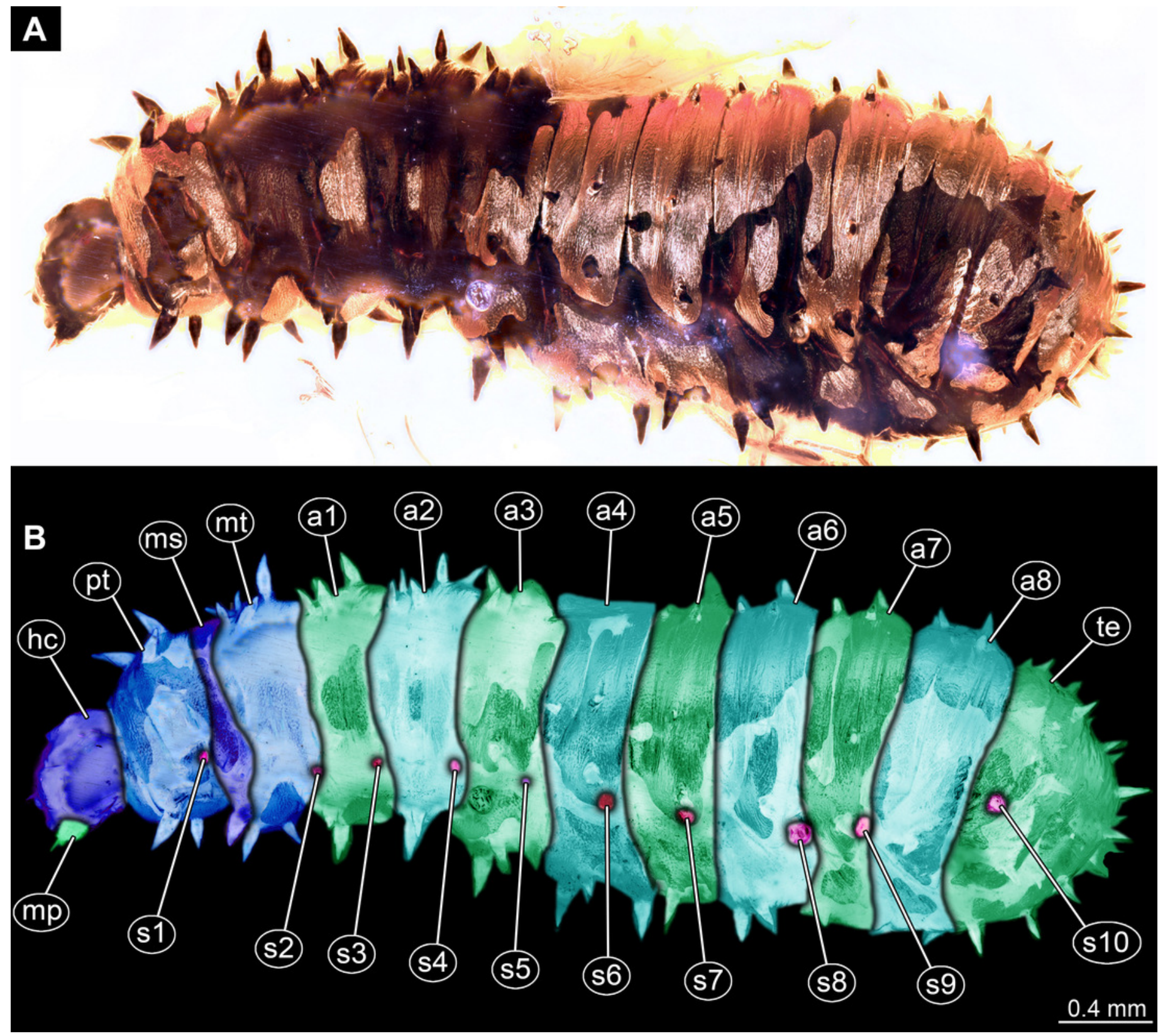
Figure 3

Fossil dipteran larva, holotype of Dinobibio hoffeinseorum sp.n. GPIH, accession number (GPIH-0024).

(A) head capsule, latero-dorsal view; (B) coloured version of A. (C) head capsule, ventrolateral view. (D) coloured version of C. Abbreviations: an, antennae; cl, clypeus; hc, head capsule; lb, labium; $\mathrm{md}$, mandible; $\mathrm{mp}$, maxillary palp; $\mathrm{mx}$, maxilla. 

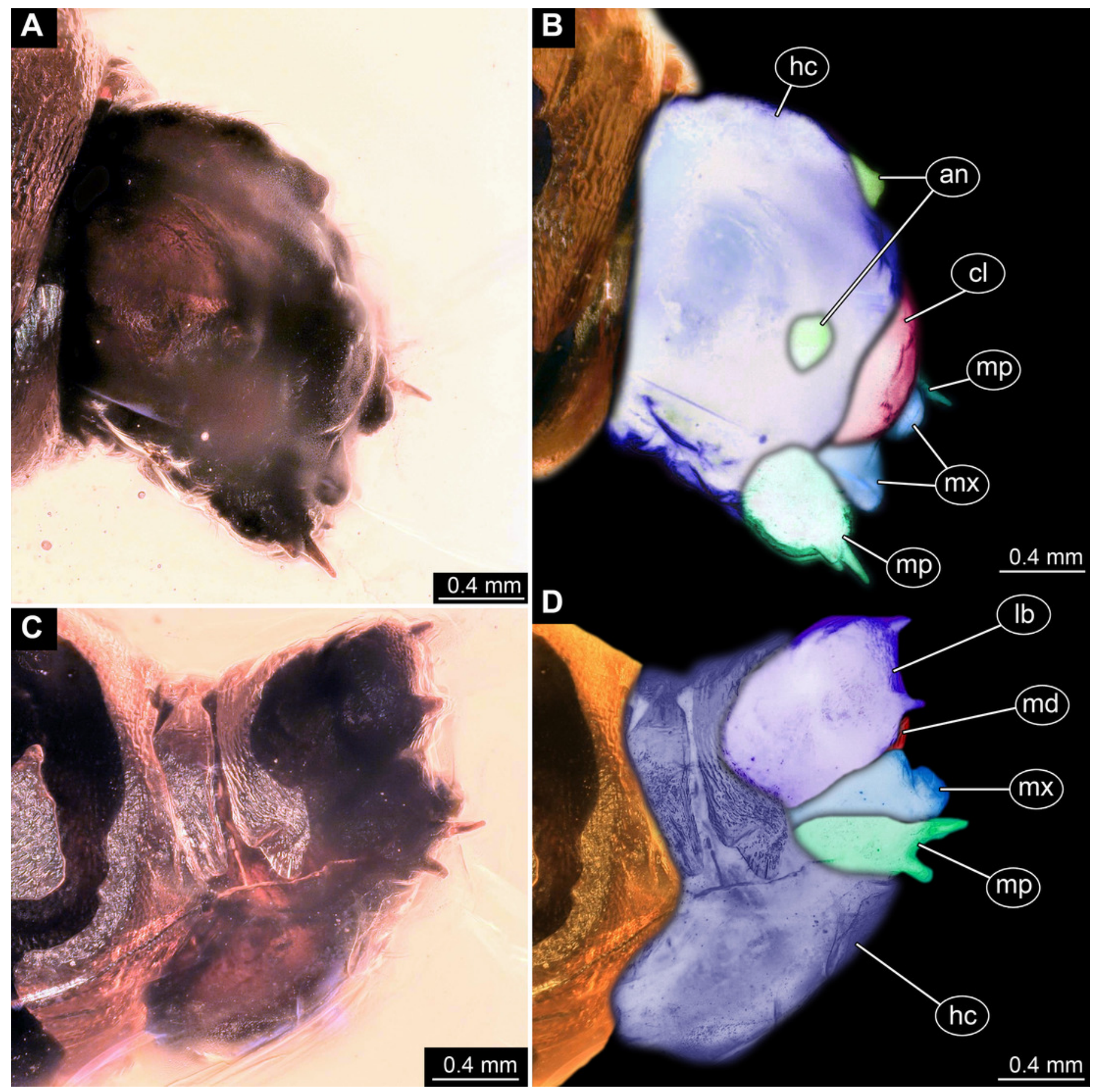


\section{Figure 4}

Extant larvae of Bibionidae. (A-C) Bibio varipies Meigen, 1830, CeNak, no collection number assigned.

(A) Penthetria funebris Meigen, 1804, ZSM, no collection number assigned. (A) habitus ventral. (B) head capsule, ventral. (C) head capusle of fourth instar larva, ventral.
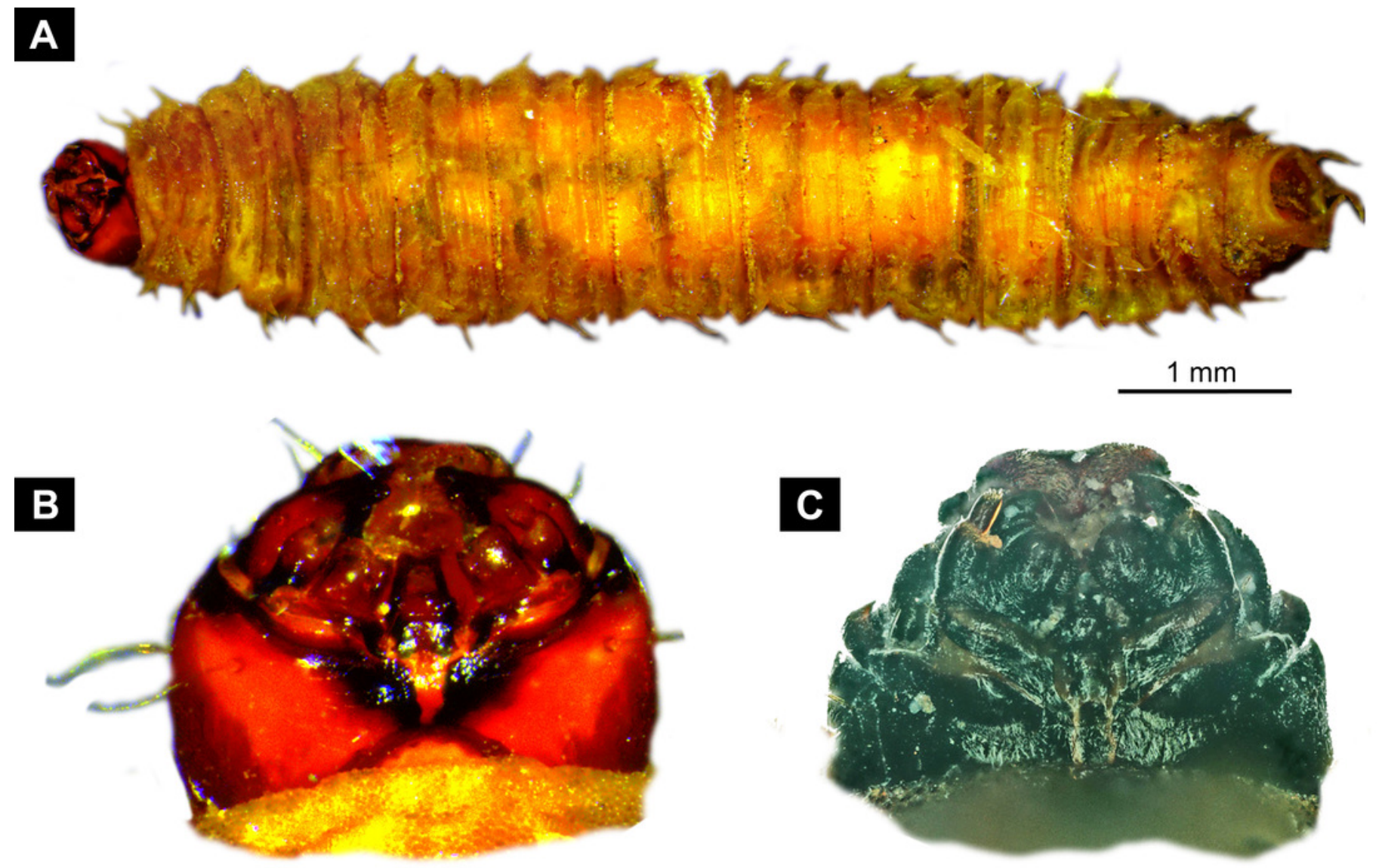

$100 \mu \mathrm{m}$

$100 \mu \mathrm{m}$ 


\section{Figure 5}

Extant larvae of Bibionidae. (A-C) Penthetria funebris Meigen, 1804, ZSM, no collection number assigned.

A) fourth instar larva, habitus dorsal, arrows indicate the position of spiracles. (B) first instar larva, habitus ventral. (C) first instar larva, spiracle 1 (red arrow in B).
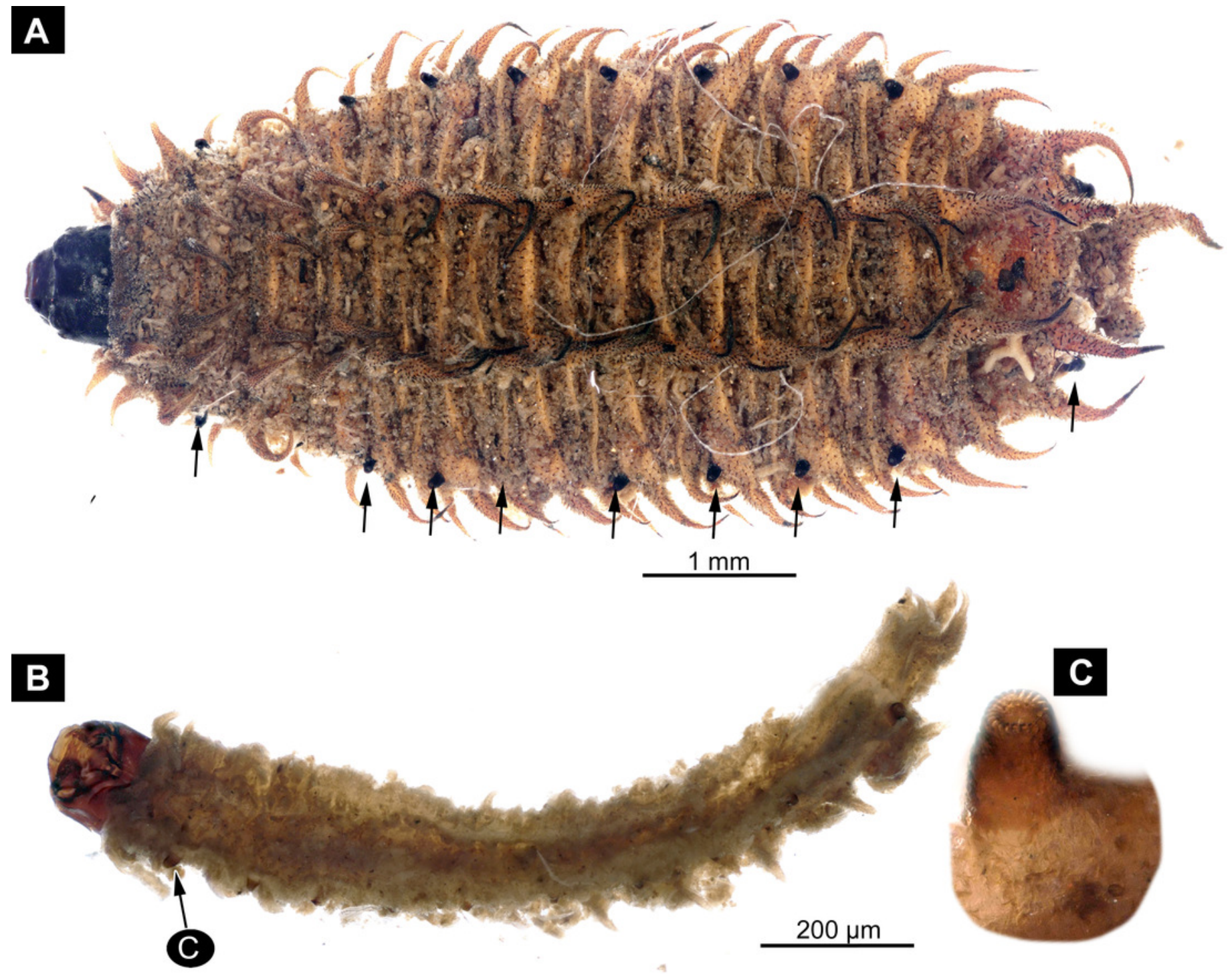


\section{Figure 6}

Fossil dipteran larva, Pachyneura, collection of GPIH, accession number (L-7617).

(A) habitus, dorsal. (B) schematic drawing of habitus, dorsal. a2-a8, abdominal segment 2-8; cl, clypeus; Abbreviations: hc, headcapsule; ms, mesothorax; mt, metathorax; pt, prothorax; s1-s10, spiracle 1-10.

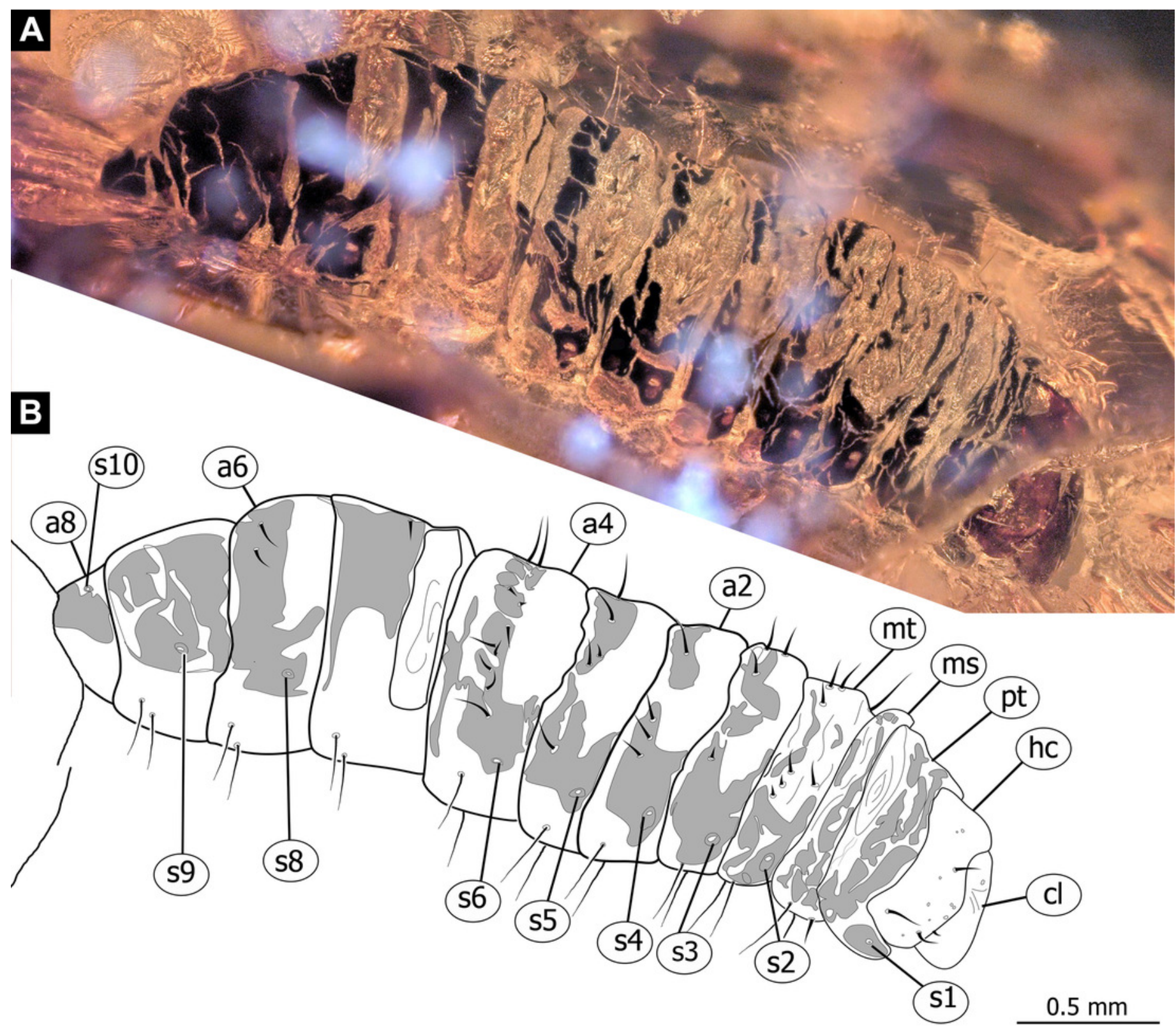




\section{Figure 7}

Fossil dipteran larva, Pachyneura, collection of GPIH (L-7617).

(A) habitus, ventral. (B) coloured version of A. Abbreviations: a1-a8, abdominal segments 1-8; c1-c6, creeping welts 1-6; hc, headcapsule; lb, labrum; md, mandibles; mp, maxillar palp; ms, mesothorax; mt, metathorax; mx, maxilla; pt, prothorax; te, trunk-end.

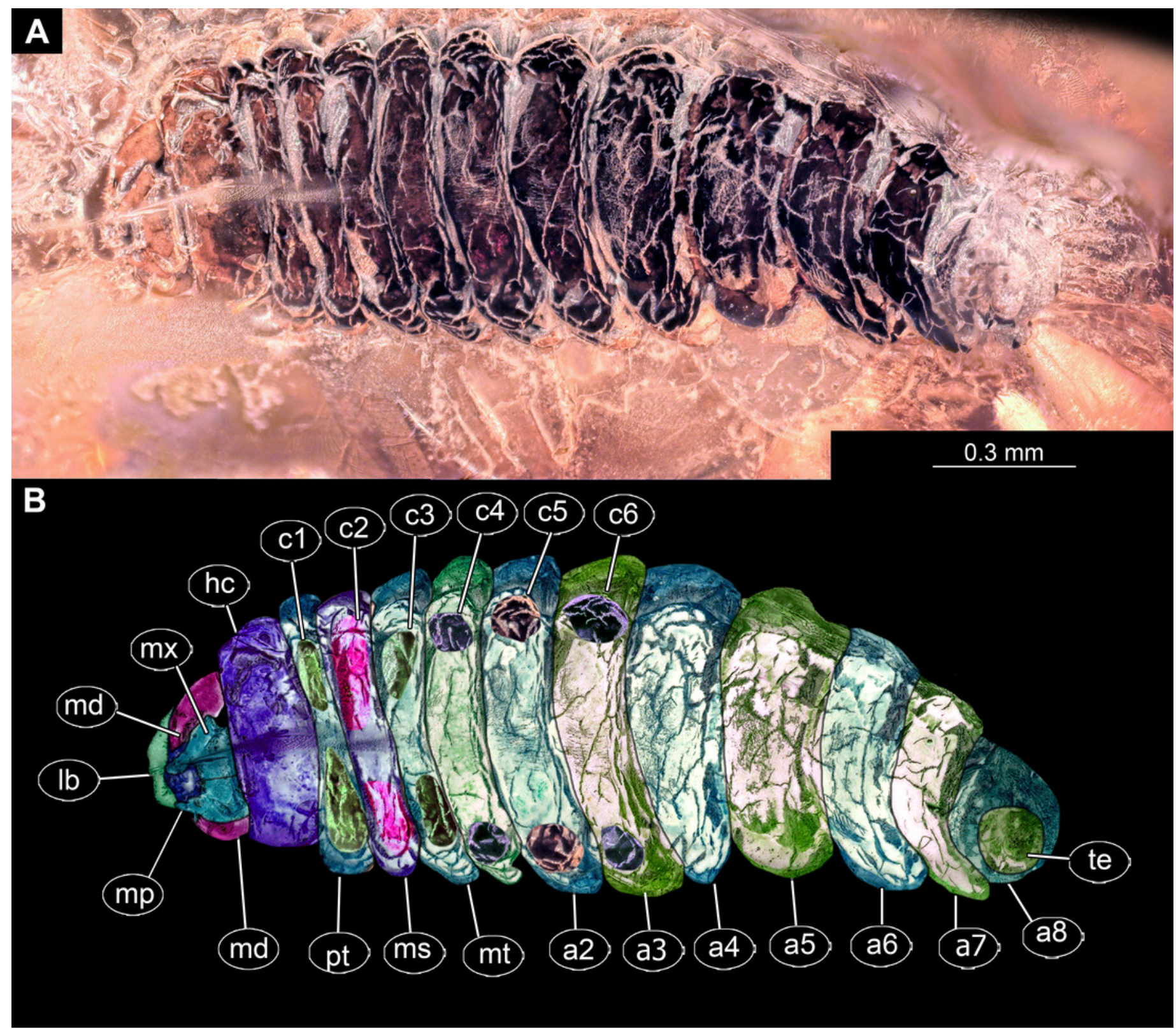


Figure 8

Fossil dipteran larva, Pachyneura, collection of GPIH, accession number (L-7617).

(A) head capsule, dorsal view. (B) head capsule, ventral view. (C) coloured version of B. (D) head capsule ventral view, schematic drawing. Abbreviations: hb, hypostomal bridge; hc, head capsule; Ib, labrum; md, mandibles; mp, maxilary palps; mx, maxillae. 

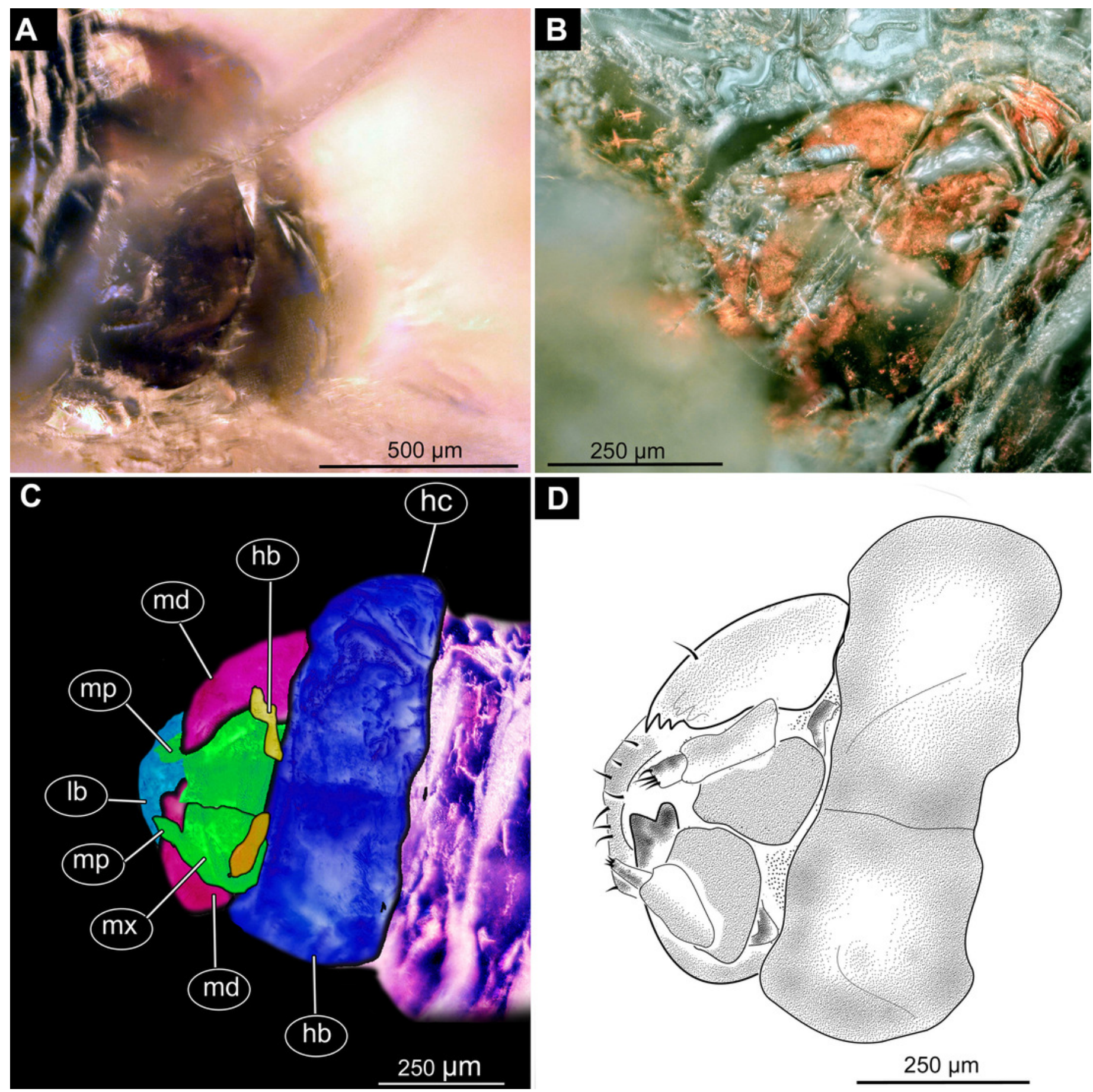
Figure 9

Fossil dipteran larva, Mycetobia, DEI, accession number Dip-00640.

(A) habitus, dorsal view. (B) coloured version of A. (C) posterior spiracles, specimen 2 of $B$.

(D) coloured version of C. Abbreviations: a2-a8, abdominal segments 2-8; as, anterior spiracle; hc, head capsule; ms, mesothorax; mt, metathorax; ps, posterior spiracle; pt, prothorax. 

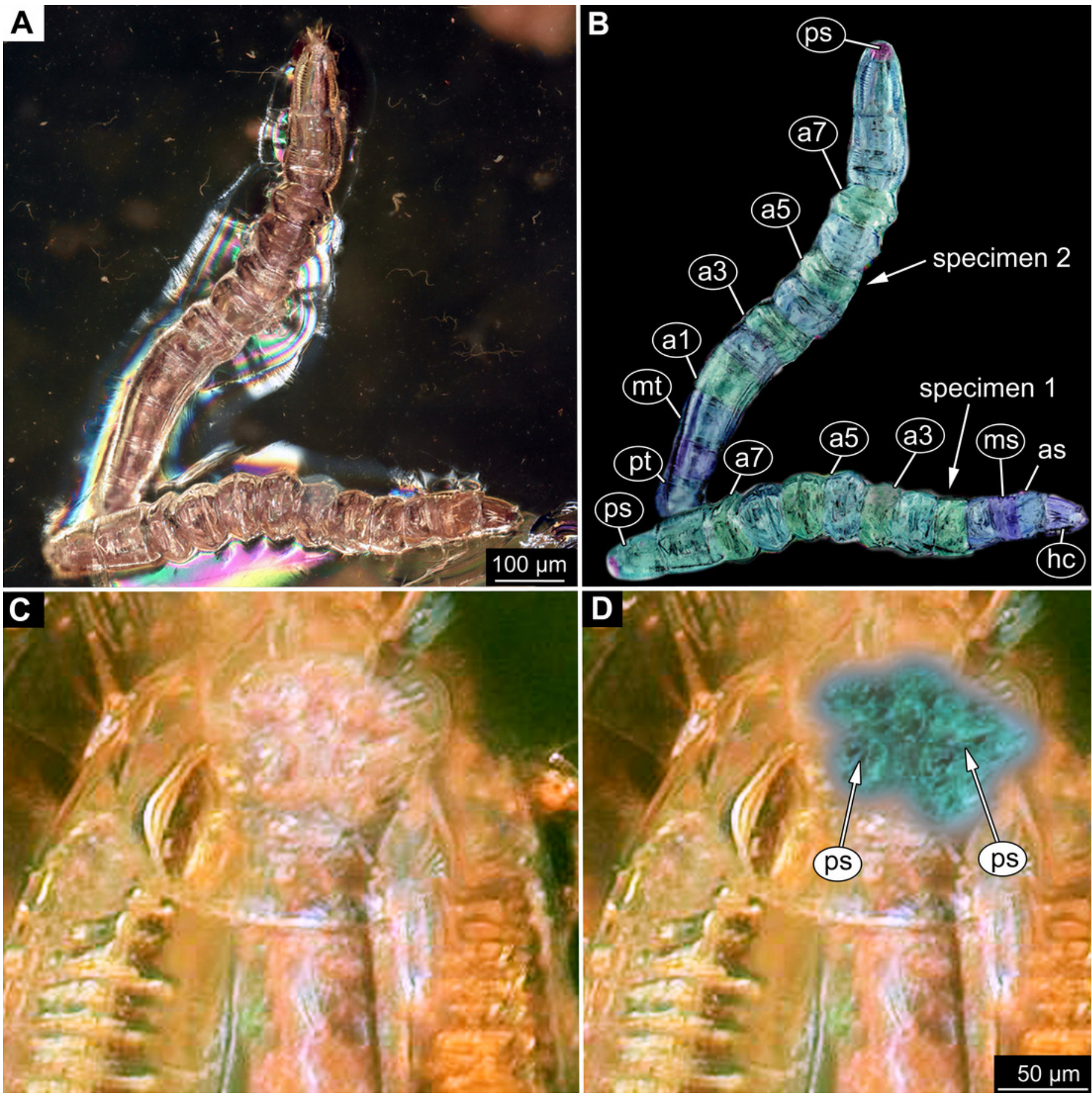


\section{Figure 10}

Fossil dipteran larva, Mycetobia, DEl accession number Dip-00640, specimen 1 of Fig. 8B.

(A) head capsule, dorsal view. (B) anterior spiracle. (C) coloured version of A. (D) head capsule, ventral view. (E) coloured version of D. Abbreviations: an, antenna; as, anterior spiracle; hc, head capsule; lb, labrum; md, mandibles; mn, mentum; mp, maxilar palps; mx, maxillae; ps, posterior spiracle. 


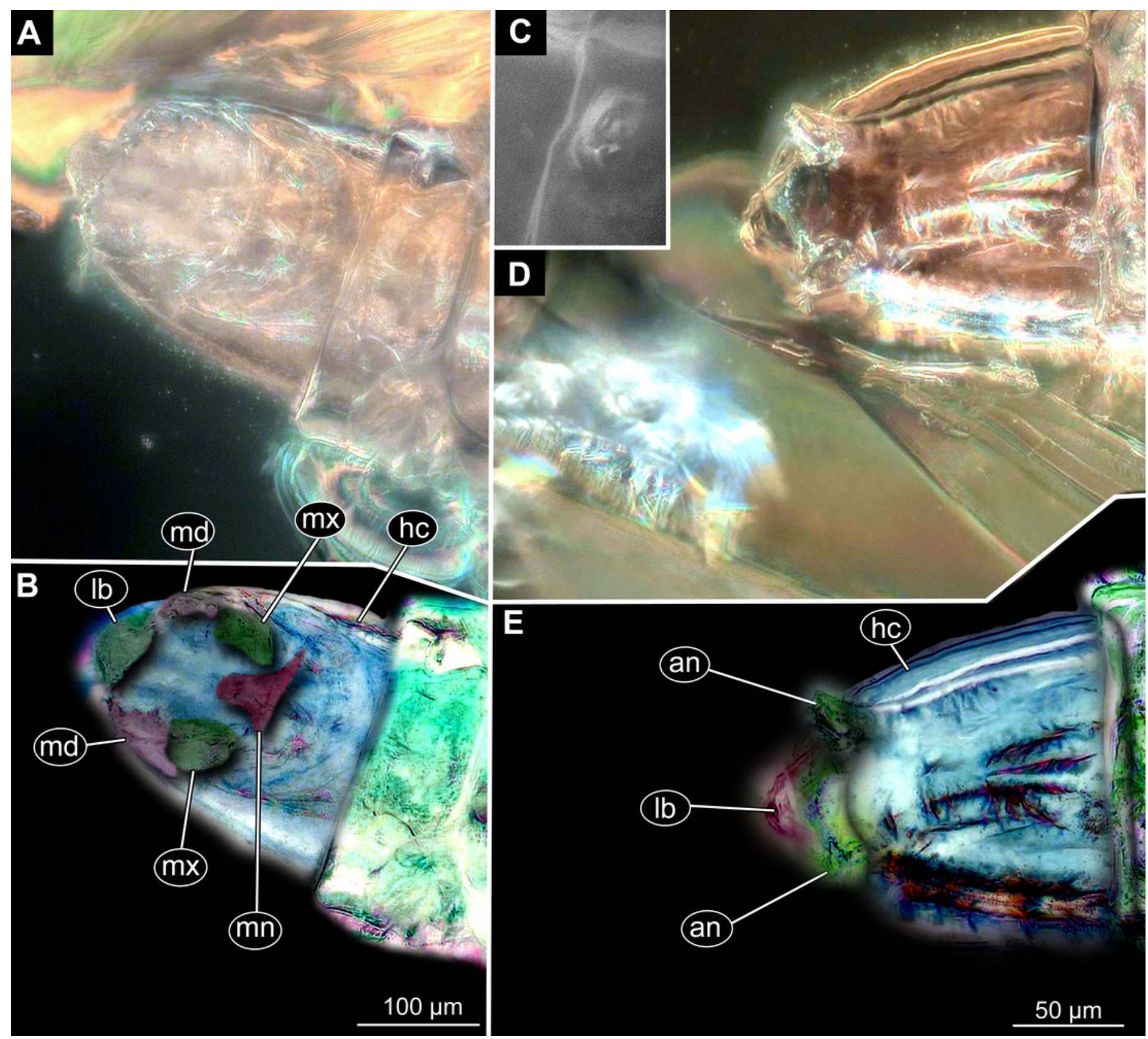




\section{Figure 11}

Extant dipteran larva, Mycetobia pallipes Meigen, 1818, ZSM, no collection number assigned.

(A) habitus, lateral. (B) coloured version of A. (C) head capsule, lateral view. (D) coloured version of C. Abbreviations: a2-a8, abdominal segment 2-8; as, anterior spiracle; hc, head capsule; md, mandible; mn, mentum; ms, mesothorax; $\mathrm{mt}$, methathorax; $\mathrm{mx}$, maxillae; $\mathrm{pt}$, prothorax; tp, posterior pit of tentorium.

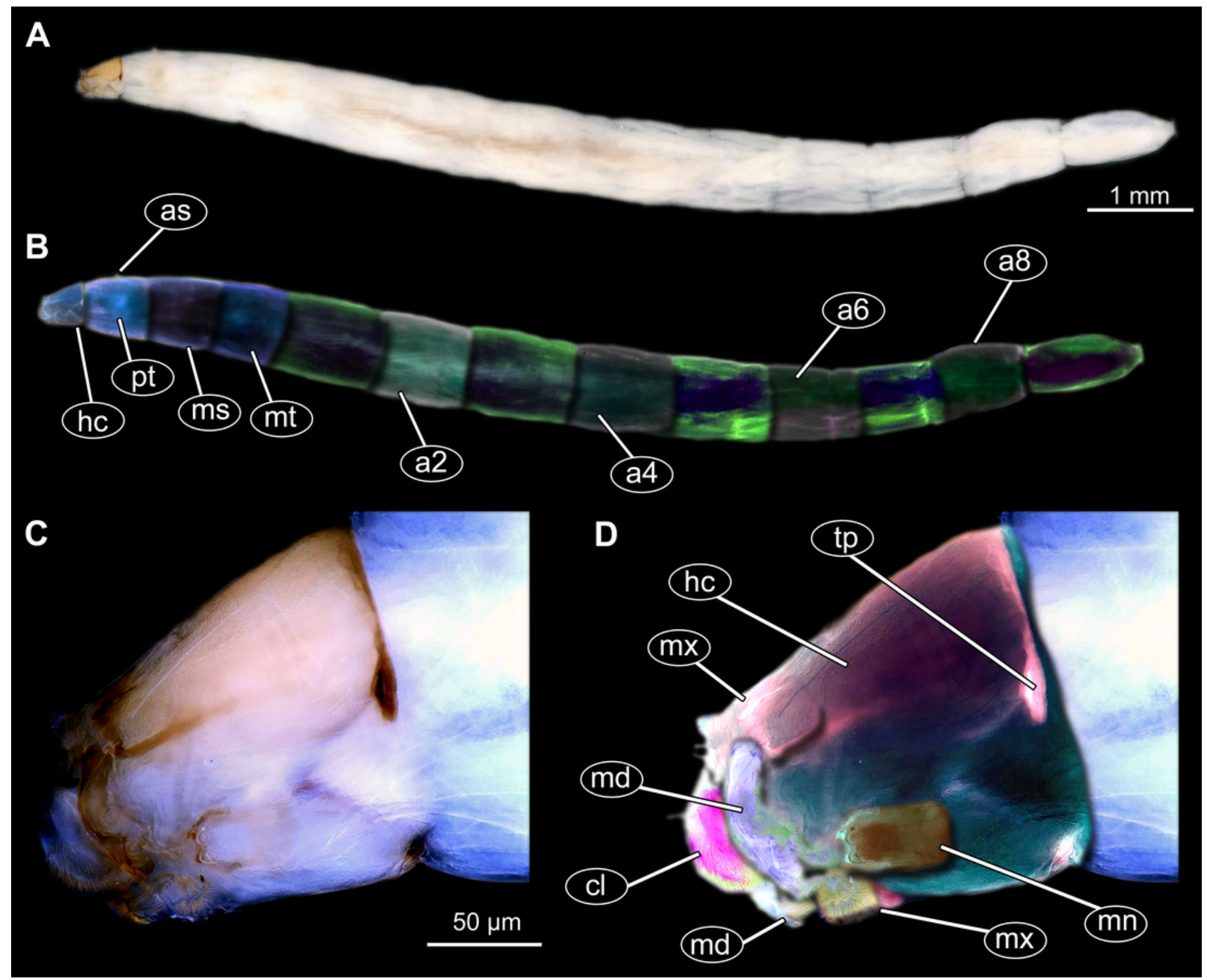




\section{Figure 12}

Fossil pupa, Mycetobia connexa (Mycetobia "morphotype 1"), GPIH, collection number 1851-DN.

(A) habitus, ventro-lateral view. (B) coloured version of A. Abbreviations: a3-a7, abdominal segments 3-7; an, antennae; fs, frontal setae; p1, front legs; p2, midlegs; p3, hind legs; te, trunk-end; wn, wings.
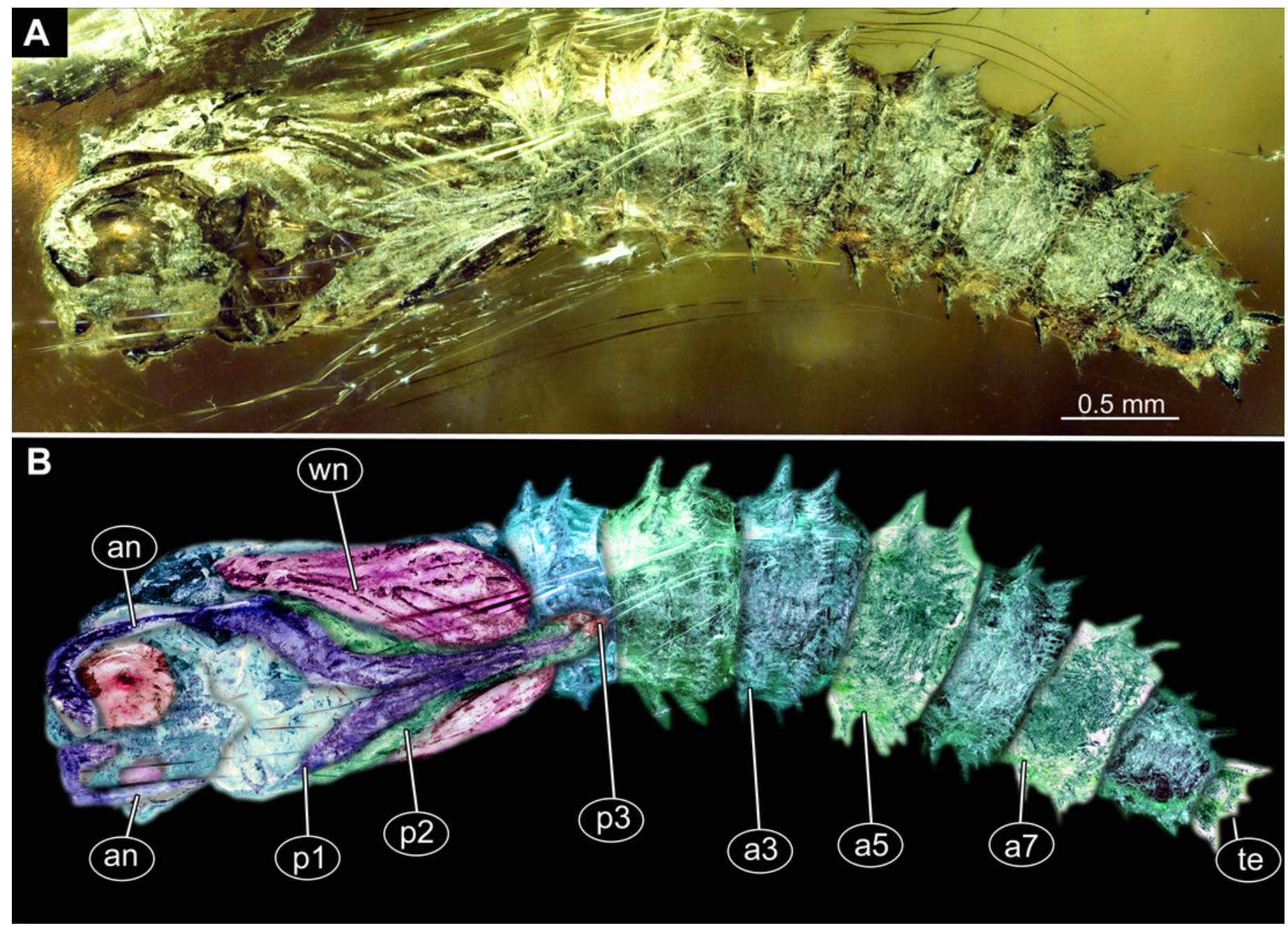


\section{Figure 13}

Fossil pupa, Mycetobia "morphotype 2", PED, collection number PED-4866.

(A) habitus, lateral view. (B) coloured version of A. Abbreviations: a1-a8, abdominal segments 1-8; an, antennae; ey, eyes; ms, mesothorax; mt, metathorax; p1, front legs; p2, midlegs; p, prothorax; te, trunk-end; th, thoracic horns; wn, wings.
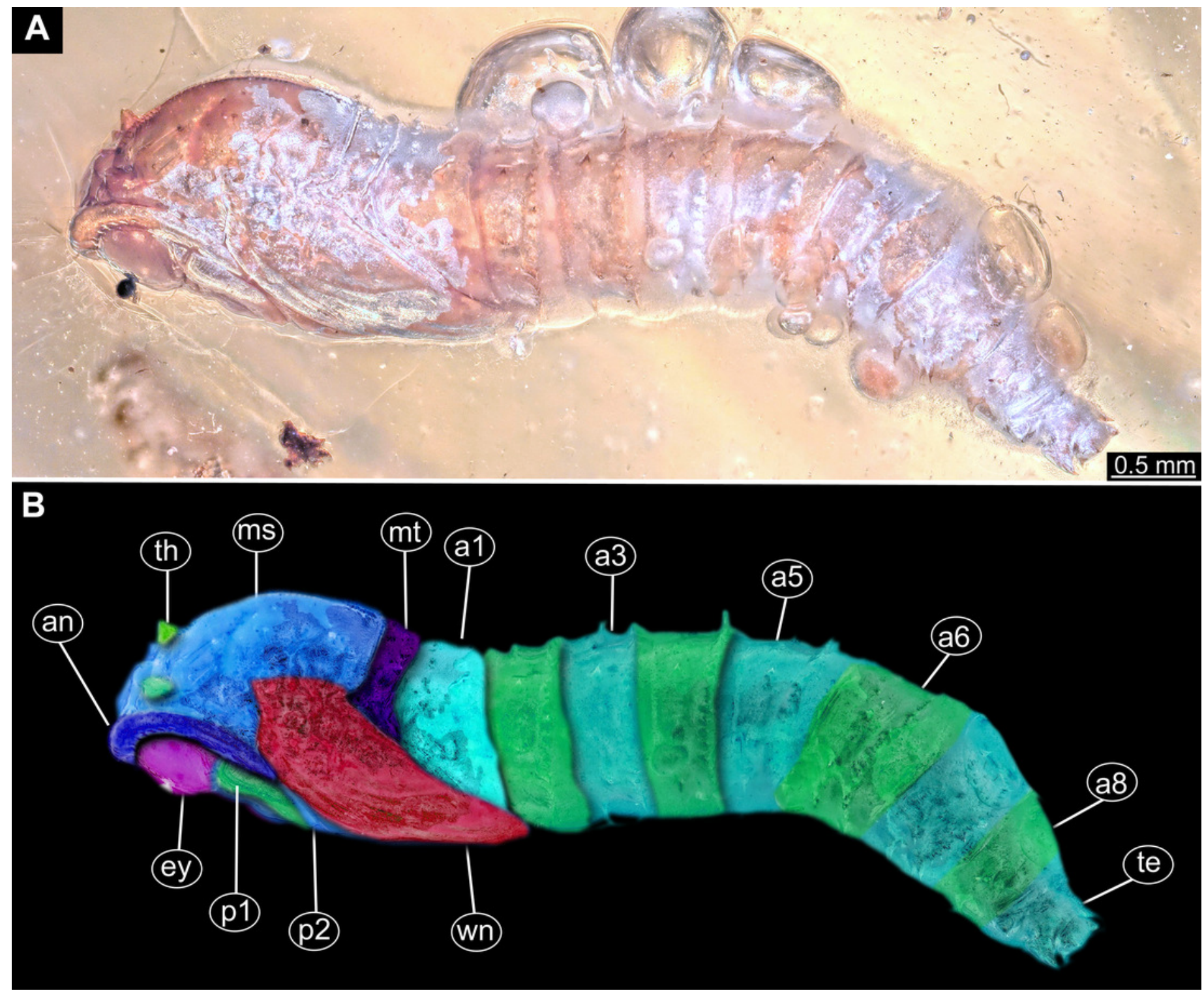


\section{Figure 14}

Fossil pupa, Mycetobia "morphotype 3", pharate adult, DEI, collection number CCHHDEI-608-2.

(A) habitus, dorsal view. (B) habitus, ventral view.
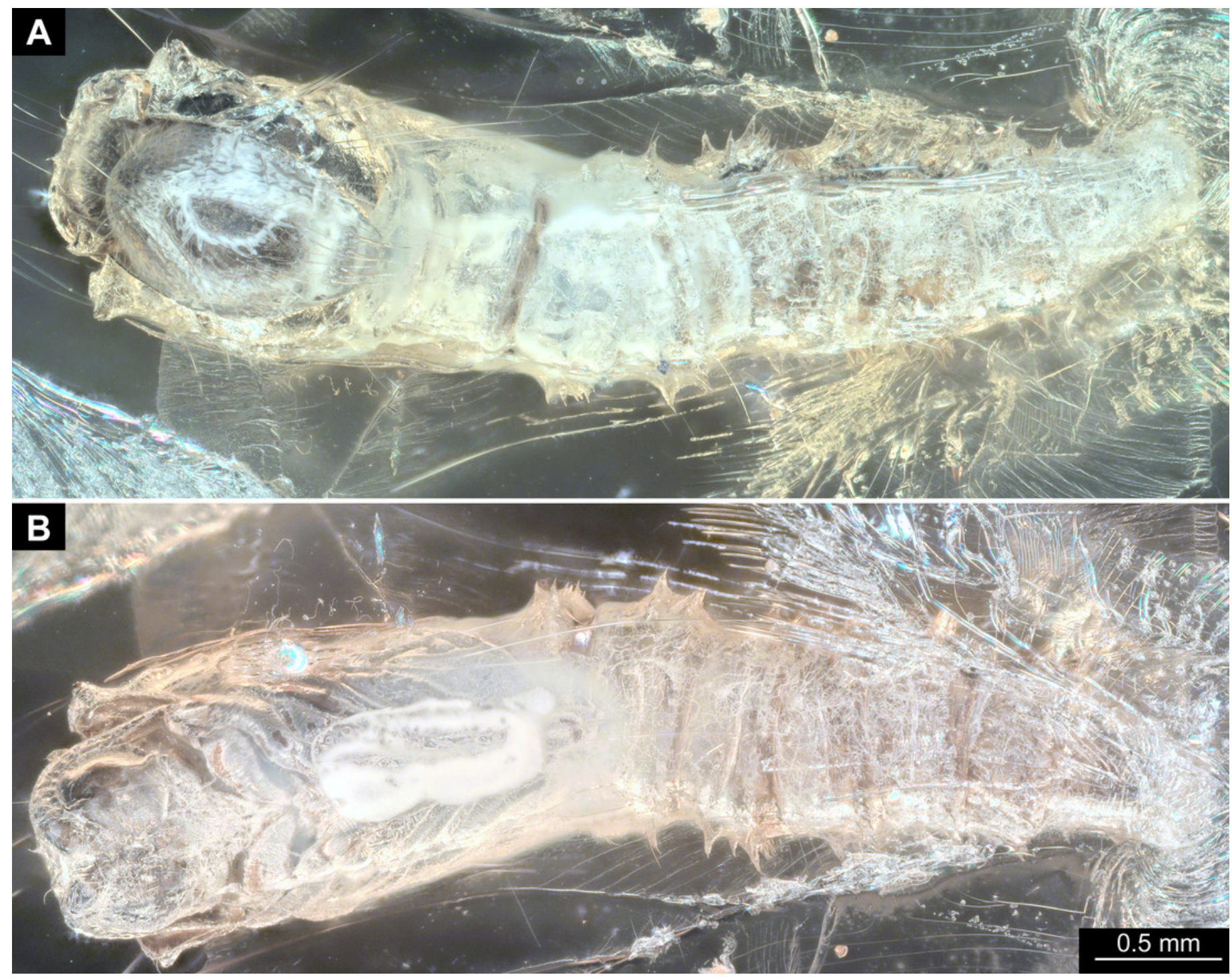


\section{Figure 15}

Extant pupa, Mycetobia pallipes Meigen, 1818, ZSM, no collection number assigned

(A) habitus, dorsal view. (B) coloured version of A. (C) habitus, ventral view. (D) coloured version of C. Abbreviations: an-antennae; a3-a7, abdominal segments 3-7: ey, eyes; fs, frontal setae; mt, mesothorax; p1, front legs; p2, midlegs; p3, hind legs; te, trunk-end; th, thoracic horn; wn, wing. 


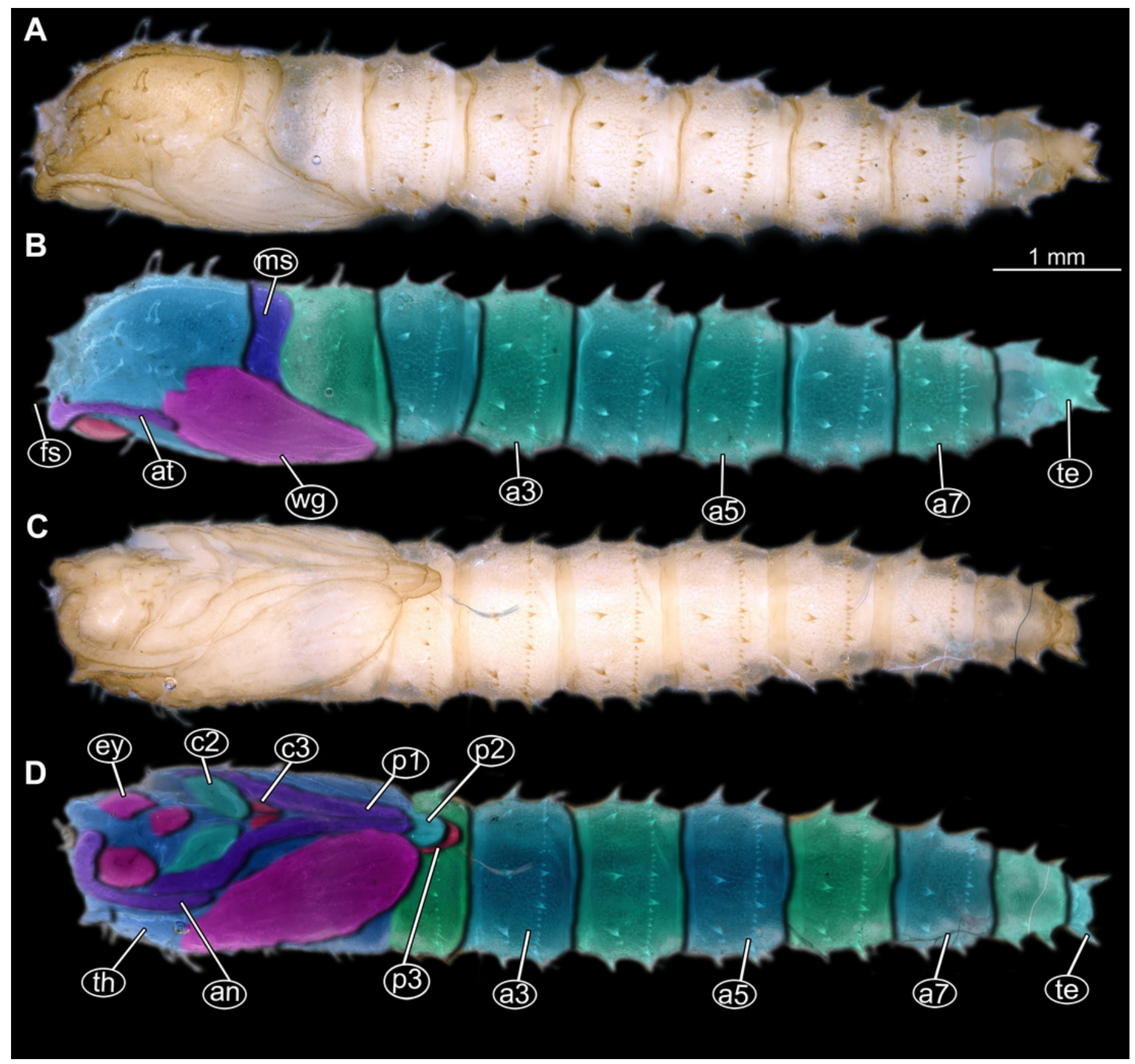




\section{Figure 16}

Fossil larva, Sylvicola, DEI, collection number Dip-00642.

(A) habitus, lateral view. (B) coloured version of A. (C) head capsule, lateral view. (D) coloured version of C. Abbreviations: a1-a8, abdominal segments 1-8; an, antennae; as, anterior spiracle; hc, head capsule; lb, labrum; md, mandible, mn, mentum; mx, maxilla; ms, mesothorax; te, trunk end.
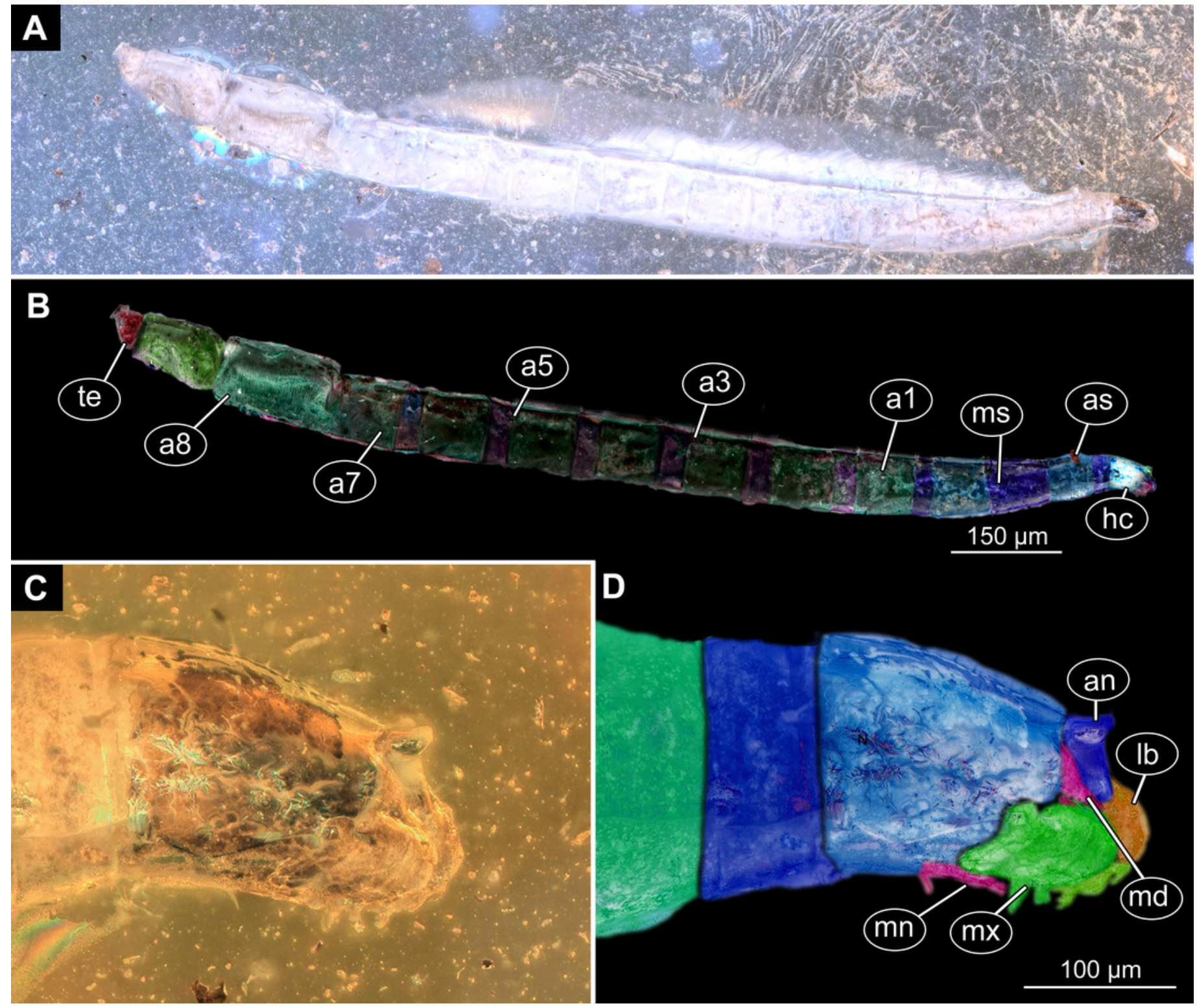


\section{Figure 17}

Reconstructed ontogenetic sequence for representatives of Mycetobia in the Eocene.

\section{Ontogenetic sequence of fossil window gnats}

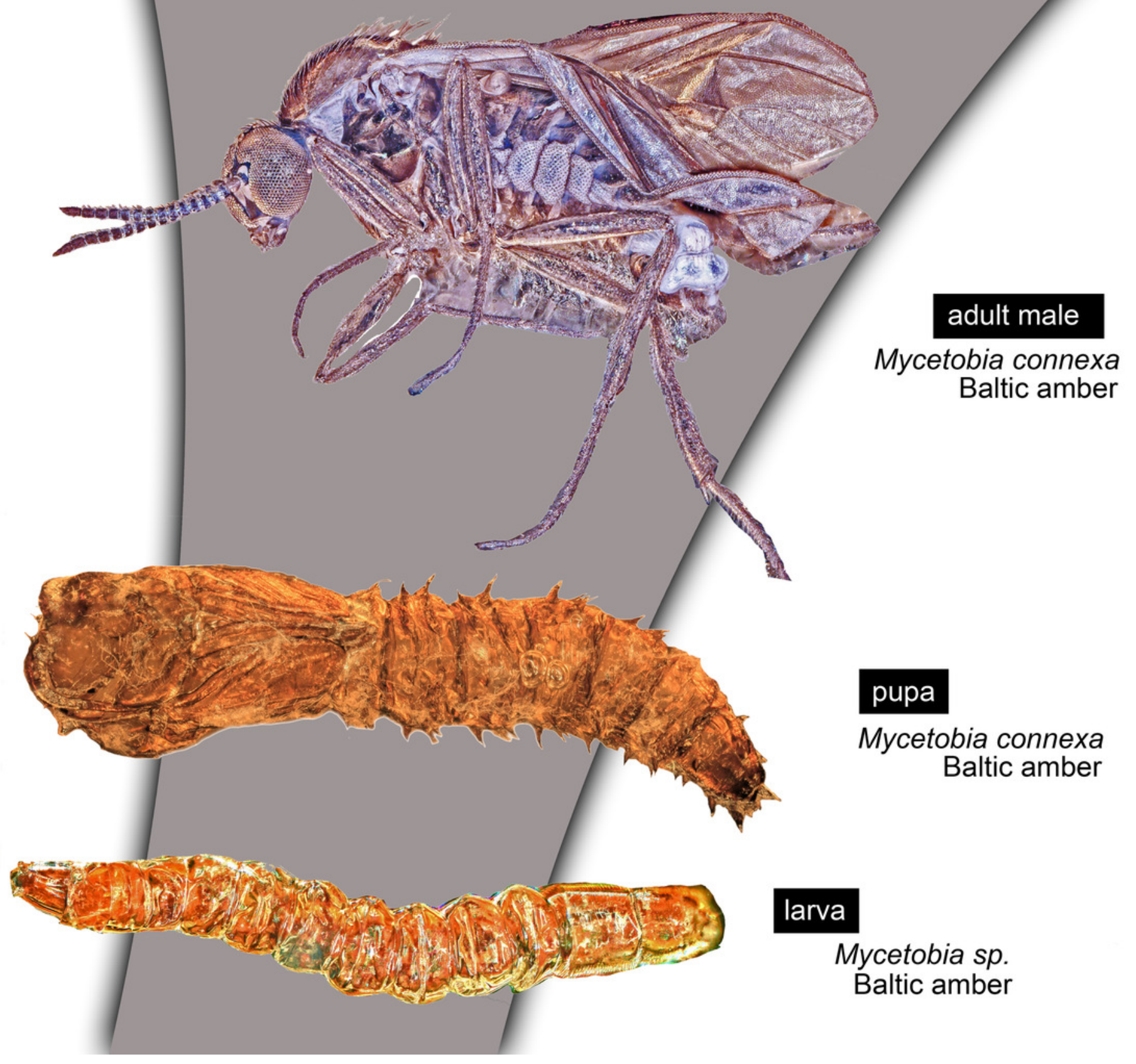




\section{Figure 18}

Summary statistics.

(A) biplot of fossil larvae of Mycetobia ( $n=36$ ), head capsule length vs. head capsule width, red circles indicate hypothetical divisions into different larval stages based on the gaps in the data point distribution. I-IV, number of hypothetical larval stages. (B) distribution of the size cohorts within a sample of the fossil larvae of Mycetobia; upper-row-left, histogram of the head capsule width distribution ( $n=26)$; upper-row-center, histogram of the head capsule length distribution ( $n=25)$; upper-row-right, histogram of the body length distribution $(n=36)$; lower-row-left, ranged plot (values ordered in ascending order) of the head capsule width, hypothetical division into different larval stages based on gaps in data point distribution indicated with I-IV as numbers of supposed larval stages; lower-row-centered, ranged plot (values ordered in ascending order) of head capsule length; lower-row-right, ranged plot (values ordered in ascending order) of body length.
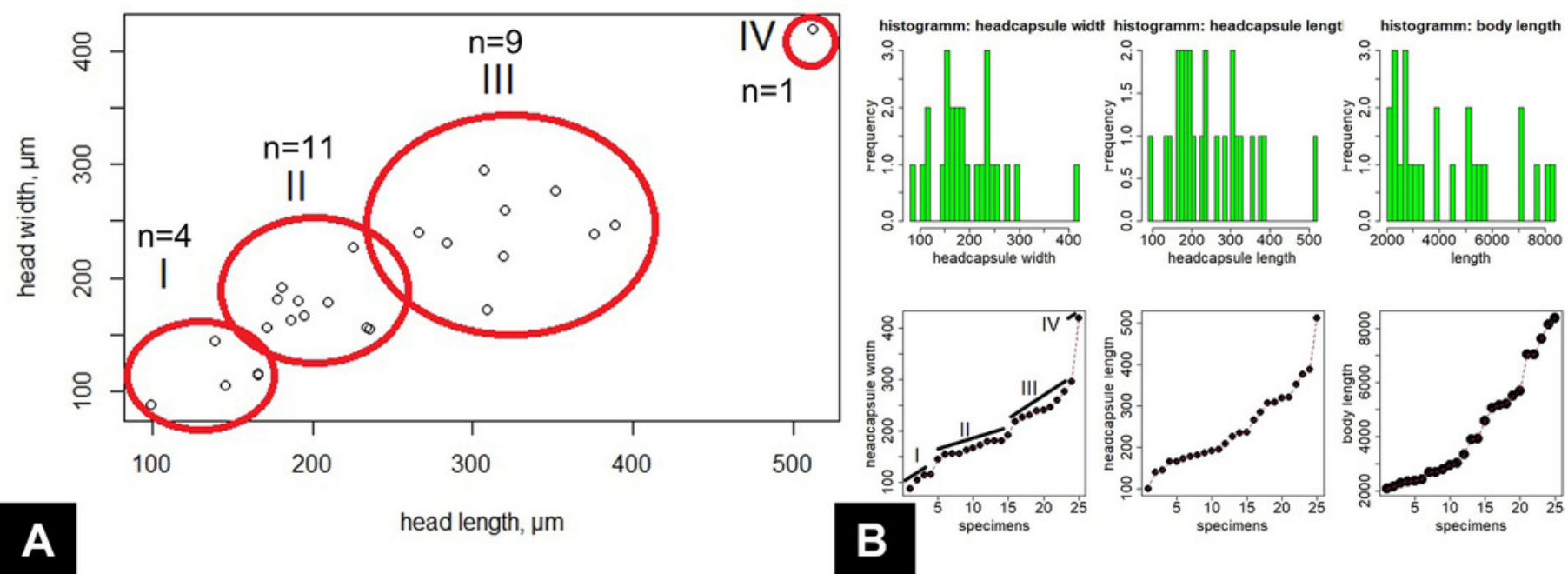
Figure 19

Figure 19. Natural logarithm of the mean larval head capsule width (red) and head capsule length (blue) of fossil larvae of Mycetobia, plotted against associated instar number.

The fourth larval stage is represented by a single specimen, therefore the actual values are plotted instead of the mean. Red dots and the line representing the head capsule width, while blue represents the head capsule length. Error bars are representative of the value's standard deviation.

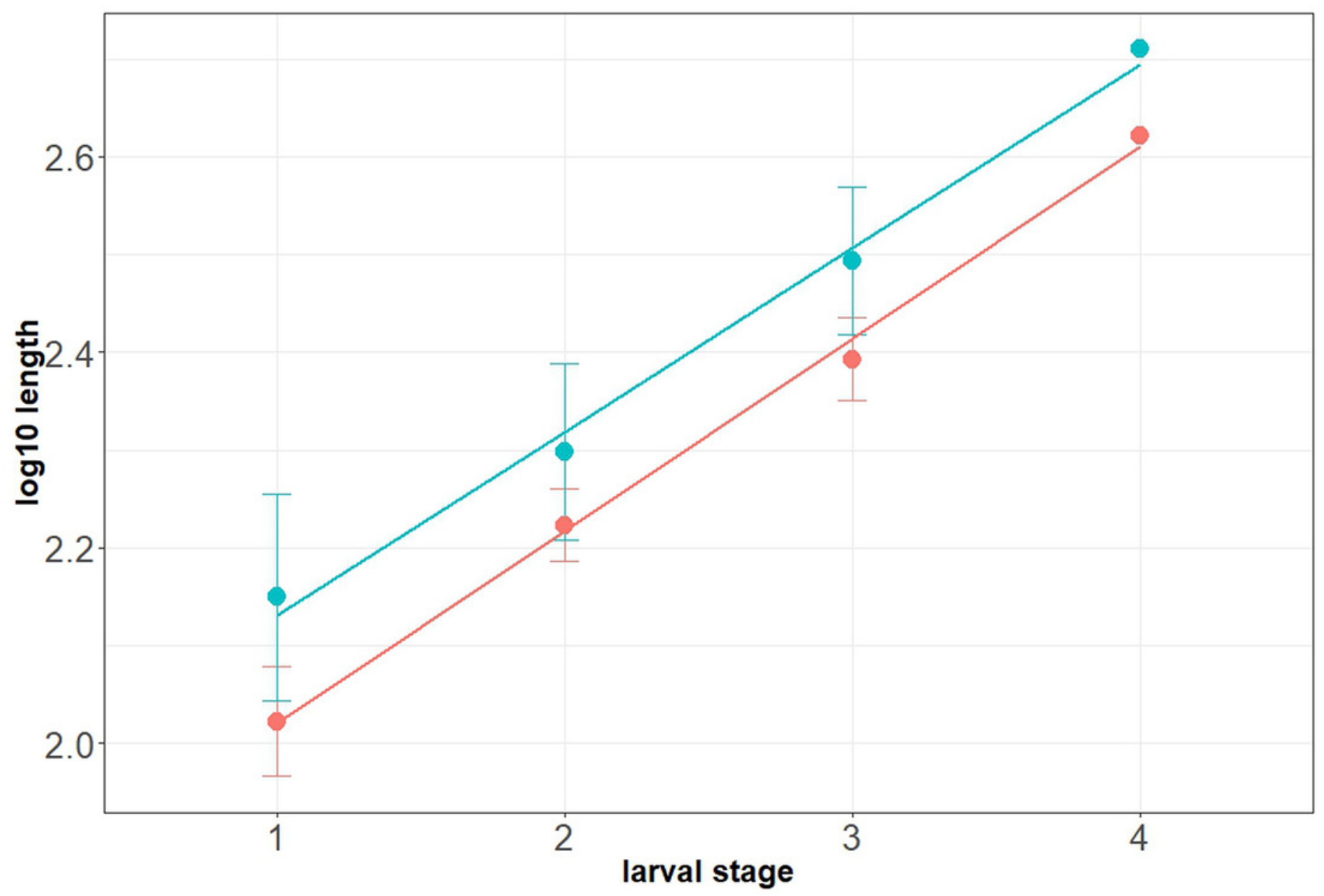




\section{Table 1 (on next page)}

Table 1. List of material examined 
1 Table 1. List of material examined 


\begin{tabular}{|c|c|c|c|c|c|}
\hline $\begin{array}{l}\text { ID- } \\
\text { Number }\end{array}$ & Taxa & Specimens & Syninclusions & Deposited & Origin \\
\hline $\begin{array}{l}\text { GPIH- } \\
\text { Schlee- } \\
0024\end{array}$ & $\begin{array}{l}\text { Dinobibio } \\
\text { hoffeinseorum }\end{array}$ & 1 & Acalyptrata & GPIH & Baltic \\
\hline $\begin{array}{l}\text { Dip- } \\
00642\end{array}$ & larvae Sylvicola (?) & 1 & Plant material+ stellate hairs & DEI & Baltic \\
\hline PED-4395 & Mycetobia connexa & $\begin{array}{l}\text { male, } \\
\text { female, } \\
\text { pupal exuvia }\end{array}$ & partial inclusion of an adult beetle & PED & Baltic \\
\hline BI-2350 & Mycetobia larvae & 1 & none & GPIH & Bitterfeld \\
\hline $\begin{array}{l}\text { GPIH- } \\
3706 \mathrm{~W}\end{array}$ & Mycetobia larvae & 1 & Phoridae adult + stellate hairs & GPIH & Baltic \\
\hline Dip-00639 & Mycetobia larvae & 1 & & DEI & Baltic \\
\hline PED-4965 & Mycetobia larvae & 1 & & PED & Baltic \\
\hline PED-4970 & Mycetobia larvae & 1 & & PED & Baltic \\
\hline PED-5695 & Mycetobia larvae & 1 & $\begin{array}{l}\text { Cicadellidae nymph, larva of Coccidoidea, worker ant } \\
\text { and non-biting midge female (Diptera: Chironomidae: } \\
\text { Tanytarsini) }\end{array}$ & PED & Baltic \\
\hline $\begin{array}{l}\text { GPIH-L- } \\
7592\end{array}$ & Mycetobia larvae & 2 & $\begin{array}{l}\text { Fragment of the Diptera Brachycera female, mites, } \\
\text { stellate hairs }\end{array}$ & GPIH & Baltic \\
\hline Dip-00640 & Mycetobia larvae & 3 & 2 males, 1 female Rheosmittia pertenuis & DEI & Baltic \\
\hline PED-4748 & Mycetobia larvae & 4 & & PED & Baltic \\
\hline $\begin{array}{l}\text { GPIH- } \\
\text { Schlee- } \\
0247 \\
\end{array}$ & Mycetobia larvae & 9 & "Lepidoptera" (Trichoptera), + fragment of a beetle & GPIH & Baltic \\
\hline $\begin{array}{l}\text { AKBS- } \\
00071\end{array}$ & Mycetobia pupa $\mathrm{mt} 1$ & 1 & Lasius schiefferdeckeri+Ctenobethylus geopperti & GPIH & Baltic \\
\hline $\begin{array}{l}\text { GPIH- } \\
1851 \mathrm{DN}\end{array}$ & Mycetobia pupa $\mathrm{mt} 1$ & 1 & $\begin{array}{l}2 \text { keratoplatidae males, sciaridae male }+ \text { probabbly } \\
\text { male of Anisopodidae }\end{array}$ & GPIH & Baltic \\
\hline Dip-00641 & Mycetobia pupa $\mathrm{mt} 1$ & 1 & Plant material, insect tarsi fragment & DEI & Baltic \\
\hline $\begin{array}{l}\text { GPIH-N- } \\
7095\end{array}$ & Mycetobia pupa mt 1 & 1 & $\begin{array}{l}\text { Neurothidae larvae, ants } 2 \text {, Dolichopodidae flies x2, } \\
\text { Trichoptera adult, insects i.s. x2 }\end{array}$ & GPIH & Baltic \\
\hline PED-4998 & Mycetobia pupa $\mathrm{mt} 1$ & 1 & spider webs & PED & Baltic \\
\hline $\begin{array}{l}\text { GPIH-L- } \\
7514\end{array}$ & Mycetobia pupa $\mathrm{mt} 2$ & 1 & Plant material + stellate hair & GPIH & Baltic \\
\hline PED-4866 & Mycetobia pupa $\mathrm{mt} 2$ & 1 & $\begin{array}{l}\text { dult rove beetle (Coleoptera: Staphylinidae) and two } \\
\text { adult gall midges (Diptera; Cecidomyiidae) }\end{array}$ & PED & Baltic \\
\hline $\begin{array}{l}\text { GPIH - } \\
7516\end{array}$ & Pachyneuridae larvae & 1 & stellate hairs & GPIH & Baltic \\
\hline Dip-00649 & Mycetobia larvae & 5 & Orthocladiinae female & DEI & Baltic \\
\hline Dip-00650 & Mycetobia pupa & 1 & & DEI & Bitterfeld \\
\hline Dip-00651 & Mycetobia pupa & 1 & & DEI & Baltic \\
\hline Dip-00652 & $\begin{array}{l}\text { Mycetobia pharrate } \\
\text { adult }\end{array}$ & 1 & & DEI & Baltic \\
\hline Dip-00653 & Mycetobia pupa & 1 & & DEI & Baltic \\
\hline Dip-00654 & Nematocera larvae sp & 3 & & DEI & Baltic \\
\hline Dip-00655 & $\begin{array}{l}\text { Mycetobia pup 2,2 } \\
\text { larvae }\end{array}$ & 4 & Adult sciaroidea, adult limoniidae & DEI & Baltic \\
\hline Dip-00656 & Mycetobia larvae & 3 & Ants, Cecidomyiidae,check photo & DEI & Baltic \\
\hline Dip-00657 & Mycetobia pupa $\mathrm{mt} 1$ & 1 & & DEI & Baltic \\
\hline Dip-00658 & Mycetobia larvae & 1 & & DEI & Baltic \\
\hline Dip-00659 & Mycetobia pupa mt1 & 1 & & DEI & Baltic \\
\hline Dip-00660 & $\begin{array}{l}\text { Mycetobia pharrate } \\
\text { adult }\end{array}$ & 1 & & DEI & Baltic \\
\hline Dip-00661 & Mycetobia pupa mt 1 & 1 & & DEI & Bitterfeld \\
\hline
\end{tabular}




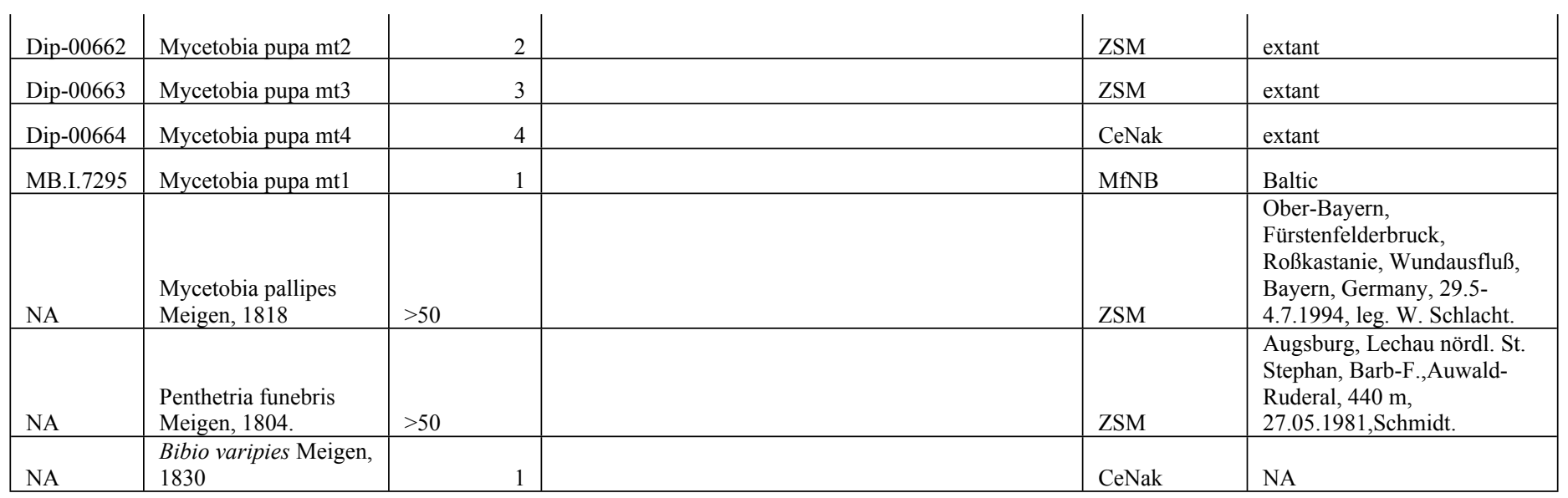

2 


\section{Table 2 (on next page)}

Table 2. Morphometry of the fossil Mycetobia larvae from Baltic and Bitterfeld ambers.

Number in the parentheses after accession number indicates number of the Mycetobia

syninclusion (if more than one in the same piece of amber). "L"- length, "W"-width 
1 Table 2. Morphometry of the fossil Mycetobia larvae from Baltic and Bitterfeld ambers. Number 2 in the parentheses after accession number indicates number of the Mycetobia syninclusion (if 3 more than one in the same piece of amber). "L"- length, "W"-width.

\begin{tabular}{|c|c|c|c|c|}
\hline Acession number & $\begin{array}{l}\text { L total, } \\
\mu \mathrm{m}\end{array}$ & $\begin{array}{l}\text { head } \mathrm{L}, \\
\mu \mathrm{m}\end{array}$ & $\begin{array}{l}\text { head W, } \\
\mu \mathrm{m}\end{array}$ & $\begin{array}{l}\text { larval } \\
\text { stage }\end{array}$ \\
\hline Dip-00640 (1) & 2676.177 & 145.201 & 105.129 & 1 \\
\hline GPIH-0247/8 & 3346.186 & 165.624 & 115.993 & 1 \\
\hline PED-4748(3) & 2283.494 & 99.005 & 87.693 & 1 \\
\hline Dip-00656 & 2067 & 166 & 115 & 1 \\
\hline Dip-00640 (2) & 2151.442 & 186.238 & 162.515 & 2 \\
\hline Dip-00640(3) & 2693.354 & 209.082 & 178.836 & 2 \\
\hline Dip-00640 (4) & 2405.655 & 171.311 & 155.919 & 2 \\
\hline GPIH-3706 W & 2957.863 & 190.825 & 180.487 & 2 \\
\hline BI2350 & 3909.86 & 235.719 & 155.103 & 2 \\
\hline GPIH-0247(7) & 3034.273 & 195.118 & 166.481 & $\underline{2}$ \\
\hline PED-4748(1) & 5048.093 & 309.328 & 171.883 & 2 \\
\hline PED-4970 & 4591.883 & 233.701 & 156.178 & 2 \\
\hline Dip-00656(2) & 2784 & 181 & 192 & 2 \\
\hline Dip-00655(1) & 2364 & 139 & 145 & $\underline{2}$ \\
\hline Dip-00649(1) & 5166 & 178 & 181 & $\underline{2}$ \\
\hline GPIH-0247(9) & 3 & 320.337 & 259.113 & 3 \\
\hline PED-4748(2) & 5207.932 & 388.551 & 246.06 & 3 \\
\hline PED-4748(4) & 10222.51 & & 191.139 & 3 \\
\hline PED-4965 & 7027.351 & 319.331 & 218.775 & 3 \\
\hline PED-5695 & 5503.7 & 284.294 & 230.87 & 3 \\
\hline Dip-00639 & 7609.245 & 306.751 & 295.106 & 3 \\
\hline Dip-00658 & 8139 & 376 & 239 & 3 \\
\hline Dip-00656 (1) & 5693 & 266 & 240 & 3 \\
\hline Dip-00655(2) & 2344 & 225 & 227 & 3 \\
\hline Dip-00649(2) & 8385 & 352 & 277 & 3 \\
\hline GPIH-0247(2) & 3929.665 & 512.765 & 418.808 & 4 \\
\hline GPIH-0247(1) & 5328.197 & NA & NA & NA \\
\hline GPIH-0247(3) & 4150.859 & NA & NA & NA \\
\hline GPIH-0247(4) & 4898.89 & NA & NA & NA \\
\hline GPIH-0247(5) & 1819.851 & NA & NA & NA \\
\hline GPIH-0247(6) & 3486.205 & NA & NA & NA \\
\hline GPIH-1-7592(1) & 7194.75 & NA & NA & NA \\
\hline GPIH-1-7592(2) & 6096.312 & NA & NA & NA \\
\hline GPIH-1-7592(3) & 5701.261 & $\mathrm{NA}$ & NA & NA \\
\hline GPIH-1-7592(4) & 6454.761 & NA & NA & NA \\
\hline GPIH-1-7592(5) & 4017.086 & NA & NA & NA \\
\hline
\end{tabular}




\section{Table 3(on next page)}

Table 3. Morphometry of the fossil Mycetobia pupae from Baltic and Bitterfeld ambers.

Number in the parentheses after accession number indicates number of the Mycetobia syninclusion (if more than one in the same piece of amber). 
1 Table 3. Morphometry of the fossil Mycetobia pupae from Baltic and Bitterfeld ambers. Number 2 in the parentheses after accession number indicates number of the Mycetobia syninclusion (if 3 more than one in the same piece of amber).

4

\begin{tabular}{|c|c|c|c|}
\hline Accession number & length, $\mu \mathrm{m}$ & parameter & Morphotype \\
\hline Dip-00655 & 1777.074 & abdomen & morphotype 1 \\
\hline Dip-00655 & 1013.289 & thorax+head & morphotype 1 \\
\hline Dip-00655 & 2679.723 & total & morphotype 1 \\
\hline Dip-00655 & 2484.743 & abdomen & morphotype 1 \\
\hline Dip-00655 & 1614.781 & thorax+head & morphotype 1 \\
\hline Dip-00655 & 3842.338 & total & morphotype 1 \\
\hline Dip-00652 & 362.857 & thorax+head & morphotype 3 \\
\hline Dip-00652 & 527.673 & abdomen & morphotype 3 \\
\hline Dip-00652 & 826.356 & total & morphotype 3 \\
\hline Dip-00653 & 2420.659 & abdomen & morphotype 1 \\
\hline Dip-00653 & 1779.554 & thorax+head & morphotype 1 \\
\hline Dip-00653 & 3919.83 & total & morphotype 1 \\
\hline GPIH-1851DN & 3021.056 & abdomen & morphotype 1 \\
\hline GPIH-1851DN & 2266.877 & thorax+head & morphotype 1 \\
\hline GPIH-1851DN & 5059.427 & total & morphotype 1 \\
\hline Dip-00641 & 2340.723 & abdomen & morphotype 1 \\
\hline Dip-00641 & 1624.223 & thorax+head & morphotype 1 \\
\hline Dip-00641 & 3876.262 & total & morphotype 1 \\
\hline Dip-00650 & 320.106 & thorax+head & morphotype 3 \\
\hline Dip-00650 & 645.888 & abdomen & morphotype 3 \\
\hline Dip-00650 & 864.21 & total & morphotype 3 \\
\hline Dip-00660 & 2935.409 & abdomen & morphotype 1 \\
\hline Dip-00660 & 1924.388 & thorax+head & morphotype 1 \\
\hline Dip-00660 & 4238.969 & total & morphotype 1 \\
\hline Dip-00661 & 3647.714 & abdomen & morphotype 1 \\
\hline Dip-00661 & 2220.334 & thorax+head & morphotype 1 \\
\hline Dip-00661 & 5861.01 & total & morphotype 1 \\
\hline Dip-00657 & 2310.204 & abdomen & morphotype 1 \\
\hline Dip-00657 & 1453.298 & thorax+head & morphotype 1 \\
\hline Dip-00657 & 3835.301 & total & morphotype 1 \\
\hline GPIH-N-7095. & 2154.926 & abdomen & morphotype 1 \\
\hline GPIH-N-7095. & 1710.244 & thorax+head & morphotype 1 \\
\hline GPIH-N-7095. & 3761.555 & total & morphotype 1 \\
\hline Dip-00659 & 2466.357 & abdomen & morphotype 1 \\
\hline Dip-00659 & 1697.196 & thorax+head & morphotype 1 \\
\hline
\end{tabular}




\begin{tabular}{|l|r|l|l|} 
& & & \\
Dip-00659 & 3744.385 & total & morphotype 1 \\
\hline Dip-00651 & 2187.597 & abdomen & morphotype 1 \\
\hline Dip-00651 & 1543.324 & thorax+head & morphotype 1 \\
\hline Dip-00651 & 3343.985 & total & morphotype 1 \\
\hline AKBS-00071 & 2490.055 & abdomen & morphotype 1 \\
\hline AKBS-00071 & 1784.352 & thorax+head & morphotype 1 \\
\hline AKBS-00071 & 3630.701 & total & morphotype 1 \\
\hline PED-4395 & 2081.768 & abdomen & morphotype 1 \\
\hline PED-4395 & 1561.697 & thorax+head & morphotype 1 \\
\hline PED-4395 & 3528.726 & total & morphotype 1 \\
\hline PED-4866 & 2596.66 & thorax+head & morphotype 2 \\
\hline PED-4866 & 3041.19 & abdomen & morphotype 2 \\
\hline PED-4866 & 5379.843 & total & morphotype 2 \\
\hline PED-4998 & 2882.949 & abdomen & morphotype 1 \\
\hline PED-4998 & 2174.641 & thorax+head & morphotype 1 \\
\hline PED-4998 & 4811.619 & total & morphotype 1 \\
\hline GPIH-L-7514 & 1826.663 & thorax+head & morphotype 2 \\
\hline GPIH-L-7514 & 2936.171 & abdomen & morphotype 2 \\
\hline GPIH-L-7514 & 4858.746 & total & morphotype 2 \\
\hline
\end{tabular}

5 